Supporting Information

for the

Article Entitled

\title{
Siloxide Podand Ligand as a Scaffold for Molybdenum Catalyzed Alkyne Metathesis and Isolation of a Dynamic Metallatetrahedrane Intermediate
}

\author{
Authored by \\ Richard R. Thompson, Madeline E. Rotella, Pu Du, Xin Zhou, Frank R. Fronczek, Revati \\ Kumar, Osvaldo Gutierrez* and Semin Lee* \\ Department of Chemistry \\ Louisiana State University, Baton Rouge, Louisiana 70803 \\ Department of Chemistry and Biochemistry \\ University of Maryland, College Park, Maryland 20742
}

TABLE OF CONTENTS

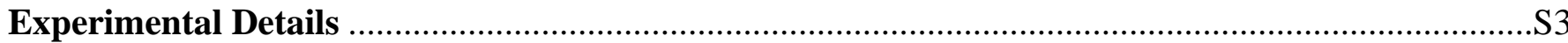

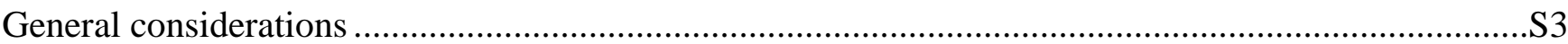

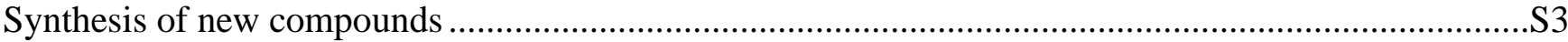

General Procedure for Alkyne metathesis .....................................................................................

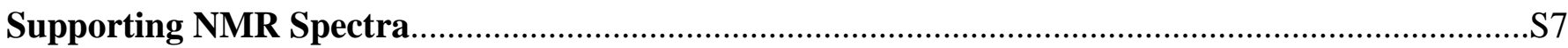

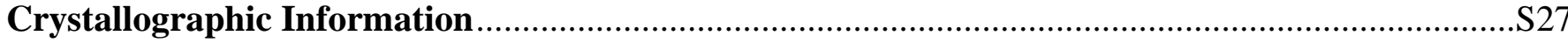

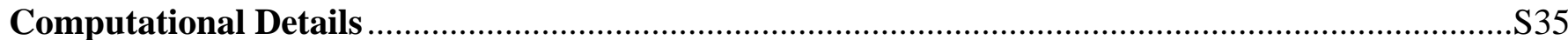

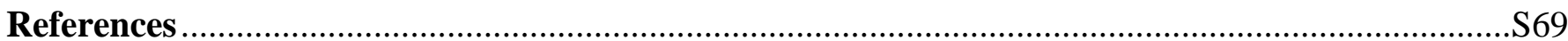




\section{$\underline{\text { Experimental Details }}$}

\section{General considerations}

All manipulations were performed under an inert atmosphere of Ar using standard Schlenk-line or glovebox techniques. Anhydrous toluene, diethyl ether and tetrahydrofuran were purchased and dried by passage through two columns of activated alumina and a Q-5 column. Benzene- $d_{6}$ was degassed by three cycles of freeze-pump thaw and then stored over $4 \AA$ molecular sieves. Celite and molecular sieves were dried under reduced pressure at $150{ }^{\circ} \mathrm{C}$ for three days. Cooling for the reactions was performed in the internal freezer $\left(-37^{\circ} \mathrm{C}\right)$ of the glovebox used. $\mathrm{Mo}(\mathrm{CO})_{6}, 2$-bromoacetophenone, oxayl bromide, 1,2dimethoxyethane, tetramethylammonium bromide, 4-bromotoluene, 2-bromomesitylene and anhydrous npentane, were all purchased from Acros Organics and used as received. $\mathrm{C}_{6} \mathrm{H}_{3}\left(\mathrm{C}_{6} \mathrm{H}_{4} \mathrm{Br}\right)_{3}{ }^{1}$ and 1-methoxy4-(phenylethynl)benzene ${ }^{2}$ were synthesized via previously reported methods. ${ }^{1} \mathrm{H}$ and ${ }^{13} \mathrm{C}\left\{{ }^{1} \mathrm{H}\right\} \mathrm{NMR}$ spectra were recorded on either Varian $400 \mathrm{MHz}$ or $500 \mathrm{MHz}$ NMR spectrometers with benzene- $d_{6}$ referenced at 7.16 and $128.06 \mathrm{ppm}$, respectively.

\section{Synthesis of new compounds}

\section{$\mathrm{C}_{6} \mathrm{H}_{3}\left(\mathrm{C}_{6} \mathrm{H}_{4} \mathrm{SiPh}_{2} \mathrm{OH}\right)_{3}(1)$}

To a solution/suspension of $\mathrm{C}_{6} \mathrm{H}_{3}\left(\mathrm{C}_{6} \mathrm{H}_{4} \mathrm{Br}\right)_{3}(2 \mathrm{~g}, 3.68$ $\mathrm{mmol})$ in $100 \mathrm{~mL}$ ether was dropwise added $\mathrm{t}-\mathrm{BuLi}(1.8$ $\mathrm{M}, 14.3 \mathrm{~mL})$ at $-78{ }^{\circ} \mathrm{C}$. The solution immediately formed precipitates while adding (1-2eq). After further addition (5-7eq) the precipitates disappeared and formed a transparent red-brown solution. The solution was stirred at $-78{ }^{\circ} \mathrm{C}$ for $2 \mathrm{~h}$. **Depending on the concentration of the reaction, grey precipitates might form after time** $\mathrm{Ph}_{2} \mathrm{SiCl}_{2}(5.6 \mathrm{~g}, 4.6 \mathrm{~mL}, 22.1 \mathrm{mmol})$ was added dropwise to the reaction mixture. The cooling bath was removed and the reaction mixture was allowed

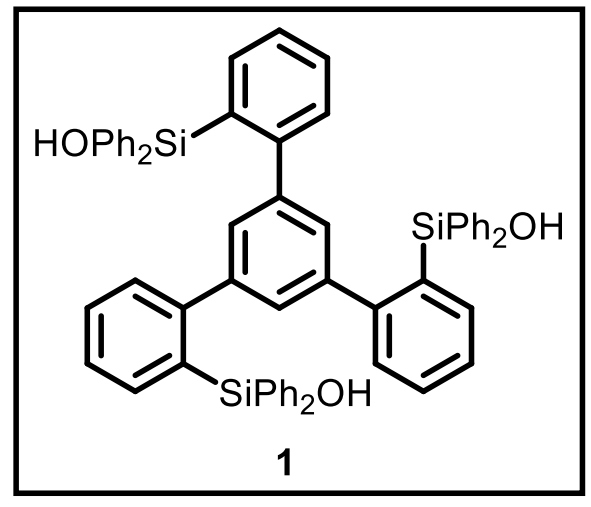
to warm to $\mathrm{rt}$ and stirred for $3 \mathrm{~h}$. Large amount of salt precipitates form at $\mathrm{rt}$ and the red/brown solution turns to light yellow. The reaction mixture was cooled using an ice bath. The reaction was quenched with water $(\sim 30 \mathrm{~mL})$ and the ice bath was removed. The reaction was stirred at $\mathrm{rt}$ for $30 \mathrm{~min}$. The mixture was extracted with ether $(\times 3)$ and washed with brine. The organic phase was collected and dried with $\mathrm{Mg}_{2} \mathrm{SO}_{4}$, then filtered.

\section{Purification method A}

Silica gel was added to the filtered organic phase and concentrated via rotary evaporator. Dryloaded on to a column and separated via column chromatography. Elution gradient: Hexanes : ethylacetate $=95: 5 \rightarrow 8: 2$. ${ }^{*} *$ The desired product has low solubility in this column condition. Therefore, the product may crystalize out in the test tubes. Also, some product may remain in the column and would require $100 \%$ ethyl acetate to flush out of the column.** The desired fractions were collected and concentrated and was further purified by recrystallization from acetone and hexanes. Minimal amount of acetone was added and heated to dissolve most of the solids. Large amount of hexanes $(\sim 200 \mathrm{~mL})$ was added and the mixture was place in the freezer overnight. White crystalline powders were collect by filtration or decanting. 


\section{Purification method B}

The filtered organic phase was concentrated via rotary evaporator. $\mathrm{CH}_{2} \mathrm{Cl}_{2}$ was added and sonicated to disperse the crystalline compounds. The mixture was filtered through a short pad of silica gel and washed with $\mathrm{CH}_{2} \mathrm{Cl}_{2}$. $* * \mathrm{Ph}_{2} \mathrm{Si}(\mathrm{OH})_{2}$ is major by product and it is not too soluble in $\mathrm{CH}_{2} \mathrm{Cl}_{2}$ and does not elute using $\mathrm{CH}_{2} \mathrm{Cl}_{2} * *$ The filtrate was collect and concentrated. The mixture was purified via recrystallization mentioned in method $\mathrm{A}$.

Yield $=2.42(72.8 \%) .{ }^{1} \mathrm{H}$ NMR $\left(400 \mathrm{MHz}, \mathrm{CDCl}_{3}, 25{ }^{\circ} \mathrm{C}\right): 4.45(3 \mathrm{H}, \mathrm{s}, \mathrm{SiOH}), 6.89(3 \mathrm{H}, \mathrm{dd}$, $\left.{ }^{3} \mathrm{~J}_{\mathrm{HH}}=5.6 \mathrm{~Hz},{ }^{4} \mathrm{~J}_{\mathrm{HH}}=2.2 \mathrm{~Hz}, \mathrm{Ar}-H\right), 6.91\left(3 \mathrm{H}, \mathrm{s}, \mathrm{C}_{6} H_{3}\right), 7.17\left(12 \mathrm{H}, 3,{ }^{3} \mathrm{~J}_{\mathrm{HH}}=7.3 \mathrm{~Hz}, p-\mathrm{Si} P h_{2}\right)$, $7.26\left(6 \mathrm{H}, \mathrm{m}, m-\mathrm{Si} P h_{2}\right), 7.47\left(3 \mathrm{H}, \mathrm{dd},{ }^{3} \mathrm{~J}_{\mathrm{HH}}=8.8 \mathrm{~Hz},{ }^{3} \mathrm{~J}_{\mathrm{HH}}=3.2 \mathrm{~Hz}, \operatorname{Ar}-H\right), 7.54\left(12 \mathrm{H}, \mathrm{d},{ }^{3} \mathrm{~J}_{\mathrm{HH}}=\right.$ $\left.6.8 \mathrm{~Hz}, o-\mathrm{Si} P h_{2}\right) .{ }^{13} \mathrm{C}\left\{{ }^{1} \mathrm{H}\right\} \mathrm{NMR}\left(125.77 \mathrm{MHz}, \mathrm{C}_{6} \mathrm{D}_{6}, 25{ }^{\circ} \mathrm{C}\right): 149.06(A r), 147.91$ (Ar), 137.57 (Ar), $137.14(A r), 134.66$ (Ar), 134.00 (Ar), 130.19 (Ar), 129.82 (Ar), $129.48(A r), 128.68(A r)$, $127.97(A r), 126.09(A r)$. HRMS-ESI (m/z): calcd. for $\mathrm{C}_{60} \mathrm{H}_{48} \mathrm{NaO}_{3} \mathrm{Si}_{3}{ }^{+},[\mathrm{M}+\mathrm{Na}]^{+}, 923.28035$, found, 923.27874 .

\section{$\left[\mathrm{C}_{6} \mathrm{H}_{3}\left(\mathrm{C}_{6} \mathrm{H}_{4} \mathrm{SiPh}_{2} \mathrm{O}\right)_{3}\right] \mathrm{Mo} \equiv \mathrm{CMes}(2)$}

1 (184 mg/0.205 mmol) was dissolved into $5 \mathrm{ml}$ of THF and benzyl potassium $(82 \mathrm{mg} / 0.63 \mathrm{mmol})$ was dissolved in $10 \mathrm{ml}$ of THF and both solutions were chilled to $-37^{\circ} \mathrm{C}$. To the stirring, red-orange benzyl potassium solution was added the solution of 1, dropwise. Upon complete addition of $\mathbf{1}$, the orange solution became a colorless (or off-white) suspension which was chilled again to $-37{ }^{\circ} \mathrm{C}$. $\mathrm{Mo}(\equiv \mathrm{CMes}) \mathrm{Br}_{3}$ (DME) $(114 \mathrm{mg} / 0.205 \mathrm{mmol})$ was dissolved into $50 \mathrm{ml} \mathrm{THF}$ and chilled to $-37{ }^{\circ} \mathrm{C}$ and to this stirring solution was added the $\mathbf{K}_{3} \mathbf{S i P}$ solution dropwise. The color of the solution changed from orange to yellow to darkyellow brown concomitant with the precipitation of saltbyproducts. The reaction stirred at room-temperature for $6 \mathrm{~h}$ at which point solvent was removed under reduced pressure, the product extracted into toluene and the $\mathrm{KBr}$ impurity removed by

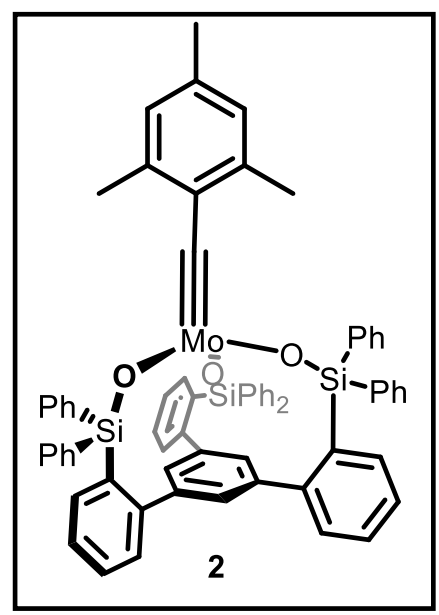
filtering through 3" celite plug on a medium porosity fritted funnel. Single crystals suitable for X-ray diffraction studies (orange-hexagonal plates) were grown from slow-evaporation of toluene while yellow, pure powder was obtained by chilling a concentrated toluene solution to $37{ }^{\circ} \mathrm{C}$. This powder was then isolated by filtering onto a fine porosity fritted funnel and washing with pentane. The solid was then dried under reduced pressure. Yield $=115 \mathrm{mg}(49.8 \%) .{ }^{1} \mathrm{H}$ NMR (400 MHz, $\left.\mathrm{C}_{6} \mathrm{D}_{6}, 25^{\circ} \mathrm{C}\right): 1.87\left(3 \mathrm{H}, \mathrm{s}, p-\mathrm{CH}_{3}\right), 1.97\left(6 \mathrm{H}, \mathrm{s}, o-\mathrm{CH}_{3}\right), 6.17\left(2 \mathrm{H}, \mathrm{s}, \mathrm{C}_{6} \mathrm{H}_{2} \mathrm{Me}_{3}\right)$, $6.88\left(3 \mathrm{H}, \mathrm{d},{ }^{3} \mathrm{~J}_{\mathrm{HH}}=8.0 \mathrm{~Hz}, \mathrm{Ar}-H\right), 7.05-7.10(24 \mathrm{H}, \mathrm{m}$, Overlap of several Ar- $H), 7.28(3 \mathrm{H}, \mathrm{s}$, $\left.\mathrm{C}_{6} \mathrm{H}_{3} \mathrm{Ar}_{3}\right), 7.78\left(3 \mathrm{H}, \mathrm{d},{ }^{3} \mathrm{~J}_{\mathrm{HH}}=8.0 \mathrm{~Hz}, \mathrm{Ar}-H\right), 7.84\left(12 \mathrm{H}, \mathrm{d},{ }^{3} \mathrm{~J}_{\mathrm{HH}}=8.0 \mathrm{~Hz}, o-\mathrm{SiPh}_{2}\right) .{ }^{13} \mathrm{C}\left\{{ }^{1} \mathrm{H}\right\}$ NMR (125.77 MHz, $\left.C_{6} D_{6}, 25{ }^{\circ} \mathrm{C}\right): 313.29(\mathrm{Mo} \equiv C), 149.59$ (Ar), $144.25(A r), 143.61(A r)$, $139.01(A r), 137.99$ (Ar), $137.53(A r), 137.32$ (Ar), 135.32 (Ar), $135.12(A r), 134.99(A r), 130.46$ (Ar), 130.09 (Ar), $129.84(A r), 129.30(A r), 126.78(A r), 126.25(A r), 20.88\left(o-C \mathrm{H}_{3}\right), 20.00(p-$ $\mathrm{CH}_{3}$ ). 


\section{$\left[\mathrm{C}_{6} \mathrm{H}_{3}\left(\mathrm{C}_{6} \mathrm{H}_{4} \mathrm{SiPh}_{2} \mathrm{O}\right)_{3}\right] \mathrm{Mo} \equiv \mathrm{CTol}(3)$}

1 (385 mg/0.427 mmol) was dissolved into $5 \mathrm{ml}$ of THF and benzyl potassium $(184 \mathrm{mg} / 1.41 \mathrm{mmol})$ was dissolved in $10 \mathrm{ml}$ of $\mathrm{THF}$ and both solutions were chilled to $-37{ }^{\circ} \mathrm{C}$. To the stirring, redorange benzyl potassium solution was added the solution of $\mathbf{1}$, dropwise. Upon complete addition of $\mathbf{1}$, the orange solution became a colorless (or off-white) suspension which was chilled again to $-37{ }^{\circ} \mathrm{C}$. $\mathrm{Mo}(\equiv \mathrm{CTol}) \mathrm{Br}_{3}(\mathrm{DME})(226 \mathrm{mg} / 0.427 \mathrm{mmol})$ was dissolved into $50 \mathrm{ml} \mathrm{THF}$ and chilled to $-37^{\circ} \mathrm{C}$ and to this stirring solution was added the K3SiP solution dropwise. The color of the solution changed from orange to yellow to dark-yellow brown concomitant with the precipitation of salt-byproducts. The reaction stirred at room-temperature for $6 \mathrm{~h}$ at which point solvent was removed under reduced pressure, the product extracted into toluene

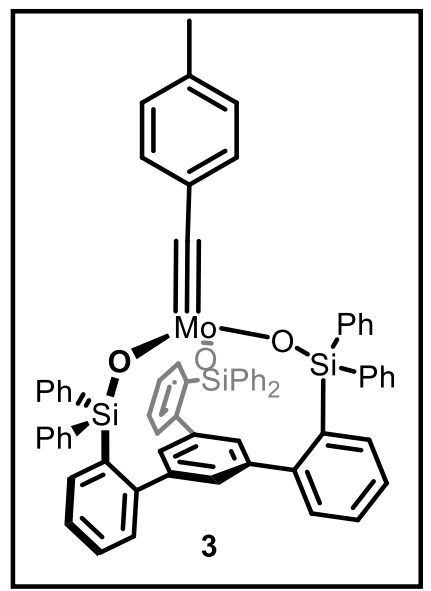
and the $\mathrm{KBr}$ impurity removed by filtering through 3" celite plug on a medium porosity fritted funnel. Single crystals (yellow plates) suitable for X-ray diffraction studies were grown from slow-evaporation of diethyl ether while yellow, pure powder was obtained by chilling a concentrated toluene solution to $-37^{\circ} \mathrm{C}$. This powder was then isolated by filtering onto a fine porosity fritted funnel and washing with pentane. The solid was then dried under reduced pressure. Yield $=140 \mathrm{mg}(30.0 \%) .{ }^{1} \mathrm{H} \mathrm{NMR}\left(400 \mathrm{MHz}, \mathrm{C}_{6} \mathrm{D}_{6}, 25{ }^{\circ} \mathrm{C}\right): 1.88(3 \mathrm{H}$, $\left.\mathrm{s}, p-\mathrm{CH}_{3}\right), 6.22\left(2 \mathrm{H}, \mathrm{d},{ }^{3} \mathrm{~J}_{\mathrm{HH}}=8.0 \mathrm{~Hz}, o-\mathrm{C} 6 \mathrm{H}_{4} \mathrm{Me}\right), 6.42\left(2 \mathrm{H}, \mathrm{d},{ }^{3} \mathrm{~J}_{\mathrm{HH}}=8.0 \mathrm{~Hz}, m-\mathrm{C}_{6} H_{4} \mathrm{Me}\right), 6.92$ $\left(3 \mathrm{H}, \mathrm{d},{ }^{3} \mathrm{~J}_{\mathrm{HH}}=8.0 \mathrm{~Hz}, \mathrm{Ar}-H\right), 7.13-6.93(24 \mathrm{H}, \mathrm{m}$, Overlap of several Ar- $H), 7.33(3 \mathrm{H}, \mathrm{s}$, $\left.\mathrm{C}_{6} \mathrm{H}_{3} \mathrm{Ar}_{3}\right), 7.78\left(3 \mathrm{H}, \mathrm{d},{ }^{3} \mathrm{~J}_{\mathrm{HH}}=8.0 \mathrm{~Hz}, \mathrm{Ar}-H\right), 7.86\left(12 \mathrm{H}, \mathrm{d},{ }^{3} \mathrm{~J}_{\mathrm{HH}}=8.0 \mathrm{~Hz}, o-\mathrm{SiPh}_{2}\right) .{ }^{13} \mathrm{C}\left\{{ }^{1} \mathrm{H}\right\}$ NMR (125.77 MHz, $\left.C_{6} D_{6}, 25{ }^{\circ} \mathrm{C}\right): 311.38(\mathrm{Mo} \equiv C), 149.50$ (Ar), 144.16 (Ar), 138.04 (Ar), $137.43(A r), 137.22(A r), 135.33(A r), 135.06(A r), 130.50(A r), 130.15(A r), 129.83(A r), 129.40$ (Ar), 129.33 (Ar), $128.76(A r), 128.57(A r), 126.31$ (Ar), $125.70(A r), 20.98\left(p-C \mathrm{H}_{3}\right)$.

\section{$\left(\mathbf{P h} 3 \mathrm{SiO}_{3} \mathrm{Mo} \equiv \mathrm{CMes}(4)\right.$}

$\mathrm{Mo}(\equiv \mathrm{CMes}) \mathrm{Br}_{3}(\mathrm{DME}) \quad(211 \mathrm{mg} / 0.379 \mathrm{mmol})$ was dissolved into $50 \mathrm{ml}$ of toluene and $\mathrm{KOSiPh}_{3}(369 \mathrm{mg} / 1.17 \mathrm{mmol})$ as a 20 $\mathrm{ml}$ of toluene solution was dropwise added to it at $-37^{\circ} \mathrm{C}$. The solution was allowed to stir for $1.5 \mathrm{~h}$ while warming to roomtemperature. All volatiles were removed under reduced pressure and the crude product extracted into $\mathrm{Et}_{2} \mathrm{O}$ and filtered through a 3" plug of celite to remove salt-byproducts. Single crystals (yellow-orange plates) suitable for X-ray diffraction studies were grown from a concentrated ethereal solution at -37 ${ }^{\circ} \mathrm{C}$. This material was then isolated by filtering onto a fine

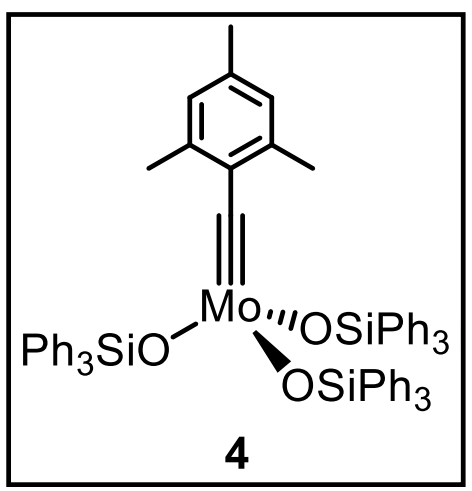
porosity fritted funnel and washing with pentane. The solid was then dried under reduced pressure. Yield $=0.402 \mathrm{~g}(78.6 \%) .{ }^{1} \mathrm{H}$ NMR $\left(400 \mathrm{MHz}, \mathrm{C}_{6} \mathrm{D}_{6}, 25{ }^{\circ} \mathrm{C}\right)$ : 
$1.93\left(6 \mathrm{H}, \mathrm{s}, o-\mathrm{CH}_{3}\right), 2.00\left(3 \mathrm{H}, \mathrm{s}, p-\mathrm{CH}_{3}\right), 6.30\left(2 \mathrm{H}, \mathrm{s}, m-\mathrm{C}_{6} H_{2}\right) 7.08\left(18 \mathrm{H}, \mathrm{td},{ }^{3} \mathrm{~J}_{\mathrm{HH}}=7.2 \mathrm{~Hz}, m^{-}\right.$ $\left.\mathrm{OSi} P h_{3}\right), 7.13\left(9 \mathrm{H}, 3,{ }^{3} \mathrm{~J}_{\mathrm{HH}}=6.8 \mathrm{~Hz}, p-\mathrm{OSi} P h_{3}\right), 7.75\left(18 \mathrm{H}, \mathrm{dd},{ }^{3} \mathrm{~J}_{\mathrm{HH}}=6.4 \mathrm{~Hz},{ }^{4} \mathrm{~J}_{\mathrm{HH}}=1.2 \mathrm{~Hz}, o-\right.$ $\left.\mathrm{OSi} P h_{3}\right) .{ }^{13} \mathrm{C}\left\{{ }^{1} \mathrm{H}\right\}$ NMR $\left(125.77 \mathrm{MHz}, C_{6} D_{6}, 25{ }^{\circ} \mathrm{C}\right): 308.36(\mathrm{Mo} \equiv C), 143.67(A r), 139.95(A r)$, 137.62 (Ar), 136.60 (Ar), 136.07 (Ar), 130.45 (Ar), 128.57 (Ar), 128.49 (Ar), 128.38 (Ar), 128.19 (Ar), $127.36(A r), 21.35\left(p-\mathrm{CH}_{3}\right), 20.62\left(o-\mathrm{CH}_{3}\right)$.

\section{$\left(\mathrm{Ph}_{3} \mathrm{SiO}\right)_{3} \mathrm{Mo} \equiv \mathrm{CTol}(5)$}

$\mathrm{Mo}(\equiv \mathrm{CTol}) \mathrm{Br}_{3}(\mathrm{DME})(296 \mathrm{mg} / 0.561 \mathrm{mmol})$ was dissolved into $150 \mathrm{ml}$ of toluene and $\mathrm{KOSiPh}_{3}(510 \mathrm{mg} / 1.62 \mathrm{mmol})$ as a $20 \mathrm{ml}$ of toluene solution was dropwise added to it at $-37{ }^{\circ} \mathrm{C}$. The solution was allowed to stir for $1.5 \mathrm{~h}$ while warming to roomtemperature. All volatiles were removed under reduced pressure and the crude product extracted into $\mathrm{Et}_{2} \mathrm{O}$ and filtered through a 3" plug of celite to remove salt-byproducts. Yellow crystals suitable for x-ray diffraction were grown from evaporation of the ethereal solution while yellow solid was isolated by storage of a concentrated etheral solution at $-37{ }^{\circ} \mathrm{C}$ overnight. This material was then isolated by filtering onto a

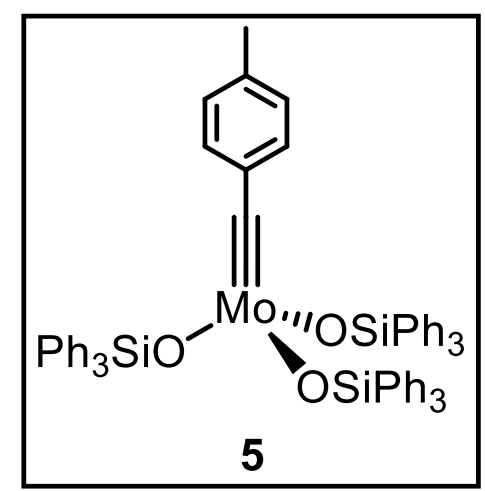
fine porosity fritted funnel and washing with pentane. The solid was then dried under reduced pressure. Yield $=150 \mathrm{mg}(26.0 \%) .{ }^{1} \mathrm{H}$ NMR $\left(400 \mathrm{MHz}, \mathrm{C}_{6} \mathrm{D}_{6}, 25\right.$ $\left.{ }^{\circ} \mathrm{C}\right): 1.96\left(3 \mathrm{H}, \mathrm{s}, p-\mathrm{CH}_{3}\right), 5.50\left(2 \mathrm{H}, \mathrm{d},{ }^{3} \mathrm{~J}_{\mathrm{HH}}=8.0 \mathrm{~Hz}, o-\mathrm{C}_{6} \mathrm{H}_{4} \mathrm{Me}\right), 6.37\left(2 \mathrm{H}, \mathrm{d},{ }^{3} \mathrm{~J}_{\mathrm{HH}}=8.0 \mathrm{~Hz}, m-\right.$ $\left.\mathrm{C}_{6} \mathrm{H}_{4} \mathrm{Me}\right) 7.06\left(18 \mathrm{H}, \mathrm{t},{ }^{3} \mathrm{~J}_{\mathrm{HH}}=7.2 \mathrm{~Hz}, m-\mathrm{OSi} P h_{3}\right), 7.13\left(9 \mathrm{H}, 3,{ }^{3} \mathrm{~J}_{\mathrm{HH}}=7.2 \mathrm{~Hz}, p-\mathrm{OSi} P h_{3}\right), 7.75$ $\left(18 \mathrm{H}, \mathrm{dd},{ }^{3} \mathrm{~J}_{\mathrm{HH}}=8.0 \mathrm{~Hz},{ }^{4} \mathrm{~J}_{\mathrm{HH}}=1.6 \mathrm{~Hz}, o-\mathrm{OSi} P h_{3}\right) .{ }^{13} \mathrm{C}\left\{{ }^{1} \mathrm{H}\right\} \mathrm{NMR}\left(125.77 \mathrm{MHz}, C_{6} D_{6}, 25{ }^{\circ} \mathrm{C}\right)$ : $301.02(\mathrm{Mo} \equiv C), 143.90(A r), 136.78(A r), 136.39(A r), 136.24(A r), 135.93(A r), 130.11(A r)$, $129.42(A r), 127.51(A r), 21.11\left(p-\mathrm{CH}_{3}\right)$.

\section{$\left[\mathrm{K}\left(\mathrm{OEt}_{2}\right)\right]\left[(\mathrm{Ph} 3 \mathrm{SiO}){ }_{4} \mathrm{Mo} \equiv \mathrm{CTol}\right](6)$}

$\mathrm{Mo}(\equiv \mathrm{CTol}) \mathrm{Br}_{3}(\mathrm{DME}) \quad(258 \mathrm{mg} / 0.488 \mathrm{mmol}) \quad$ and $\mathrm{KOSiPh}_{3}(476 \mathrm{mg} / 1.51 \mathrm{mmol})$ were each dissolved in $10 \mathrm{ml}$ of toluene and both solutions were chilled to -37 ${ }^{\circ} \mathrm{C}$. To the stirring, brown suspension of $\mathrm{Mo}(\equiv \mathrm{CMes}) \mathrm{Br}_{3}(\mathrm{DME})$ was added the solution of $\mathrm{KOSiPh}_{3}$, dropwise, leading to a purple-brown suspension. The reaction stirred at room-temperature for $2.5 \mathrm{~h}$ at which point the $\mathrm{KBr}$ impurity was removed by filtering through a 3" celite plug on a medium porosity fritted funnel. The solvent was removed under reduced pressure and $\mathrm{Et}_{2} \mathrm{O}$ was added resulting in a dark purple-brown solution as well as the rapid

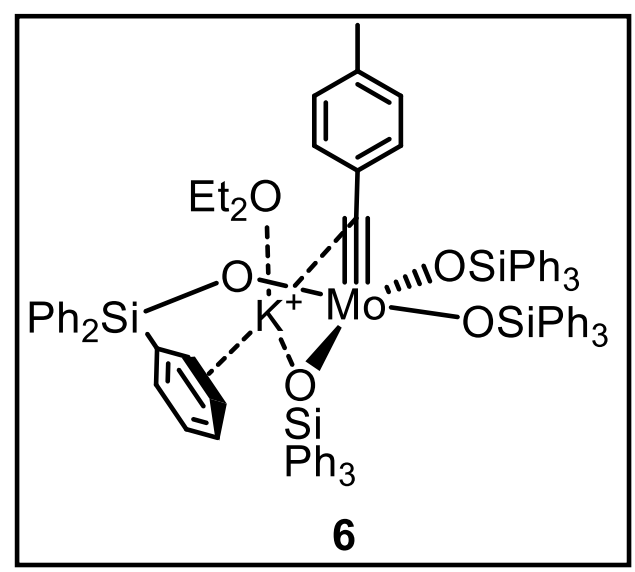
precipitation of purple microcrystalline material. Purple single crystals suitable for $\mathrm{X}$-ray diffraction studies were grown storage of the ethereal solution at $-37{ }^{\circ} \mathrm{C}$ overnight. Yield $=200 \mathrm{mg}(31.3 \%) .{ }^{1} \mathrm{H}$ NMR $\left(400 \mathrm{MHz}, \mathrm{C}_{6} \mathrm{D}_{6}, 25^{\circ} \mathrm{C}\right): 1.11(6 \mathrm{H}, \mathrm{t}$, 
$\left.{ }^{3} \mathrm{~J}_{\mathrm{HH}}=8.0 \mathrm{~Hz}, \mathrm{O}\left(\mathrm{CH}_{2} \mathrm{CH}_{3}\right)_{2}\right), 2.04\left(3 \mathrm{H}, \mathrm{s}, p-\mathrm{CH}_{3}\right), 3.27\left(4 \mathrm{H}, \mathrm{q},{ }^{3} \mathrm{~J}_{\mathrm{HH}}=8.0 \mathrm{~Hz}, \mathrm{O}\left(\mathrm{CH}_{2} \mathrm{CH}_{3}\right)_{2}\right), 6.56$ $\left(2 \mathrm{H}, \mathrm{d},{ }^{3} \mathrm{~J}_{\mathrm{HH}}=8.0 \mathrm{~Hz}, o-\mathrm{C}_{6} \mathrm{H}_{4} \mathrm{Me}\right), 6.67\left(2 \mathrm{H}, \mathrm{d},{ }^{3} \mathrm{~J}_{\mathrm{HH}}=8.0 \mathrm{~Hz}, m-\mathrm{C}_{6} \mathrm{H}_{4} \mathrm{Me}\right) 6.94\left(24 \mathrm{H}, \mathrm{t},{ }^{3} \mathrm{~J}_{\mathrm{HH}}=\right.$ $\left.8.0 \mathrm{~Hz}, m-\mathrm{OSiPh}_{3}\right), 7.07\left(12 \mathrm{H}, \mathrm{t},{ }^{3} \mathrm{~J}_{\mathrm{HH}}=8.0 \mathrm{~Hz}, p-\mathrm{OSiPh}_{3}\right), 7.74\left(24 \mathrm{H}, \mathrm{d},{ }^{3} \mathrm{~J}_{\mathrm{HH}}=8.0 \mathrm{~Hz}, o-\right.$ $\left.\mathrm{OSiPh}_{3}\right) .{ }^{13} \mathrm{C}\left\{{ }^{1} \mathrm{H}\right\}$ NMR $\left(125.77 \mathrm{MHz}, C_{6} D_{6}, 25{ }^{\circ} \mathrm{C}\right): 283.00(\mathrm{Mo} \equiv C), 142.92(A r), 139.72(A r)$, $136.71(A r), 135.95(A r), 135.69(A r), 135.17(A r), 130.55(A r), 129.04(A r), 65.90$

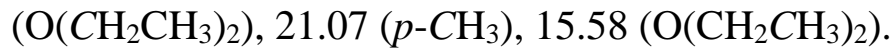

\section{$\left[\mathrm{C}_{6} \mathrm{H}_{3}\left(\mathrm{C}_{6} \mathrm{H}_{4} \mathrm{SiPh}_{2} \mathrm{O}\right)_{3}\right] \mathrm{Mo}\left(\mathrm{C}_{3} \mathrm{Et}_{3}\right)(7)$}

$3(30 \mathrm{mg} / 0.026 \mathrm{mmol})$ was dissolved in $0.6 \mathrm{ml}$ of $\mathrm{C}_{6} \mathrm{D}_{6}$ to give a yellow solution. 3-hexyne $(11 \mathrm{mg} / 128 \mathrm{mmol})$ was added to the solution, leading to a dark brown solution. Based on ${ }^{1} \mathrm{H}$ NMR spectroscopy the conversion to 7 was quantitative however the instability of it to loss of 3-hexyne barred isolation of the product. ${ }^{1} \mathrm{H}$ NMR $\left(400 \mathrm{MHz}, \mathrm{C}_{6} \mathrm{D}_{6}\right.$, $\left.25{ }^{\circ} \mathrm{C}\right): 0.49\left(9 \mathrm{H}, \mathrm{t},{ }^{3} \mathrm{~J}_{\mathrm{HH}}=7.6 \mathrm{~Hz},\left(\mathrm{CCH}_{2} \mathrm{CH}_{3}\right)_{3}\right), 1.78(6 \mathrm{H}$, $\left.\mathrm{d},{ }^{3} \mathrm{~J}_{\mathrm{HH}}=7.6 \mathrm{~Hz},\left(\mathrm{CCH}_{2} \mathrm{CH}_{3}\right)_{3}\right), 6.95\left(3 \mathrm{H}, \mathrm{d},{ }^{3} \mathrm{~J}_{\mathrm{HH}}=4.8 \mathrm{~Hz}\right.$, Ar-H), 7.11-7.13 (24H, m, Overlap of several Ar- $H), 7.32$ $\left(3 \mathrm{H}, \mathrm{s}, \mathrm{C}_{6} \mathrm{H}_{3} \mathrm{Ar}_{3}\right), 7.70\left(3 \mathrm{H}, \mathrm{d},{ }^{3} \mathrm{~J}_{\mathrm{HH}}=4.0 \mathrm{~Hz}, \mathrm{Ar}-\mathrm{H}\right), 7.83$ $\left(12 \mathrm{H}, \mathrm{d},{ }^{3} \mathrm{~J}_{\mathrm{HH}}=6.8 \mathrm{~Hz}, o-\mathrm{SiPh}_{2}\right) .{ }^{13} \mathrm{C}\left\{{ }^{1} \mathrm{H}\right\} \operatorname{NMR}(125.77$ $\left.\mathrm{MHz}, C_{6} D_{6}, 25^{\circ} \mathrm{C}\right)$ : $149.60(A r), 144.48(A r), 137.68(A r)$, $135.67(A r), 135.02(A r), 130.10(A r), 129.88(A r), 129.35$ (Ar), $128.83(A r), 128.47(A r), 127.87(A r), 126.22(A r)$,

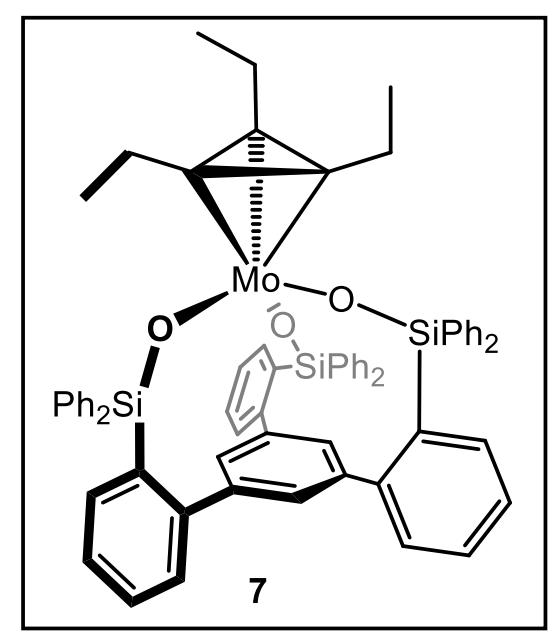
$84.45\left(\mathrm{C}_{3} \mathrm{Et}_{3}\right), 18.99\left(\mathrm{CH}_{2} \mathrm{CH}_{3}\right), 15.92\left(\mathrm{CH}_{2} \mathrm{CH}_{3}\right)$.

\section{General Procedure for Alkyne Metathesis}

Under an inert atmosphere, a $0.4 \mathrm{mM} / 0.008 \mathrm{mM}$ solution of substrate/catalyst was prepared in $0.6 \mathrm{~mL} \mathrm{C}_{6} \mathrm{D}_{6}$. The percentage of substrate conversion was monitored by integration of the $\mathrm{OCH}_{3}$ resonance periodically at set time points. 


\section{Supporting NMR spectra}

举

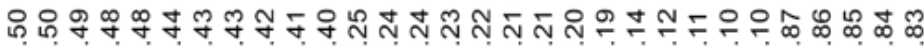

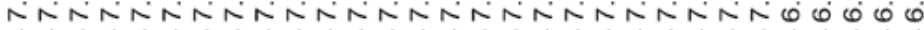
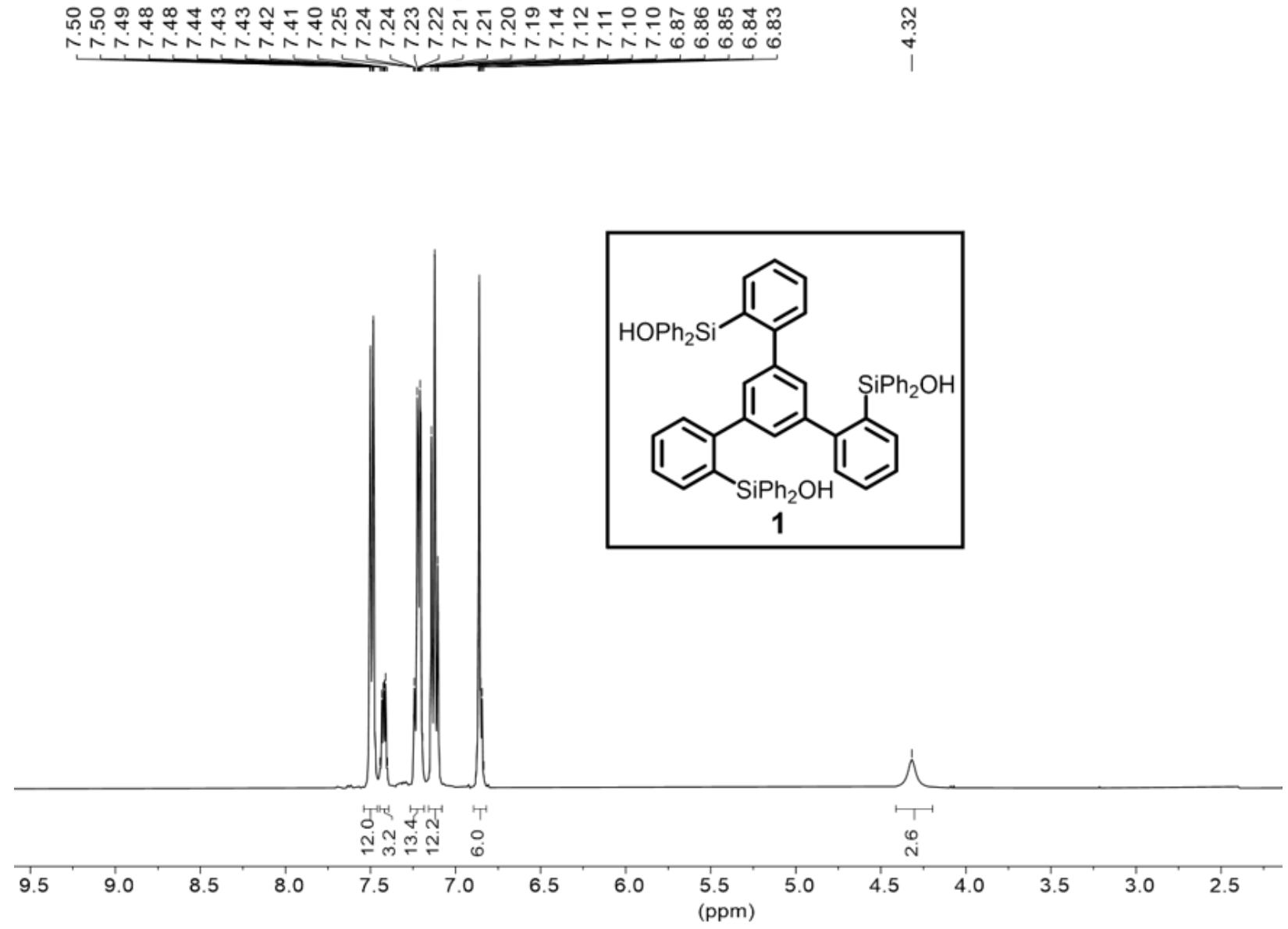

Figure S1. ${ }^{1} \mathrm{H}$ NMR $\left(400 \mathrm{MHz}, \mathrm{CDCl}_{3}, 25^{\circ} \mathrm{C}\right)$ spectrum of $\mathbf{1}$. 


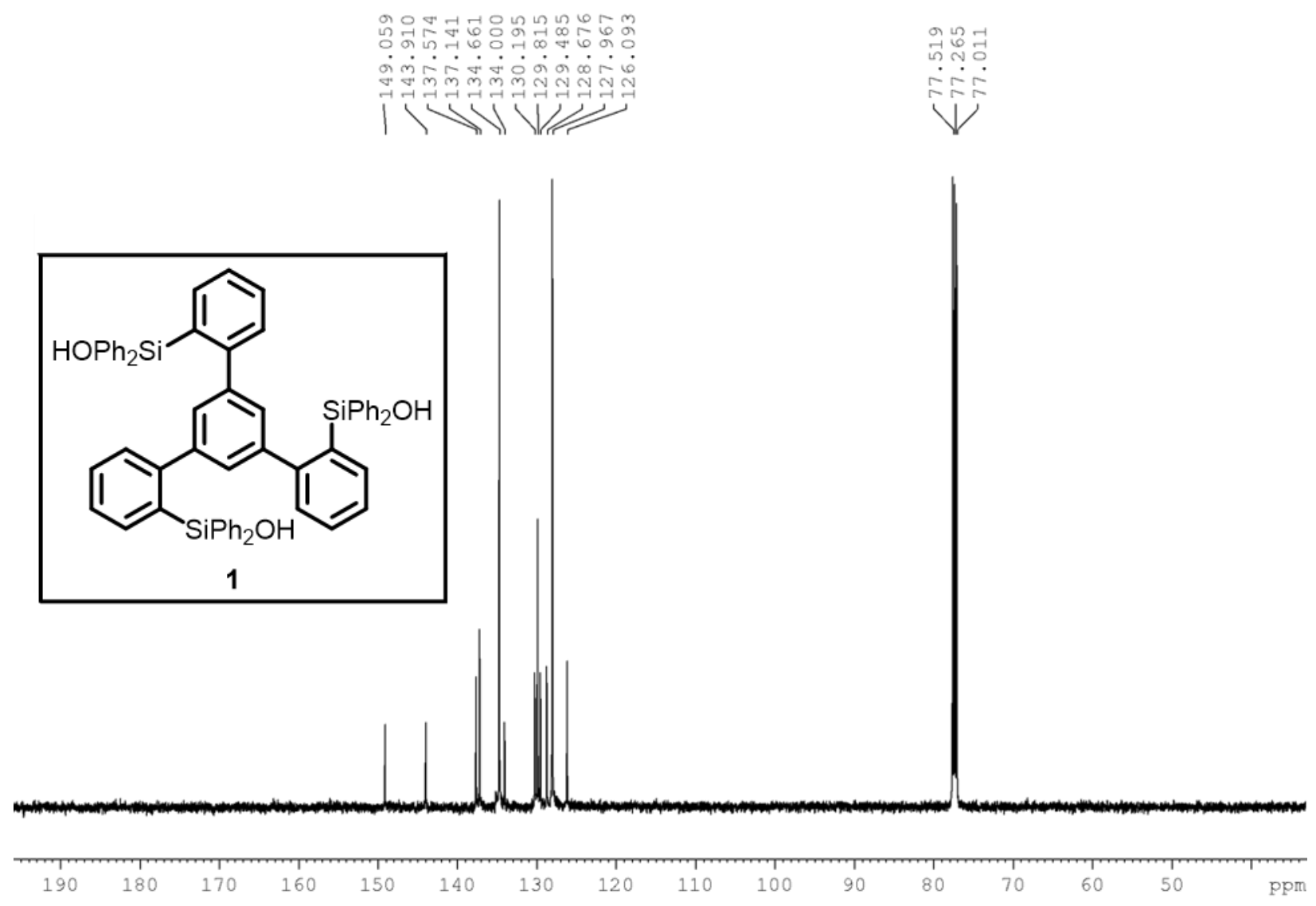

Figure S2. ${ }^{13} \mathrm{C}$ NMR $\left(125 \mathrm{MHz}, \mathrm{CDCl}_{3}, 25{ }^{\circ} \mathrm{C}\right)$ spectrum of $\mathbf{1}$. 


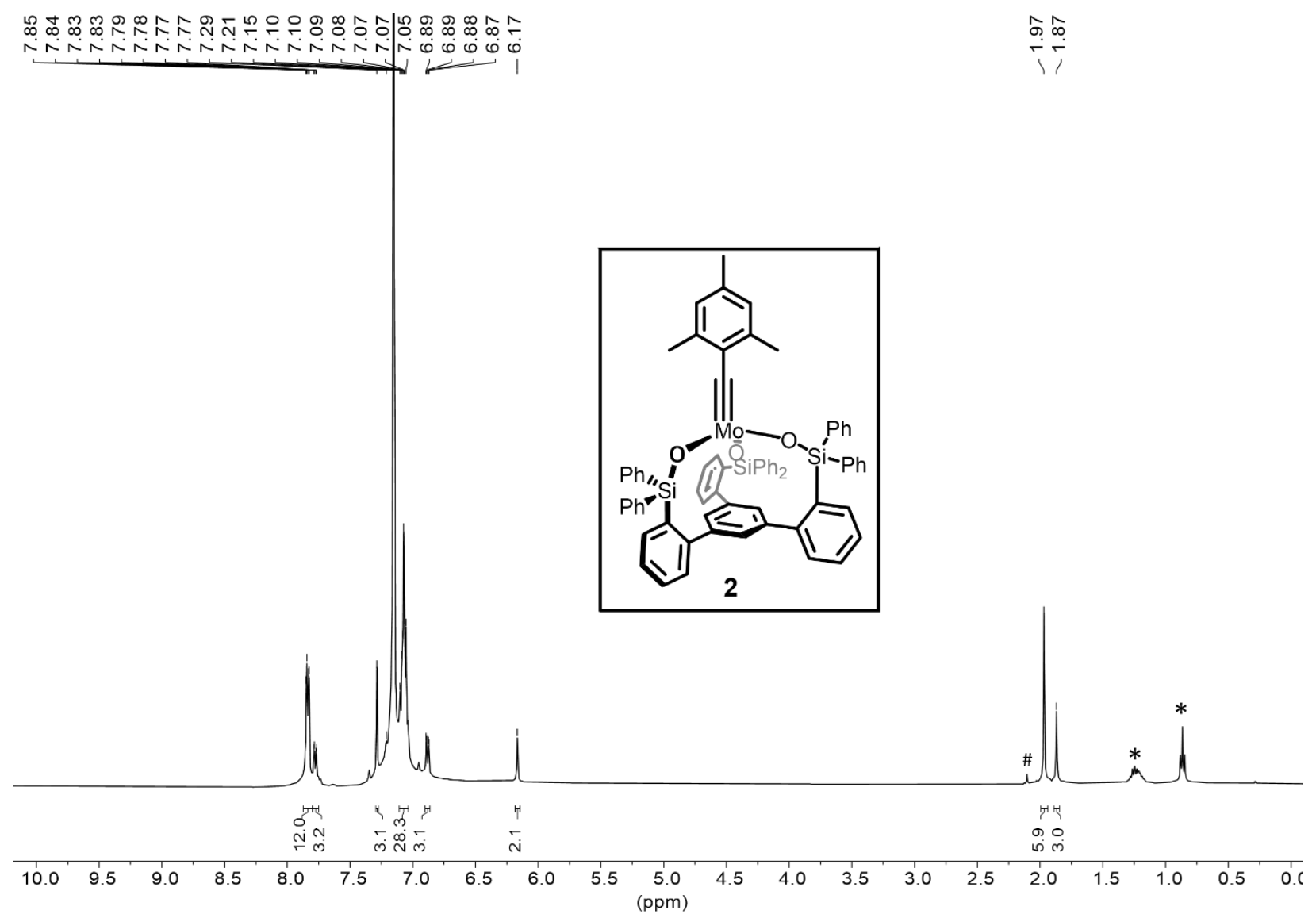

Figure S3. ${ }^{1} \mathrm{H}$ NMR $\left(400 \mathrm{MHz}, \mathrm{C}_{6} \mathrm{D}_{6}, 25{ }^{\circ} \mathrm{C}\right)$ spectrum of 2. Pentane $(*)$ and trace toluene (\#) are denoted. 


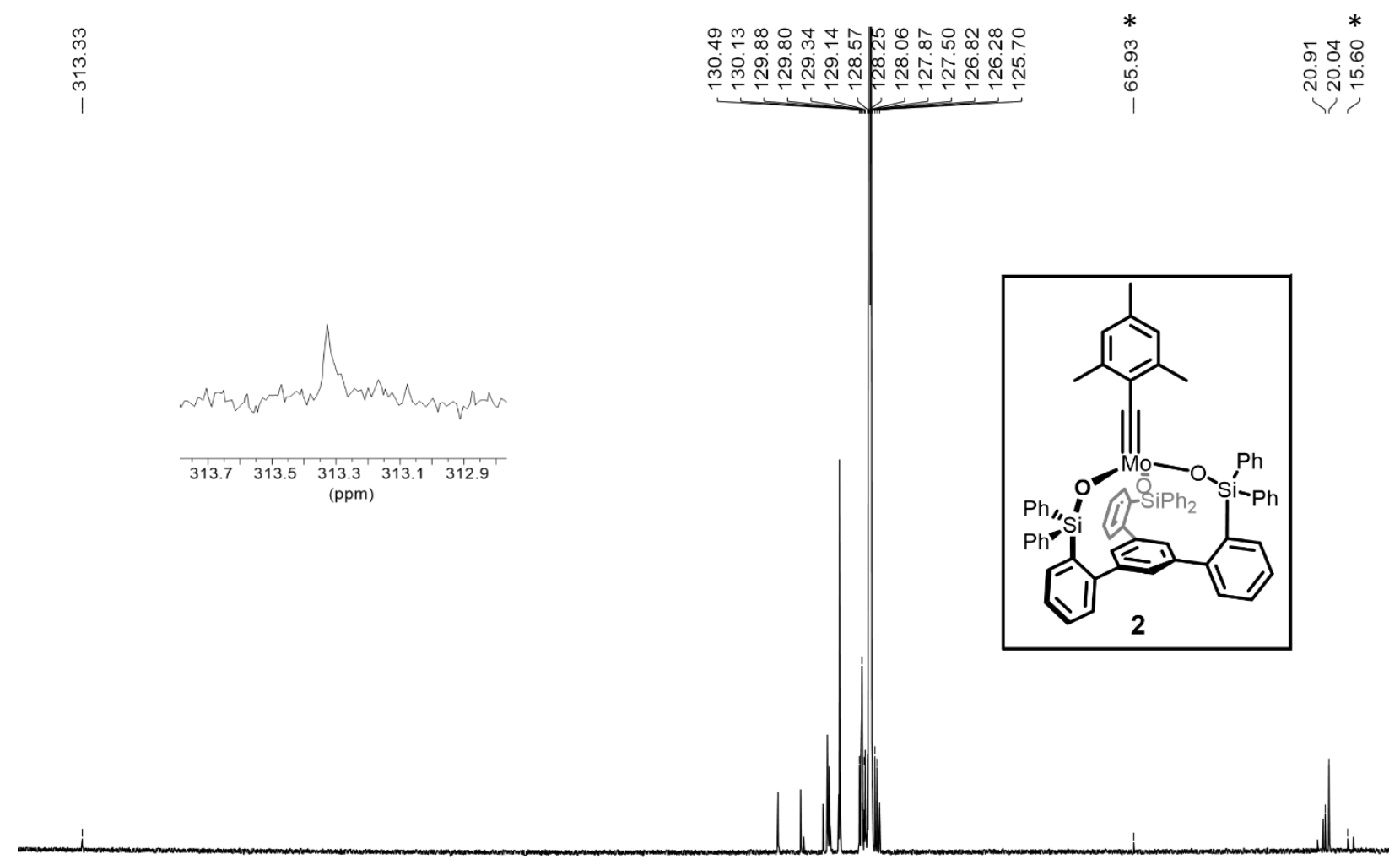

$32031030029028027026025024023022021020019018017016015014013012011010090 \quad 80 \quad 70 \begin{array}{lllllllll}1 & 50 & 40 & 30 & 20 & 10\end{array}$ (ppm)

Figure S4. ${ }^{13} \mathrm{C}$ NMR (125 MHz, $\left.\mathrm{C}_{6} \mathrm{D}_{6}, 25{ }^{\circ} \mathrm{C}\right)$ spectrum of 2. Diethyl ether is denoted (*). 


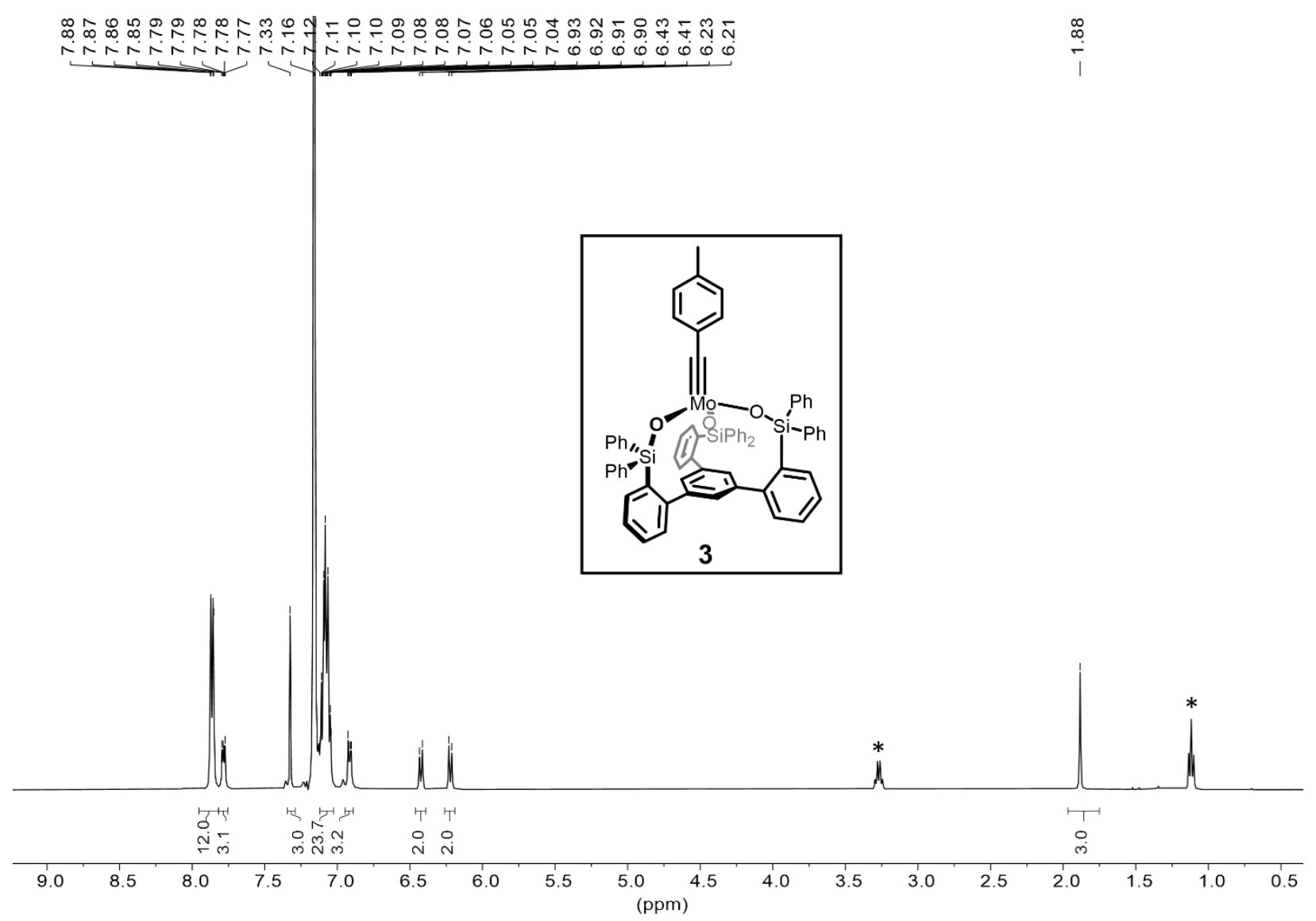

Figure S5. ${ }^{1} \mathrm{H}$ NMR $\left(400 \mathrm{MHz}, \mathrm{C}_{6} \mathrm{D}_{6}, 25{ }^{\circ} \mathrm{C}\right)$ spectrum of 3; diethyl ether which is in the crystal lattice is denoted $(*)$. 


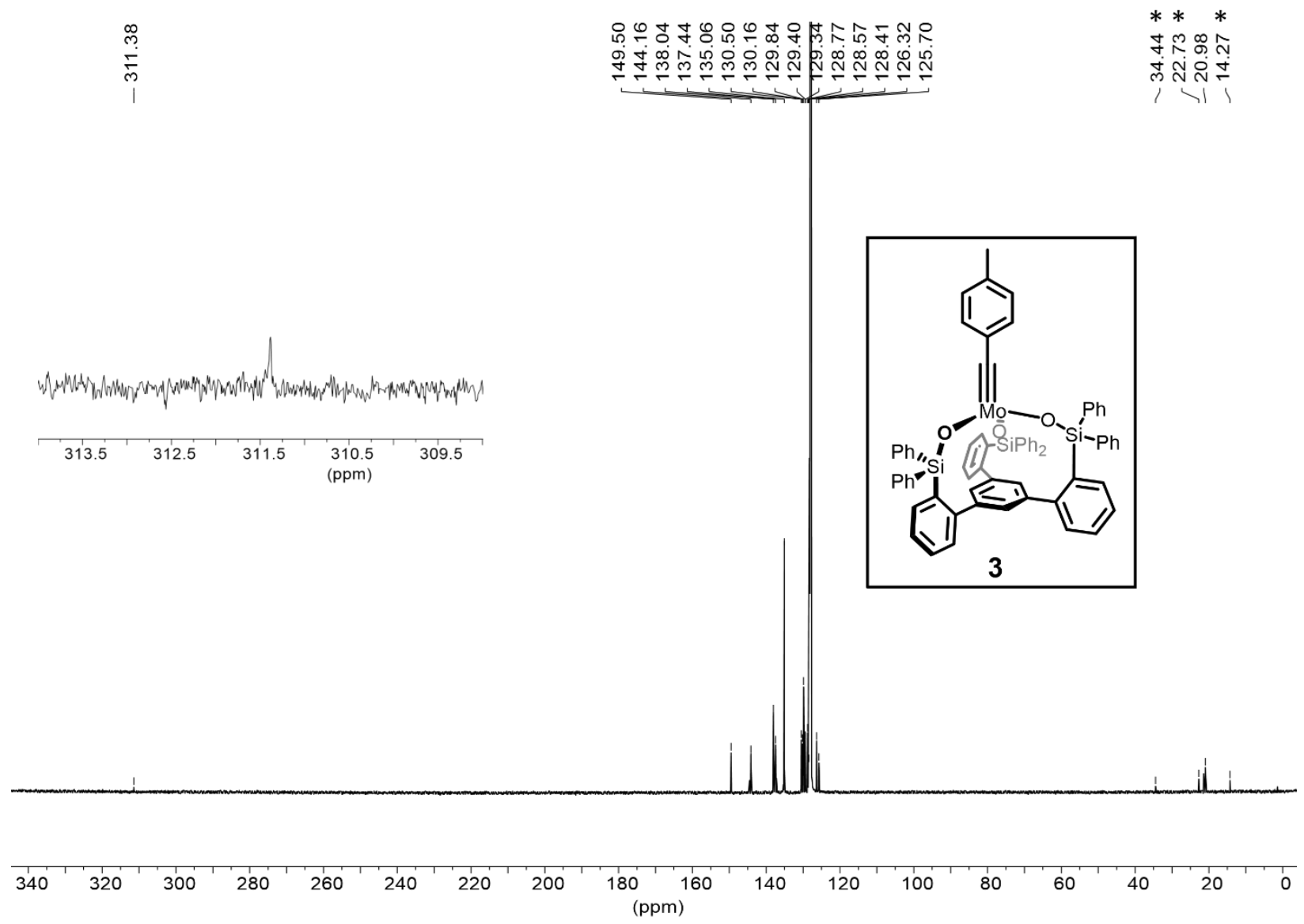

Figure S6. ${ }^{13} \mathrm{C}\left\{{ }^{1} \mathrm{H}\right\}$ NMR $\left(125 \mathrm{MHz}, \mathrm{C}_{6} \mathrm{D}_{6}, 25{ }^{\circ} \mathrm{C}\right)$ spectrum of 3 with the carbyne carbon expanded in the inset. Pentane is denoted (*). 


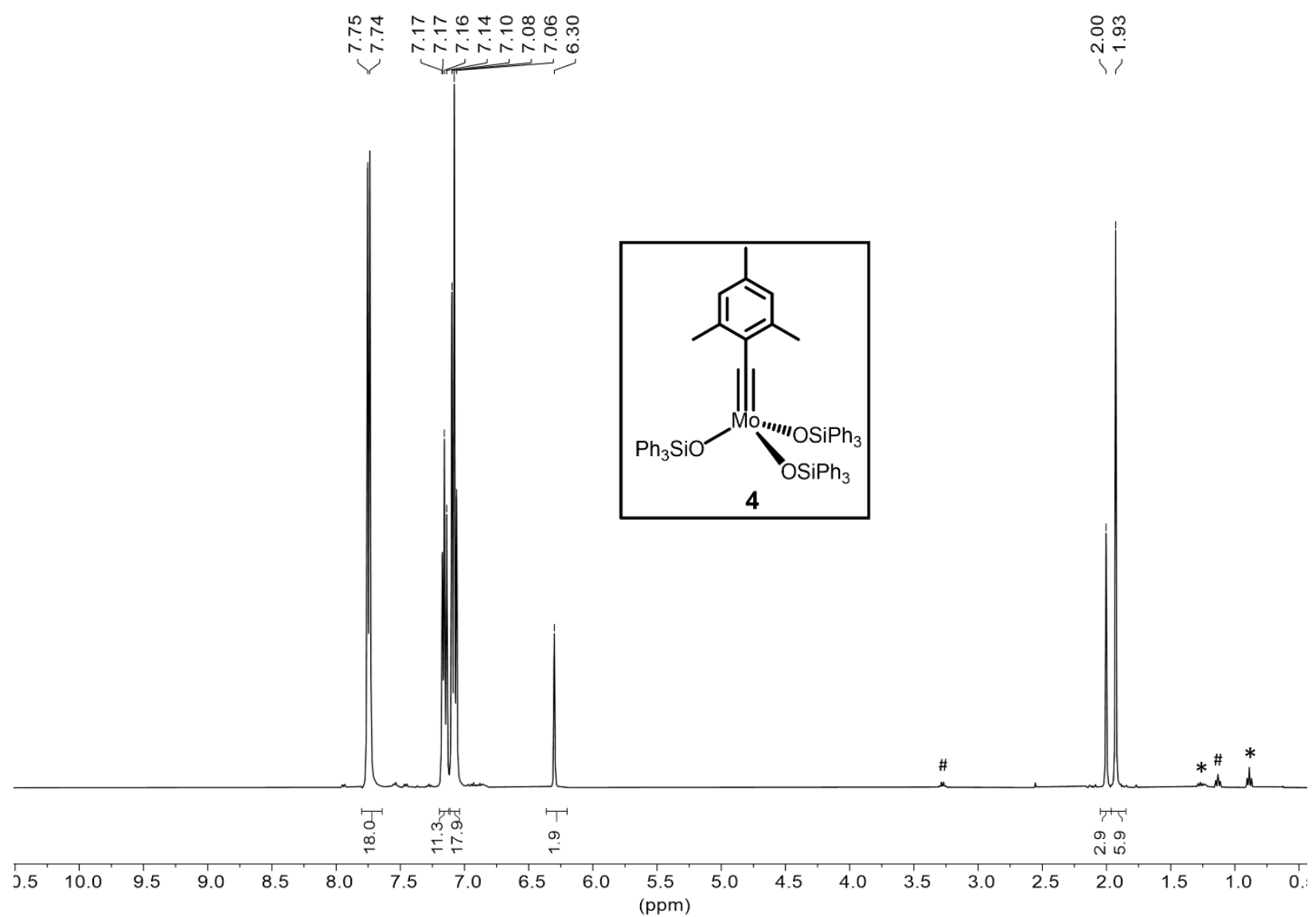

Figure S7. ${ }^{1} \mathrm{H}$ NMR (400 MHz, $\left.\mathrm{C}_{6} \mathrm{D}_{6}, 25{ }^{\circ} \mathrm{C}\right)$ spectrum of 4. Pentane (*) and diethyl ether (\#) are denoted. 


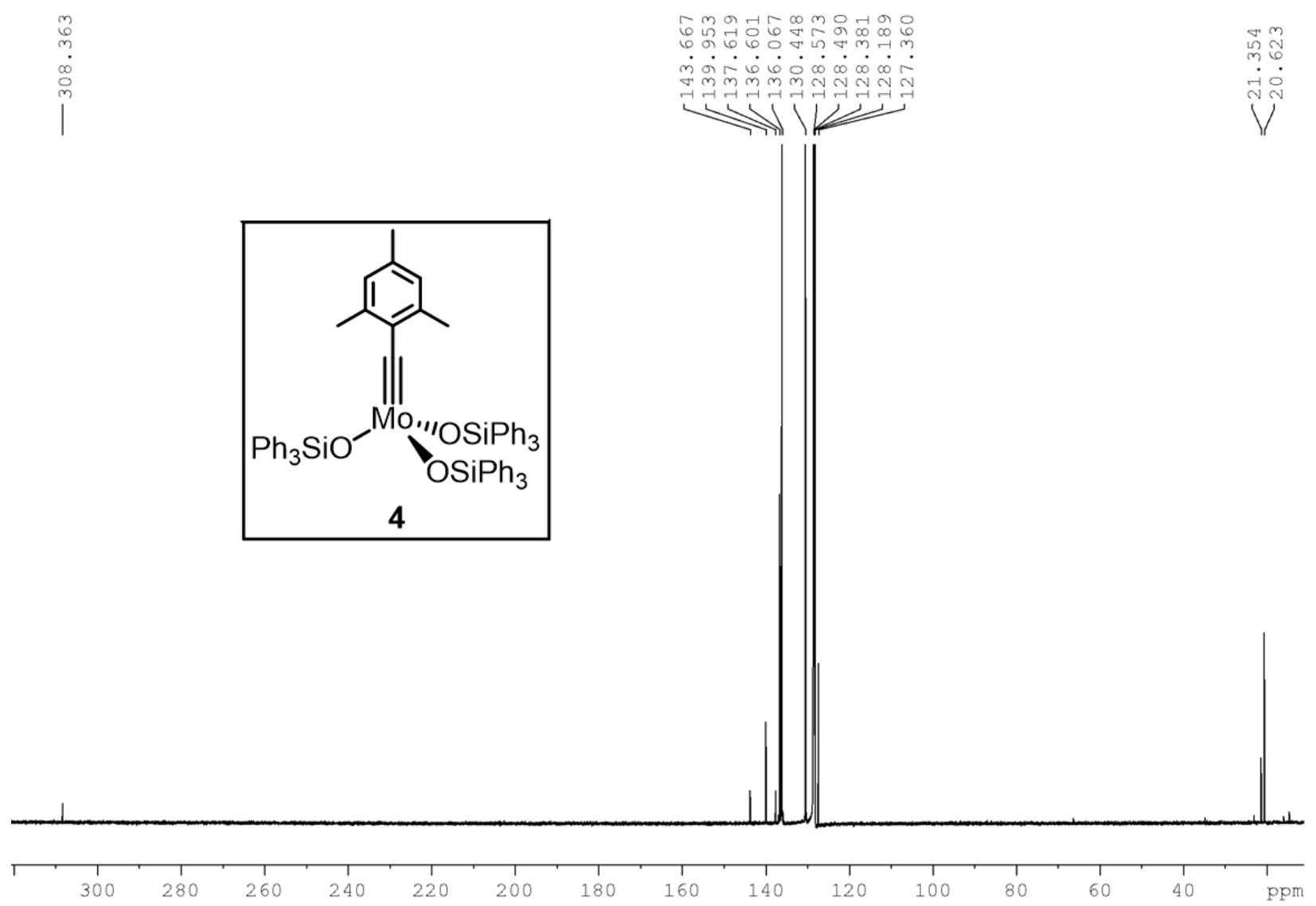

Figure S8. ${ }^{13} \mathrm{C}\left\{{ }^{1} \mathrm{H}\right\}$ NMR $\left(125 \mathrm{MHz}, \mathrm{C}_{6} \mathrm{D}_{6}, 25{ }^{\circ} \mathrm{C}\right)$ spectrum of 4. 


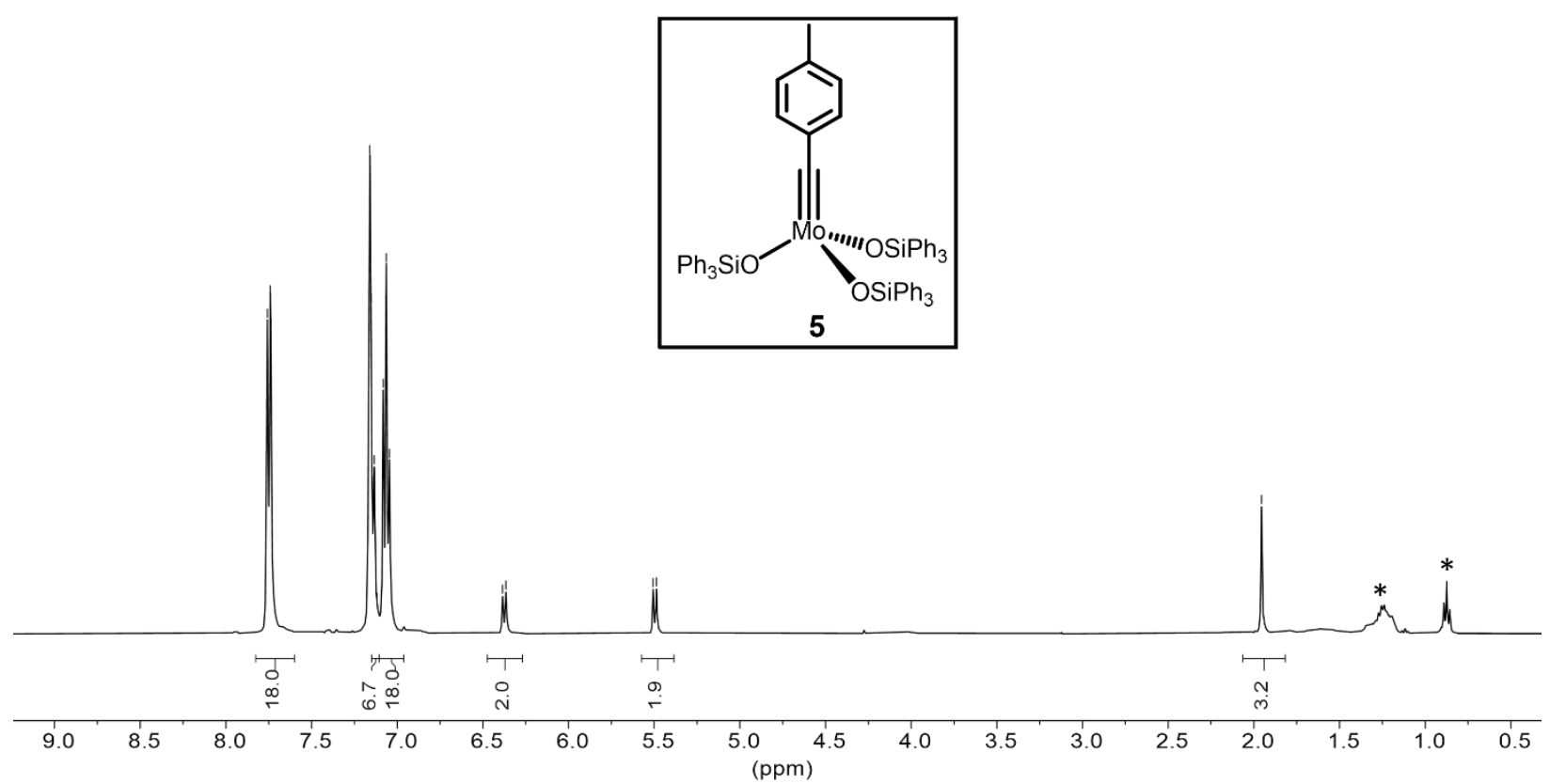

Figure S9. ${ }^{1} \mathrm{H}$ NMR $\left(400 \mathrm{MHz}, \mathrm{C}_{6} \mathrm{D}_{6}, 25{ }^{\circ} \mathrm{C}\right)$ spectrum of 5. The para $\mathrm{C}-H$ resonance of the $\mathrm{OSiPh}_{3}$ ligand partially overlaps with the $\mathrm{C}_{6} \mathrm{D}_{6}$ resonance. Pentane is denoted with (*). 


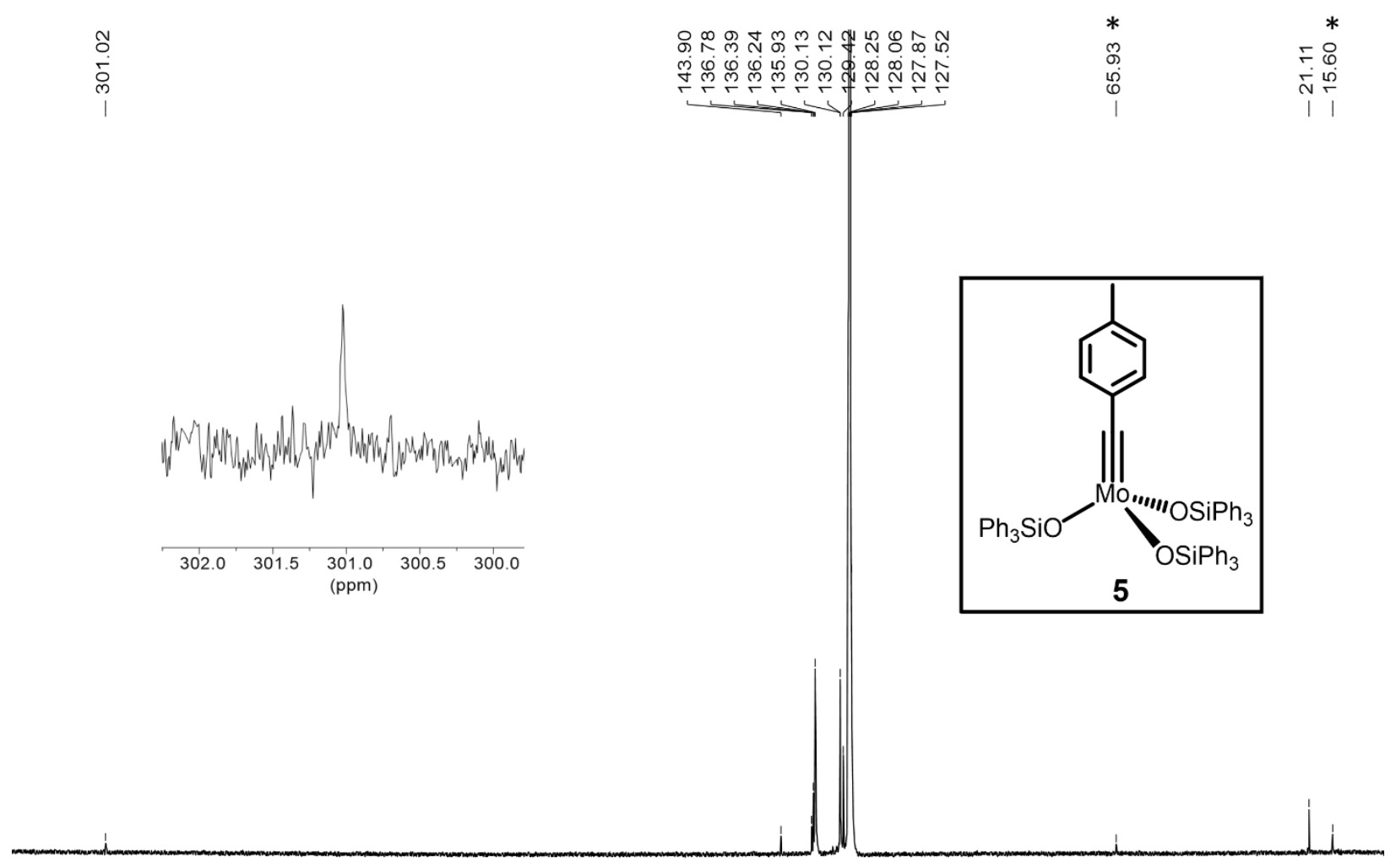

$320310300290280270260250240230220210200190180170160150140130120110100 \begin{array}{lllllllllll}1 & 80 & 70 & 60 & 50 & 40 & 30 & 20 & 10\end{array}$ (ppm)

Figure S10. ${ }^{13} \mathrm{C}\left\{{ }^{1} \mathrm{H}\right\}$ NMR $\left(125 \mathrm{MHz}, \mathrm{C}_{6} \mathrm{D}_{6}, 25{ }^{\circ} \mathrm{C}\right)$ spectrum of 5 with the carbyne carbon expanded in the inset. Diethyl ether is denoted (*). 


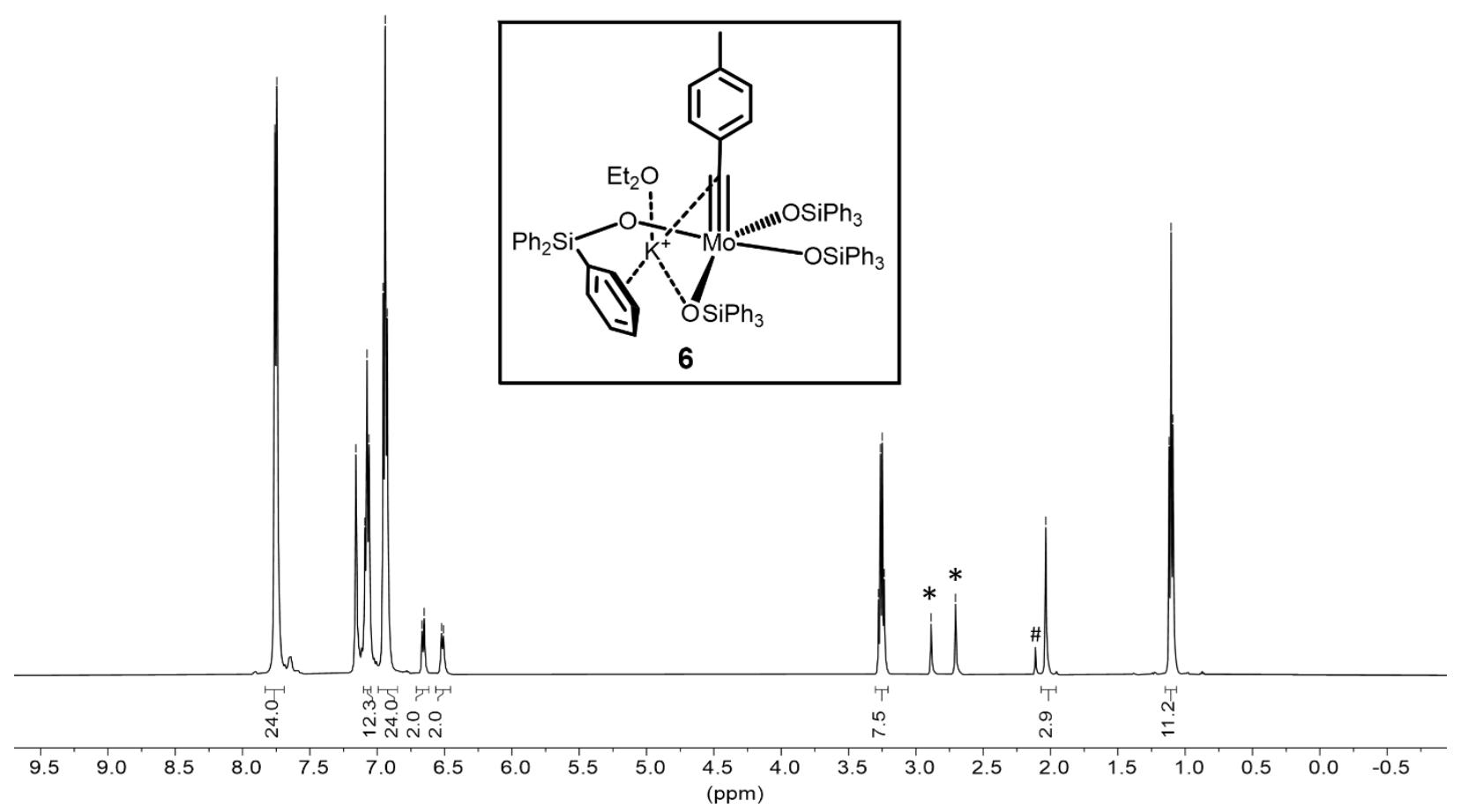

Figure S11. ${ }^{1} \mathrm{H}$ NMR $\left(400 \mathrm{MHz}, \mathrm{C}_{6} \mathrm{D}_{6}, 25{ }^{\circ} \mathrm{C}\right)$ spectrum of 6 . An unknown but persistent impurity $(*)$ found in crystalline samples is denoted. Toluene (\#) is denoted. 

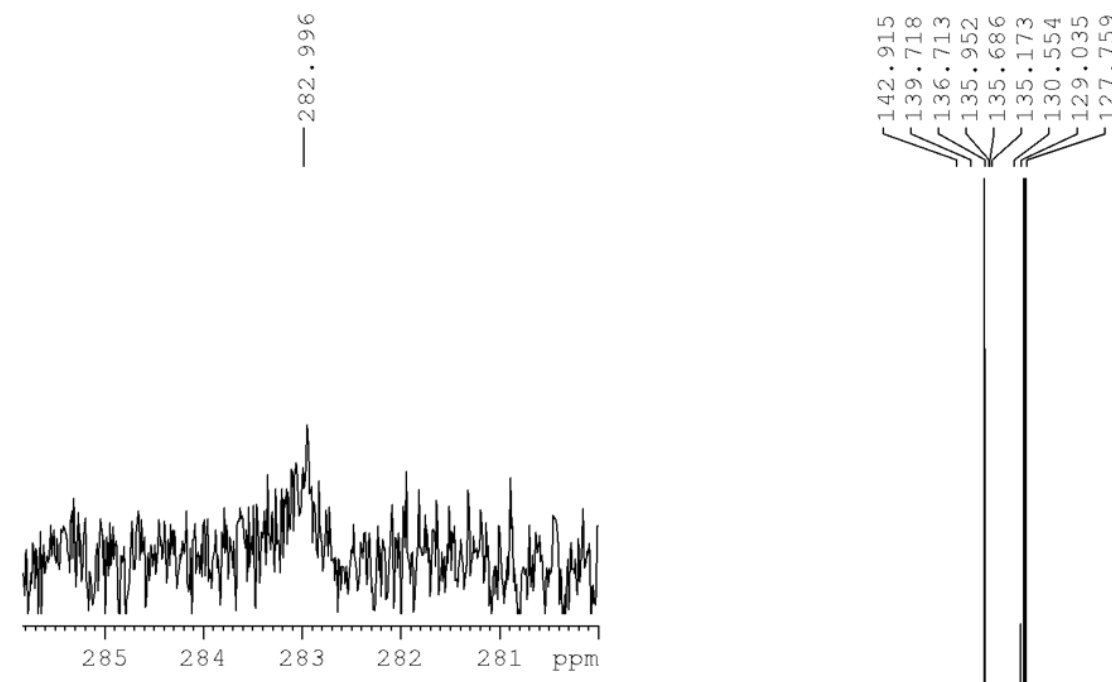

में

तi

| | |

옹
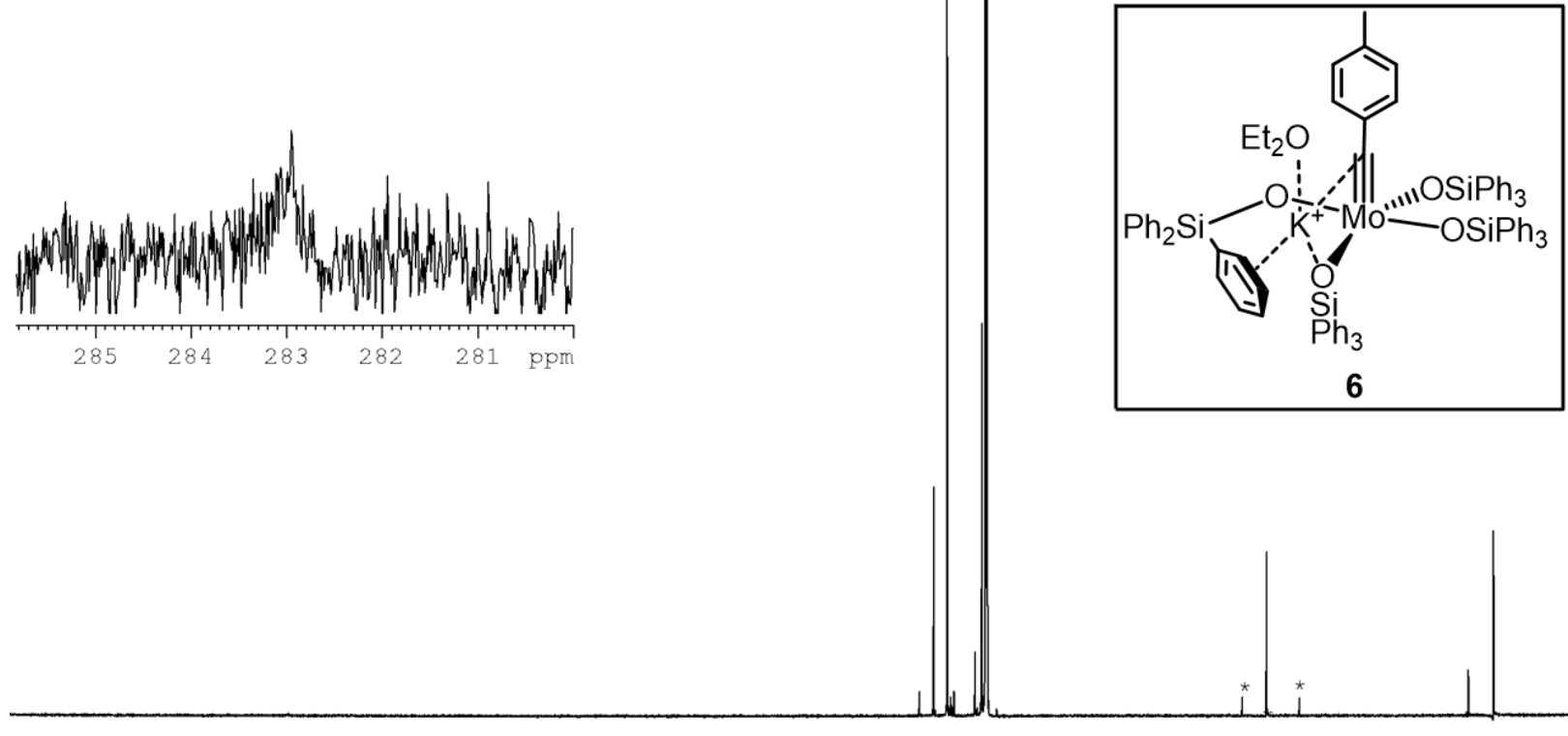

300

250

200

150

100

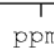

Figure S12. ${ }^{13} \mathrm{C}\left\{{ }^{1} \mathrm{H}\right\}$ NMR $\left(125 \mathrm{MHz}, \mathrm{C}_{6} \mathrm{D}_{6}, 25{ }^{\circ} \mathrm{C}\right)$ spectrum of $6 . *$ denotes an unknown but persistent impurity found in crystalline samples. The resonance at $283.00 \mathrm{ppm}$ is shown in the inset and is at lower intensity than expected due to interactions with the $\mathrm{K}^{+}$cation. 

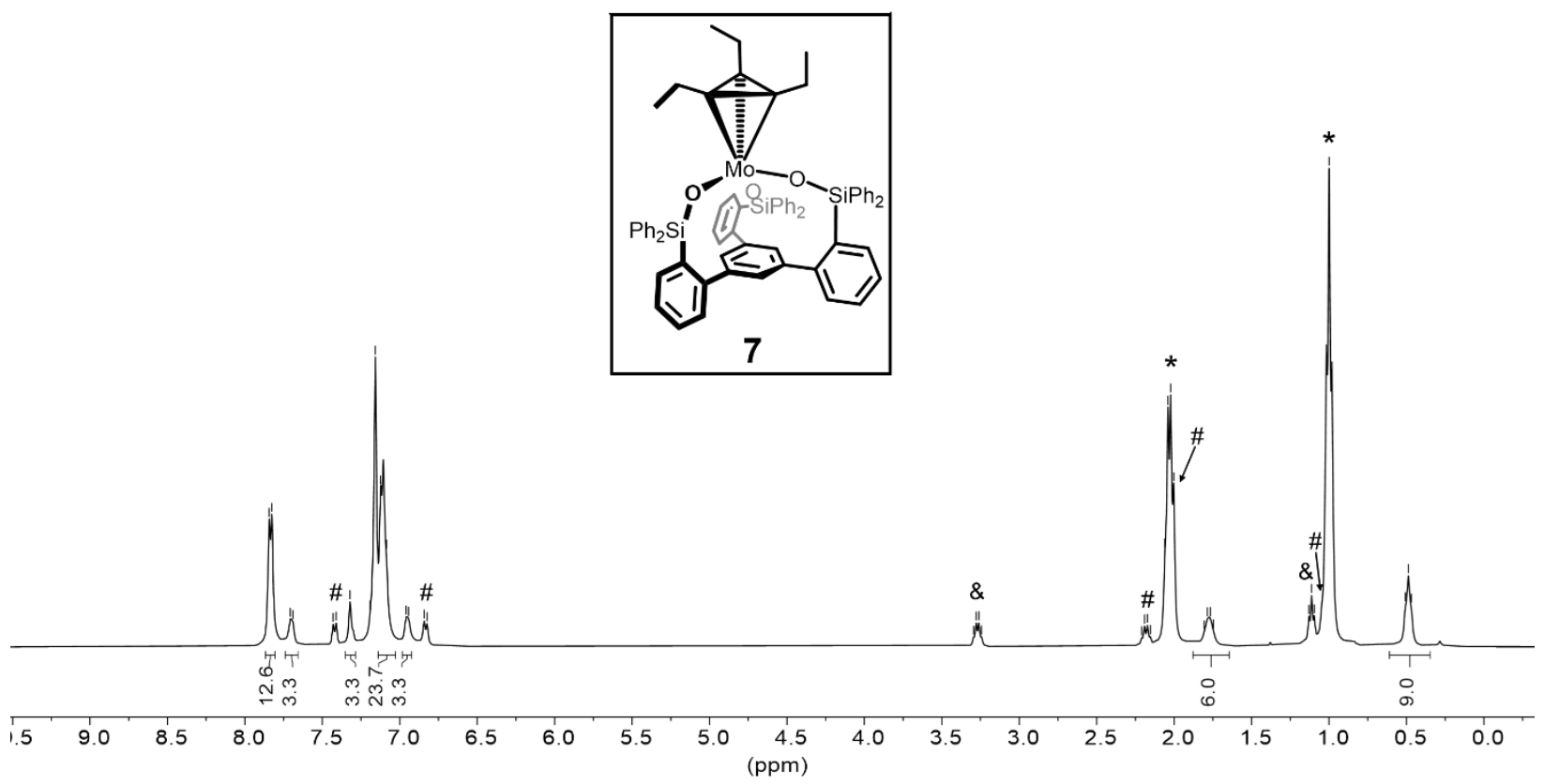

Figure S13. ${ }^{1} \mathrm{H}$ NMR (400 MHz, $\left.\mathrm{C}_{6} \mathrm{D}_{6}, 25{ }^{\circ} \mathrm{C}\right)$ spectrum of 7 generated in-situ by the addition of excess 3-hexyne to a solution of 3 . Resonances associated with 3-hexyne (*), 1-p-tolyl-1-butyne product (\#) and $\mathrm{Et}_{2} \mathrm{O}$ which recrystallized in the $\mathbf{3}$ starting material (\&) are denoted. 

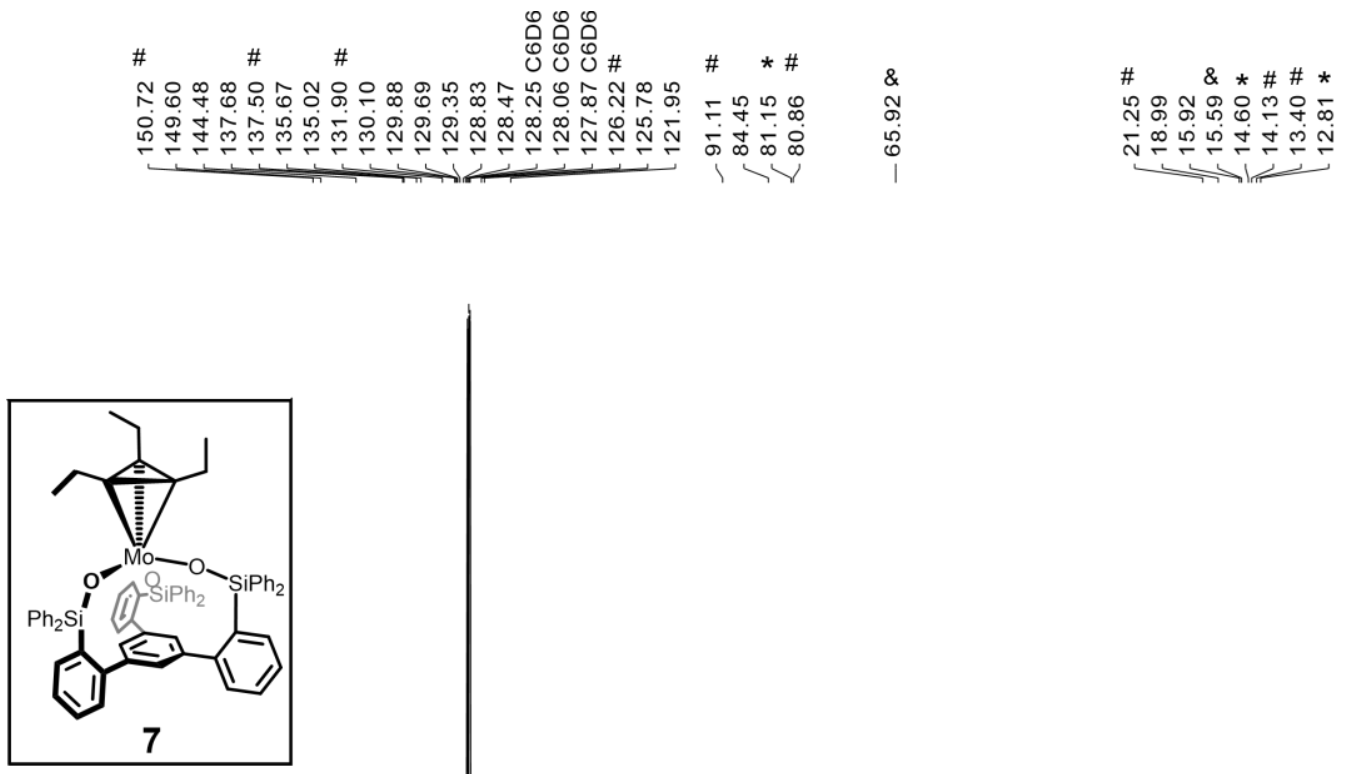

$\begin{array}{llllllllllllllllllllllll}210 & 200 & 190 & 180 & 170 & 160 & 150 & 140 & 130 & 120 & 110 & 100 & 90 & 80 & 70 & 60 & 50 & 40 & 30 & 20 & 10 & 0 & -10 & 0\end{array}$

Figure S14. ${ }^{13} \mathrm{C}$ NMR $\left(125 \mathrm{MHz}, \mathrm{C}_{6} \mathrm{D}_{6}, 25{ }^{\circ} \mathrm{C}\right)$ spectrum of 7 generated in-situ by the addition of excess 3-hexyne to a solution of $\mathbf{3}$. Resonances associated with 3-hexyne are denoted with (*) and the $p$-tolyl-1-butyne product with (\#). $\mathrm{Et}_{2} \mathrm{O}$ which recrystallized in the $\mathbf{3}$ starting material is denoted with (\&). 


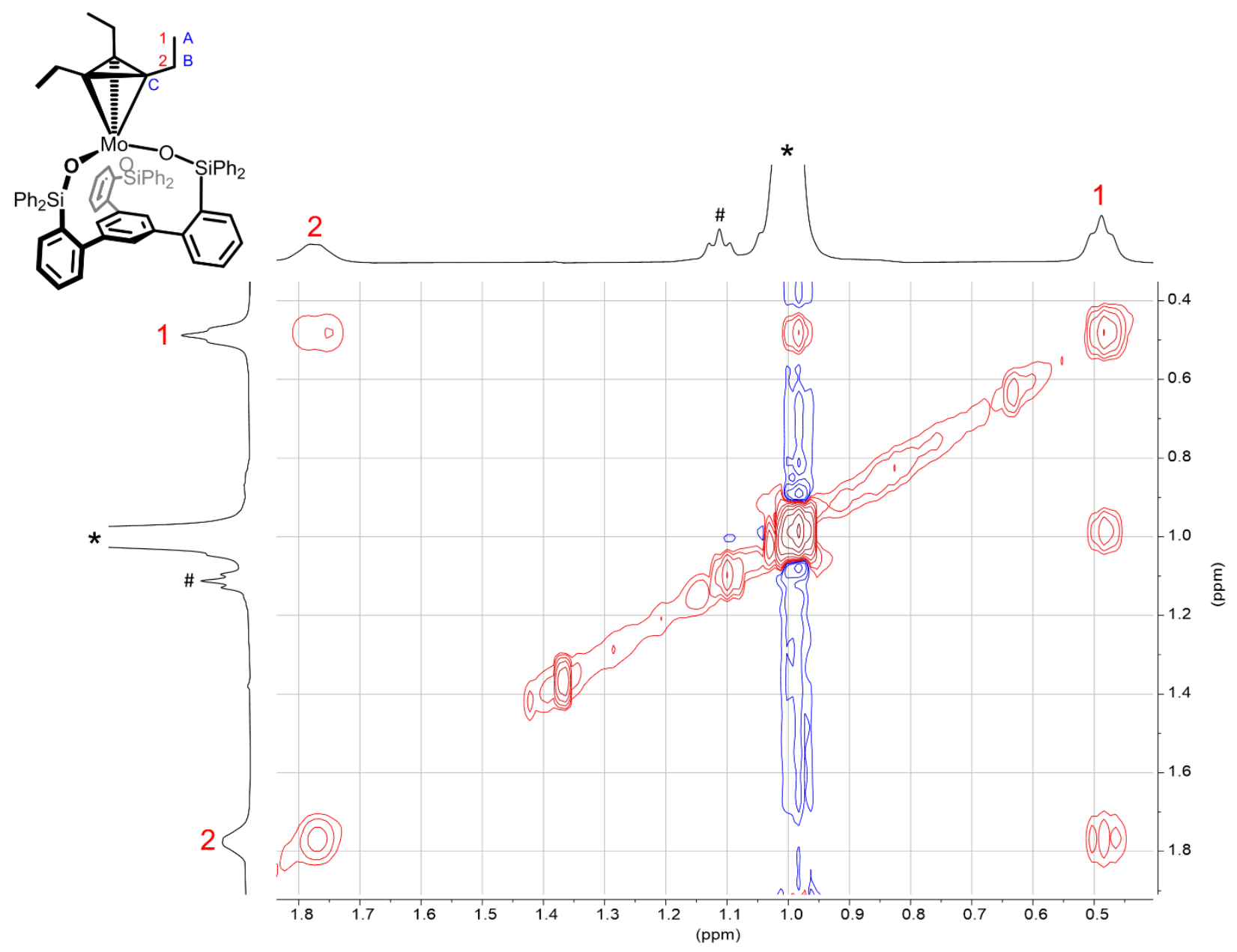

Figure S15. ${ }^{1} \mathrm{H}-{ }^{1} \mathrm{H}$ Through-bond coupling gCOSY NMR $\left(500 \mathrm{MHz}, \mathrm{C}_{6} \mathrm{D}_{6}, 25{ }^{\circ} \mathrm{C}\right)$ spectrum of 7 generated in-situ by the addition of excess 3-hexyne (*) to a solution of $\mathbf{3}$. $\mathrm{Et}_{2} \mathrm{O}$ is denoted (\#). 


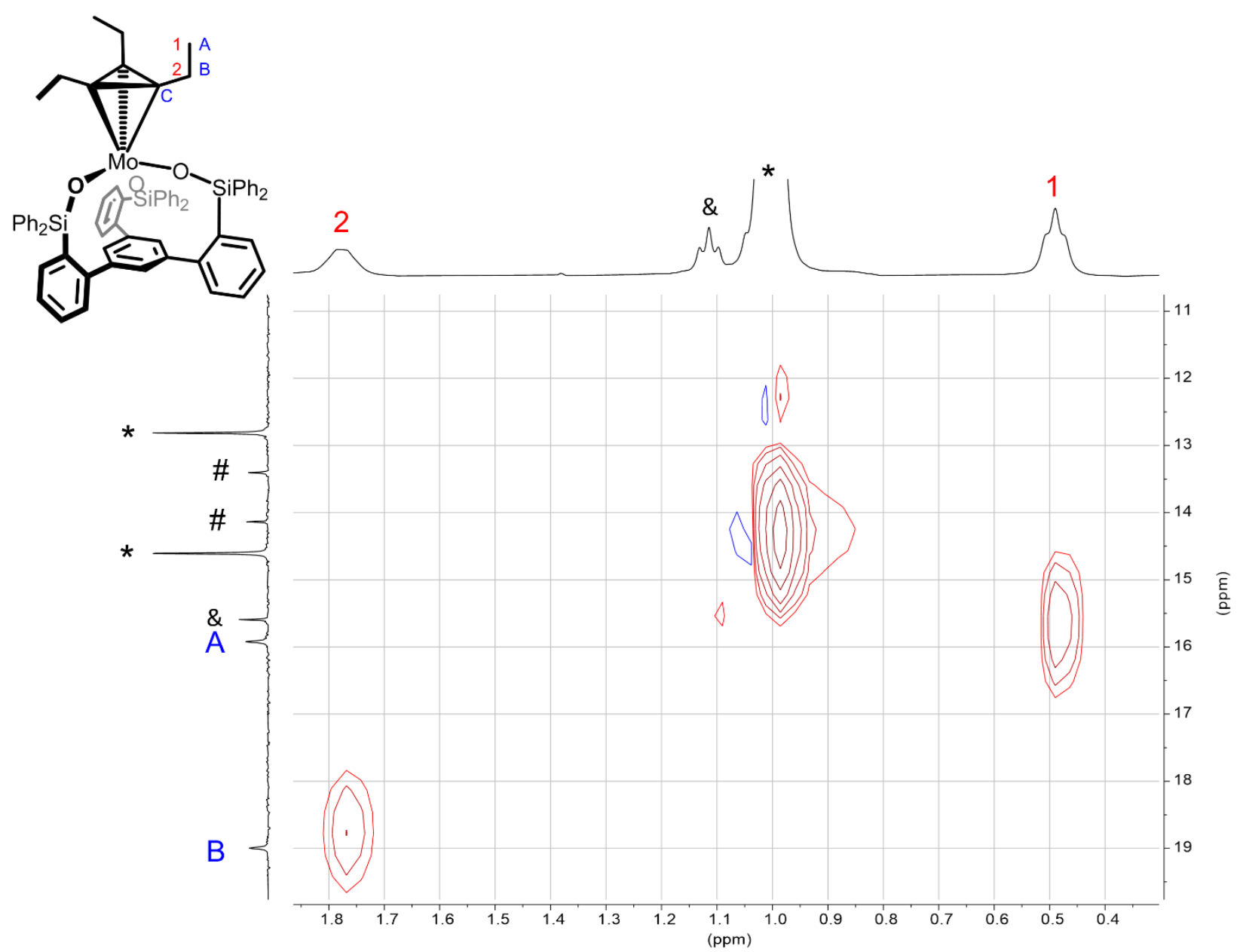

Figure S16. One-bond coupling ${ }^{1} \mathrm{H}_{-}{ }^{13} \mathrm{C}$ gHSQC NMR $\left(500 \mathrm{MHz}, \mathrm{C}_{6} \mathrm{D}_{6}, 25{ }^{\circ} \mathrm{C}\right)$ spectrum of 7 generated in-situ by the addition of excess 3-hexyne (*) to a solution of 3 . The 1-p-tolyl-1-butyne (\#) product and $\mathrm{Et}_{2} \mathrm{O}(\&)$ are denoted. 

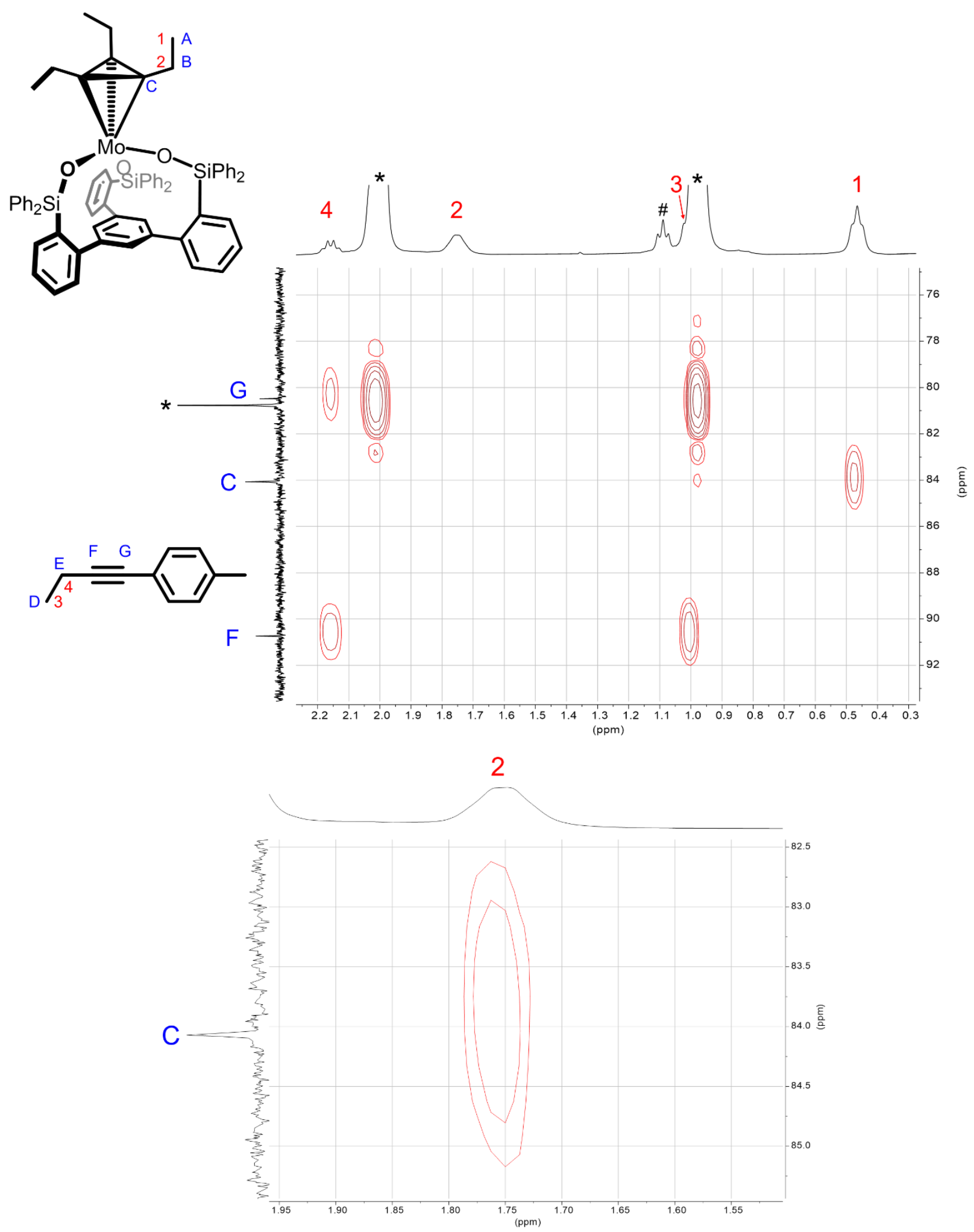

Figure S17. Long-range coupling ${ }^{1} \mathrm{H}_{-}{ }^{13} \mathrm{C}$ gHMBC NMR (500 MHz, $\left.\mathrm{C}_{6} \mathrm{D}_{6}, 25{ }^{\circ} \mathrm{C}\right)$ spectrum of 7 generated in-situ by the addition of excess 3-hexyne (*) to a solution of 3. (Top) Expanded portion showing correlation of ${ }^{1} \mathrm{H} 2$ with ${ }^{13} \mathrm{C} \mathrm{C}$ (Bottom). $\mathrm{Et}_{2} \mathrm{O}$ is denoted (\#). 


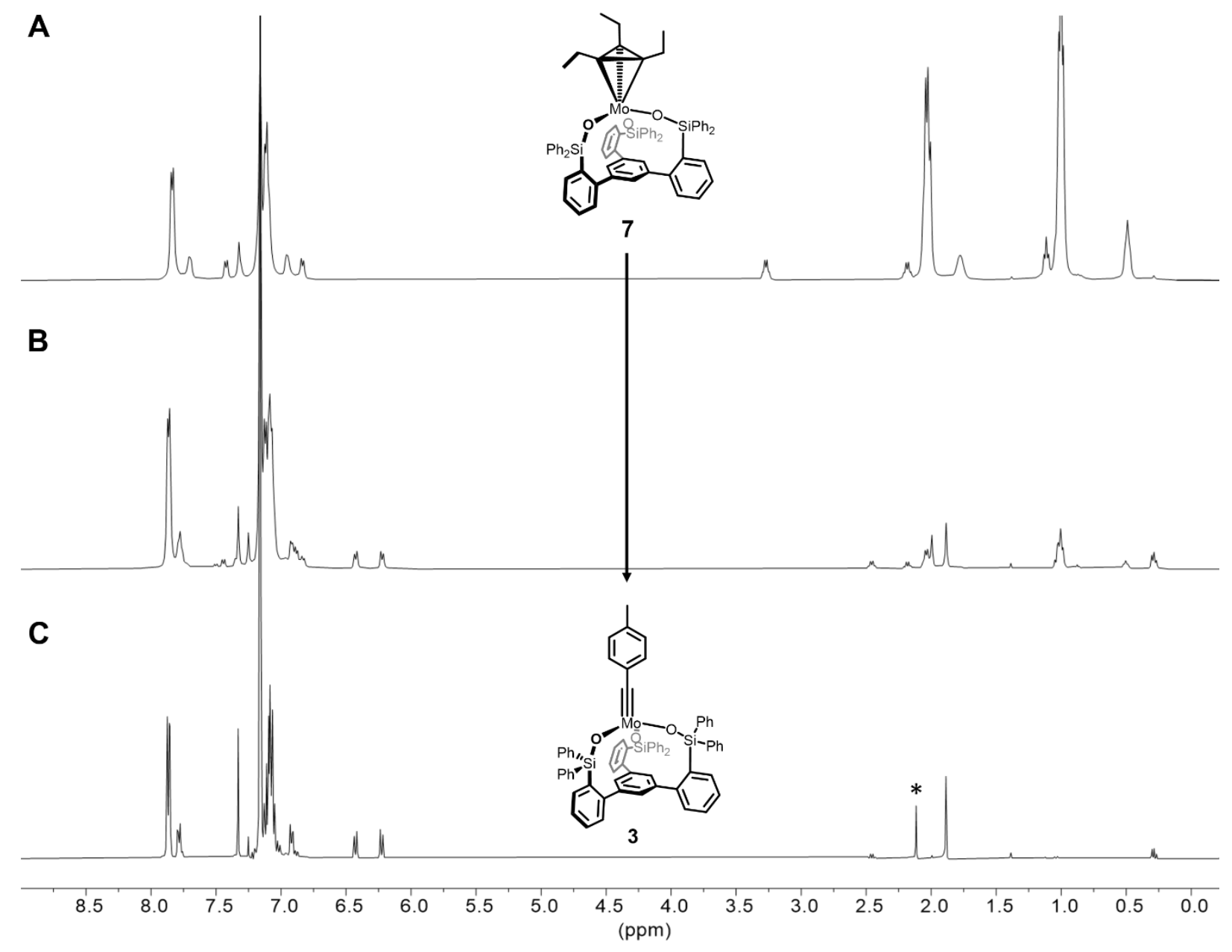

Figure S18. Stacked plots showing 7 before vacuum (A), removal of solvent to dryness (B) and addition of toluene and removal of solvent a second time (C) showing the full conversion of 7 back to 3 . Toluene is denoted $(*)$. 


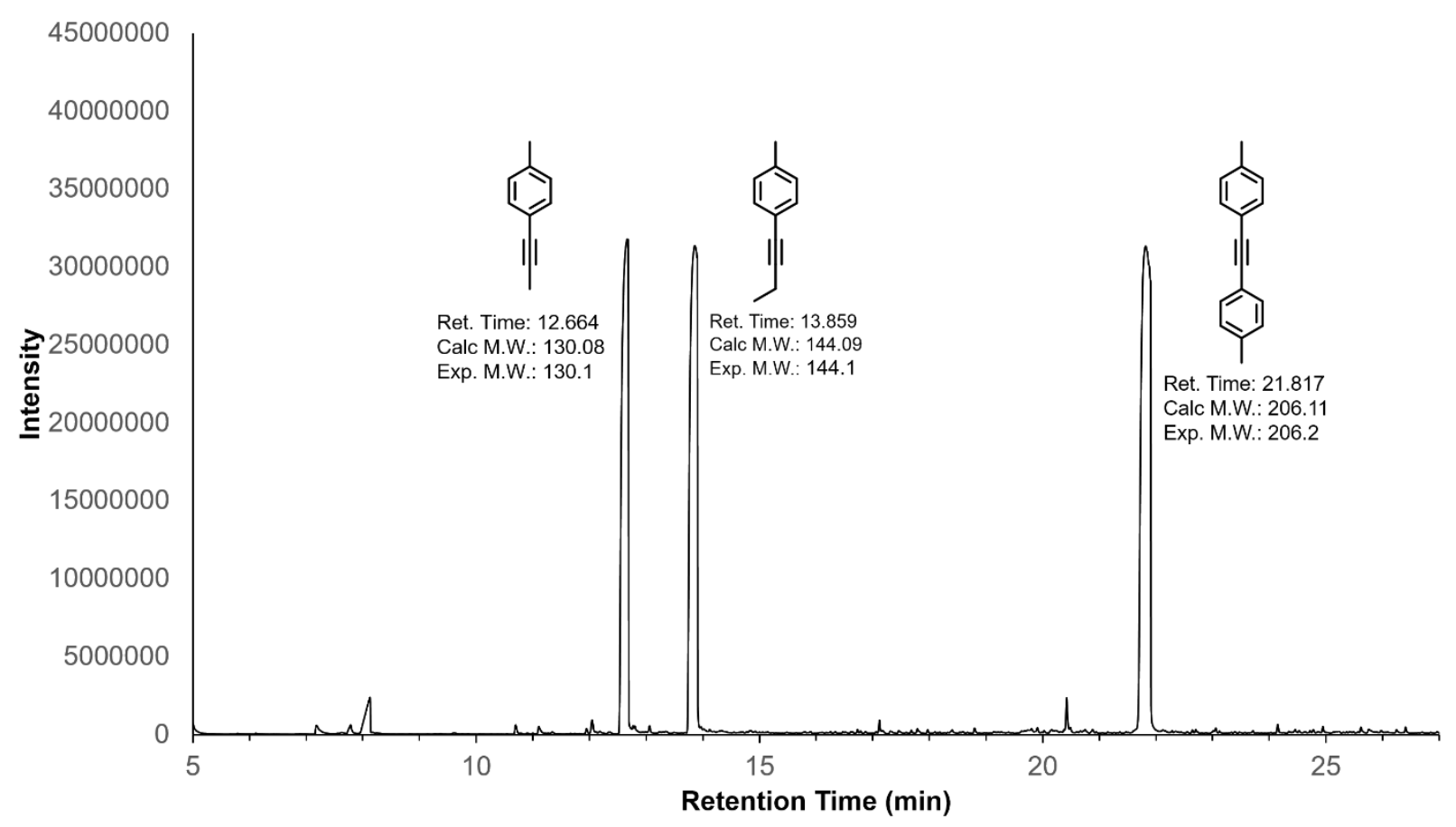

Figure S19. GC-MS of the crude mixture resulting from addition of $p$-tolylpropyne (15 eq) to a solution containing 7 and 3-hexyne (5 eq) revealing the ability of $\mathbf{7}$ to catalyze metathesis. 


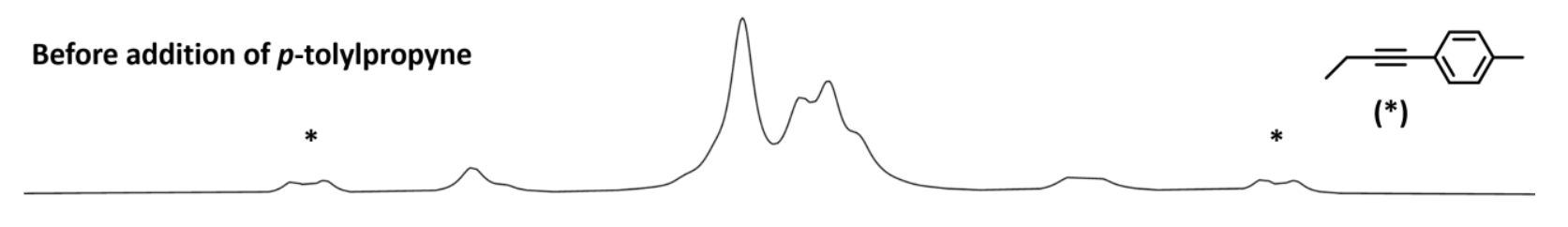

$5 \mathrm{~min}$. after addition of $p$-tolylpropyne

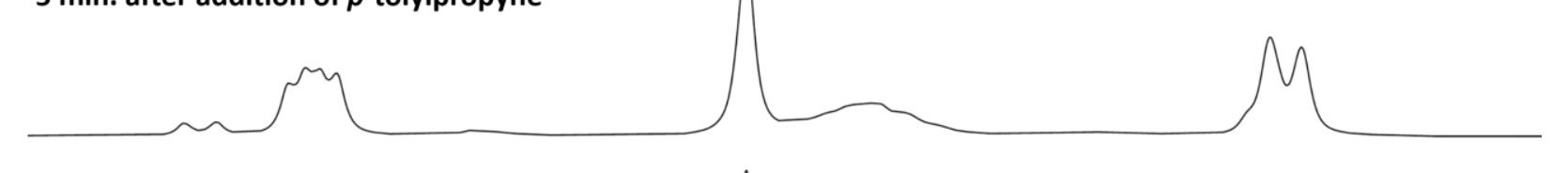

185 min. after addition of $p$-tolylpropyne
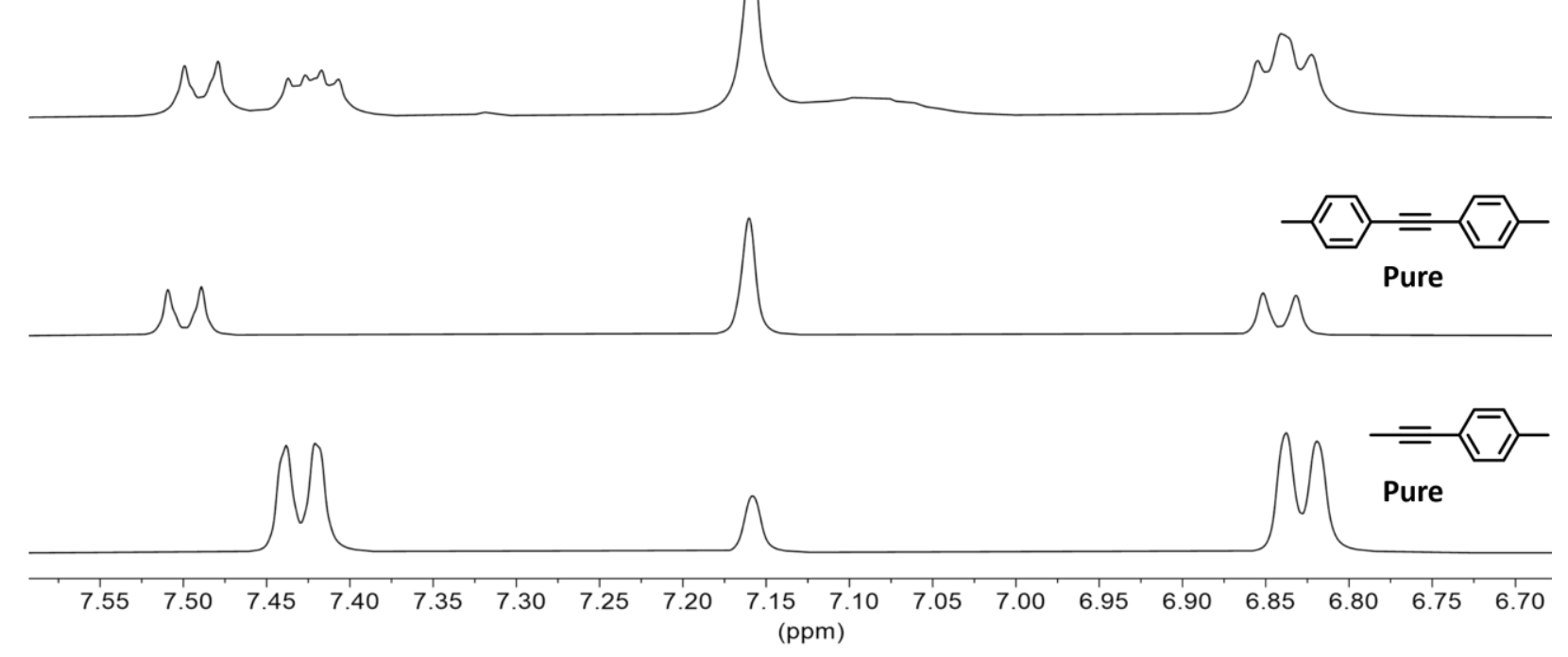

Figure S20. Stacked spectra showing the conversion of $p$-tolylpropyne into an equilibrium mixture of $p$-tolylpropyne, $p$-tolyl-2-butyne and di-p-tolylacetylene after its addition to a crude mixture of 7 with excess 3-hexyne and 1-p-tolyl-1-butyne (side-product of the formation of 7 from 3). Spectra of pure $p$-tolylpropyne and di-p-tolylacetylene are provided for reference. 


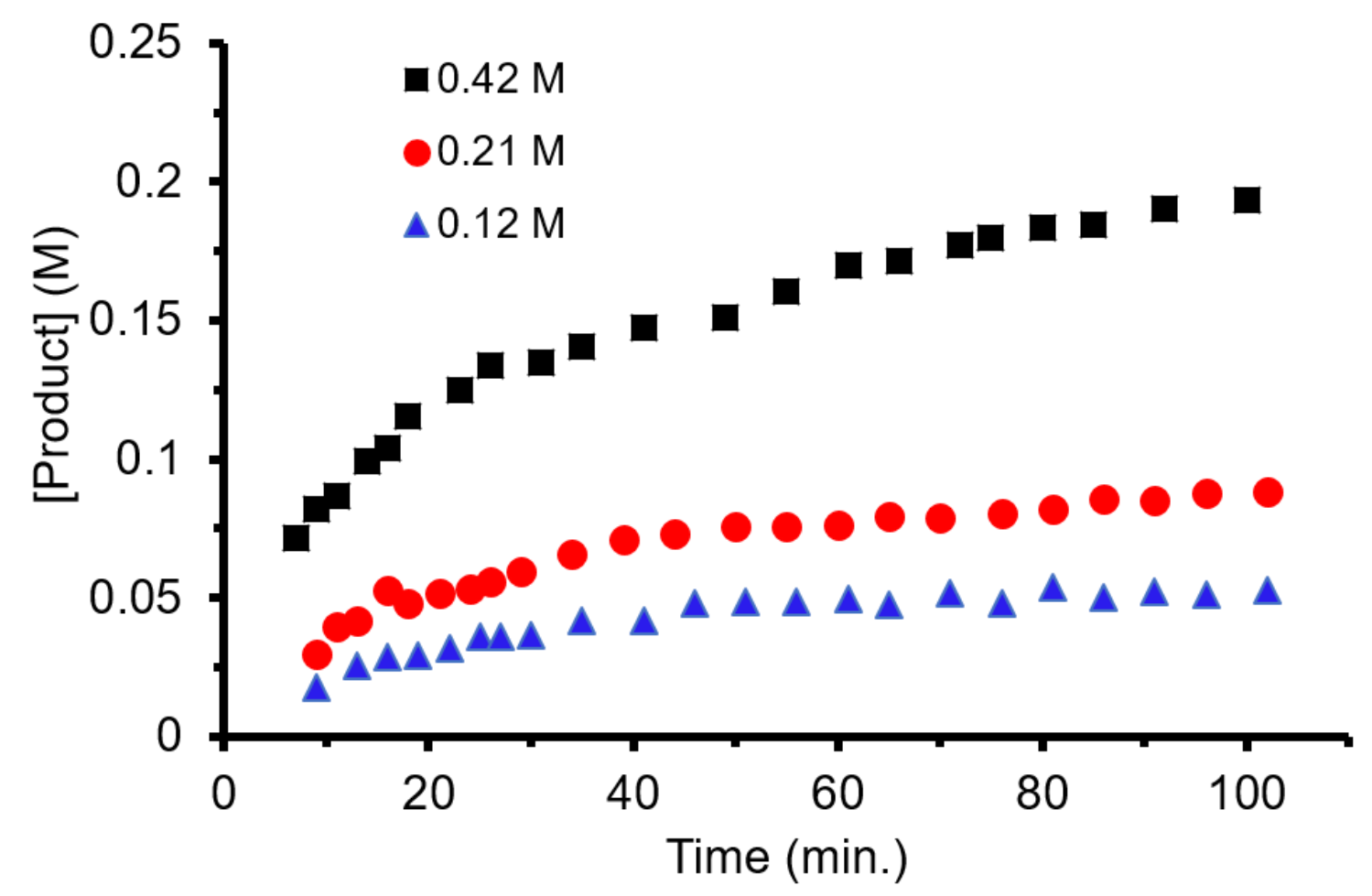

Figure S21. Dynamic scrambling of 1-methoxy-4-(phenylethynl)benzene at various concentrations of substate $\left([3]=7.8 \mathrm{mM}\right.$ in $\left.\mathrm{C}_{6} \mathrm{D}_{6}\right)$ evidencing against a zero-order kinetics.

\section{Crystallographic Information}

Crystallographic data are summarized in Tables S1 and S2. Suitable crystals for X-ray analysis of 1-7 were placed a Mitagen pin, coated in oil. The X-ray intensity data collection was carried out on a Bruker APEXII CCD area detector using graphite-monochromated Mo-K $\alpha$ radiation $(\lambda$ $=0.71072 \AA$ ) at $90(5) \mathrm{K}$. Preliminary indexing was performed from a series of thirty-six $0.5^{\circ}$ rotation frames with exposures of 10 seconds. Rotation frames were integrated using SAINT ${ }^{2}$ producing a listing of non-averaged $\mathrm{F}^{2}$ and $\sigma\left(\mathrm{F}^{2}\right)$ values. The intensity data were corrected for Lorentz and polarization effects and for absorption using SADABS. ${ }^{3}$ The initial structure was determined by the direct method on SHELXS. ${ }^{4}$ The further structure determination was performed by Fourier transform method and refined by least squares method on SHELXL ${ }^{5,6}$ All reflections were used during refinement. Non-hydrogen atoms were refined anisotropically and hydrogen atoms were refined with riding models. Disordered phenyl groups and solvents were successfully modeled. 
Table S1. Crystallographic Data for 1-3

\begin{tabular}{|c|c|c|c|}
\hline & $\mathbf{1}$ & 2 & 3 \\
\hline Molecular Formula & $\mathrm{C}_{60} \mathrm{H}_{48} \mathrm{O}_{3} \mathrm{Si}_{3} \cdot \mathrm{H}_{2} \mathrm{O}$ & $\mathrm{C}_{70} \mathrm{H}_{56} \mathrm{MoO}_{3} \mathrm{Si}_{3} \cdot\left(\mathrm{C}_{7} \mathrm{H}_{8}\right)_{0.5}$ & $\mathrm{C}_{68} \mathrm{H}_{52} \mathrm{MoO}_{3} \mathrm{Si}_{3} \cdot\left(\mathrm{C}_{4} \mathrm{H}_{10} \mathrm{O}\right)_{0.5}$ \\
\hline Fw & 919.27 & 1171.42 & 1134.36 \\
\hline $\operatorname{Temp}(\mathrm{K})$ & $90.0(5)$ & $90.0(5)$ & $90.0(5)$ \\
\hline Crystal System & Triclinic & Triclinic & Triclinic \\
\hline Space Group & $\mathrm{P}-1$ & $\mathrm{P}-1$ & $\mathrm{P}-1$ \\
\hline \multicolumn{4}{|l|}{ Cell Constants } \\
\hline$a(\AA)$ & $13.2487(13)$ & $13.4965(6)$ & $14.4720(4)$ \\
\hline$b(\AA)$ & $13.8794(13)$ & $13.6812(5)$ & $15.6027(4)$ \\
\hline$c(\AA)$ & $15.4866(15)$ & $19.5029(8)$ & $15.6668(4)$ \\
\hline$\alpha(\operatorname{deg})$ & $94.615(5)$ & $94.769(3)$ & $62.987(2)$ \\
\hline$\beta(\operatorname{deg})$ & $101.537(5)$ & $104.005(3)$ & $73.331(2)$ \\
\hline$\gamma(\operatorname{deg})$ & $117.148(5)$ & $119.322(2)$ & $64.527(2)$ \\
\hline$Z$ & 2 & 2 & 2 \\
\hline$V\left(\AA^{3}\right)$ & $2434.2(4)$ & $2958.6(2)$ & $2826.81(15)$ \\
\hline $\begin{array}{l}\text { Abs Coeff, } \mu_{\text {calc }}\left(\mathrm{mm}^{-}\right. \\
\left.{ }^{1}\right)\end{array}$ & 0.146 & 0.332 & 0.346 \\
\hline$\delta_{\text {calc }}\left(\mathrm{g} / \mathrm{cm}^{3}\right)$ & 1.254 & 1.315 & 1.333 \\
\hline $\mathrm{F}(000)\left(\mathrm{e}^{-} / \AA^{3}\right)$ & 968 & 1218 & 1178 \\
\hline $\begin{array}{l}\text { Crystal Dimensions } \\
(\mathrm{mm})\end{array}$ & $0.8 \times 0.8 \times 0.3$ & $0.4 \times 0.2 \times 0.1$ & $0.8 \times 0.4 \times 0.3$ \\
\hline \multirow[t]{2}{*}{ Radiation } & Mo K $\alpha$ & Mo K $\alpha$ & Mo K $\alpha$ \\
\hline & $(\lambda=0.71073 \AA)$ & $(\lambda=0.71073 \AA)$ & $(\lambda=0.71073 \AA)$ \\
\hline$h, k, l$ Ranges Collected & $\begin{array}{c}-19 \leq \mathrm{h} \leq 19,-20 \leq \mathrm{k} \leq 20 \\
-21 \leq 1 \leq 22\end{array}$ & $\begin{array}{c}-19 \leq \mathrm{h} \leq 19,-19 \leq \mathrm{k} \leq 19 \\
-27 \leq 1 \leq 27\end{array}$ & $\begin{array}{c}-25 \leq \mathrm{h} \leq 24,-27 \leq \mathrm{k} \leq 27,- \\
27 \leq 1 \leq 26\end{array}$ \\
\hline$\theta$ Range (deg) & $1.369-31.151$ & $1.746-30.614$ & $1.468-38.448$ \\
\hline
\end{tabular}




\begin{tabular}{|c|c|c|c|}
\hline $\begin{array}{l}\text { No. of Reflections } \\
\text { Collected }\end{array}$ & 77955 & 58418 & 115664 \\
\hline No. of Unique & 11917 & 11484 & 21069 \\
\hline \multicolumn{4}{|l|}{ Reflections } \\
\hline No. of Parameters & 616 & 729 & 802 \\
\hline Data/Parameter Ratio & 19.35 & 15.75 & 26.27 \\
\hline \multirow[t]{2}{*}{ Refinement Method } & Full-matrix & Full-matrix & Full-matrix \\
\hline & least-squares of $F^{2}$ & least-squares of $F^{2}$ & least-squares of $F^{2}$ \\
\hline $\mathrm{R}(F)^{\mathrm{a}}$ & 0.0522 & 0.0582 & 0.0475 \\
\hline $\mathrm{R}_{w}\left(F^{2}\right)^{\mathrm{b}}$ & 0.1230 & 0.1330 & 0.1070 \\
\hline $\mathrm{GOF}_{\mathrm{w}}{ }^{\mathrm{c}}$ & 1.033 & 1.021 & 1.011 \\
\hline $\begin{array}{l}\text { Largest Diff Peak and } \\
\text { Hole }\end{array}$ & 0.801 and -0.623 & 0.545 and -1.184 & 0.854 and -0.913 \\
\hline$\left(\mathrm{e}^{-} / \AA^{3}\right)$ & & & \\
\hline
\end{tabular}


Table S2. Crystallographic Data for 4-7

\begin{tabular}{|c|c|c|c|c|}
\hline & 4 & 5 & 6 & 7 \\
\hline $\begin{array}{l}\text { Molecular } \\
\text { Formula }\end{array}$ & $\mathrm{C}_{64} \mathrm{H}_{56} \mathrm{MoO}_{3} \mathrm{Si}_{3}$ & $\mathrm{C}_{62} \mathrm{H}_{52} \mathrm{MoO}_{3} \mathrm{Si}_{3}$ & $\mathrm{C}_{84} \mathrm{H}_{77} \mathrm{KMoO}_{5} \mathrm{Si}_{4}$ & $\mathrm{C}_{69} \mathrm{H}_{60} \mathrm{MoO}_{3} \mathrm{Si}_{3}$ \\
\hline Fw & 1053.29 & 1025.24 & 1413.85 & 1117.38 \\
\hline $\operatorname{Temp}(\mathrm{K})$ & $90.0(5)$ & $90.0(5)$ & $90.0(5)$ & $120.0(5)$ \\
\hline Crystal System & Triclinic & Triclinic & Monoclinic & Monoclinic \\
\hline Space Group & $\mathrm{P}-1$ & $\mathrm{P}-1$ & $\mathrm{P} 2{ }_{1} / \mathrm{n}$ & $\mathrm{C} 2 / \mathrm{c}$ \\
\hline Cell Constants & & & & \\
\hline$a(\AA)$ & $12.5913(5)$ & $11.0192(4)$ & $22.4564(13)$ & $26.916(8)$ \\
\hline$b(\AA)$ & $12.6413(5)$ & $13.8648(5)$ & $14.3353(8)$ & $13.251(4)$ \\
\hline$c(\AA)$ & $17.9154(8)$ & $19.2131(7)$ & 25.418614) & $38.898(11)$ \\
\hline$\alpha(\operatorname{deg})$ & $95.934(2)$ & $73.881(2)$ & 90 & 90 \\
\hline$\beta(\operatorname{deg})$ & $99.869(2)$ & $77.047(2)$ & $107.989(3)$ & $98.831(16)$ \\
\hline$\gamma(\operatorname{deg})$ & $102.552(2)$ & $67.851(2)$ & 90 & 90 \\
\hline$Z$ & 2 & 2 & 4 & 8 \\
\hline$V\left(\AA^{3}\right)$ & $2712.8(2)$ & 2588.21(17) & $7782.7(8)$ & 13709(7) \\
\hline $\begin{array}{l}\text { Abs Coeff, } \mu_{\text {calc }} \\
\left(\mathrm{mm}^{-1}\right)\end{array}$ & 0.354 & 0.369 & 0.332 & 0.284 \\
\hline$\delta_{\text {calc }}\left(\mathrm{g} / \mathrm{cm}^{3}\right)$ & 1.289 & 1.316 & 1.207 & 1.083 \\
\hline $\mathrm{F}(000)\left(\mathrm{e}^{-} / \AA^{3}\right)$ & 1096 & 1064 & 2952 & 4656 \\
\hline $\begin{array}{l}\text { Crystal } \\
\text { Dimensions (mm) }\end{array}$ & $0.4 \times 0.2 \times 0.2$ & $0.2 \times 0.2 \times 0.1$ & $0.3 \times 0.2 \times 0.2$ & $0.24 \times 0.17 \times 0.08$ \\
\hline Radiation & $\begin{array}{c}\text { Mo K } \alpha \\
(\lambda=0.71073 \AA)\end{array}$ & $\begin{array}{c}\text { Mo K } \alpha \\
(\lambda=0.71073 \AA)\end{array}$ & $\begin{array}{c}\text { Mo K } \alpha \\
(\lambda=0.71073 \AA)\end{array}$ & $\begin{array}{c}\text { Mo K } \alpha \\
(\lambda=0.71073 \AA)\end{array}$ \\
\hline $\begin{array}{l}h, k, l \text { Ranges } \\
\text { Collected }\end{array}$ & $\begin{array}{c}-23 \leq \mathrm{h} \leq 23,-23 \leq \mathrm{k} \\
\leq 17,-33 \leq 1 \leq 33\end{array}$ & $\begin{array}{c}-20 \leq \mathrm{h} \leq 20,-26 \leq \mathrm{k} \\
\leq 26,-36 \leq 1 \leq 36\end{array}$ & $\begin{array}{c}-30 \leq \mathrm{h} \leq 30,-19 \leq \mathrm{k} \leq \\
19,-34 \leq 1 \leq 34\end{array}$ & $\begin{array}{c}-32 \leq \mathrm{h} \leq 32,-15 \leq \mathrm{k} \\
\leq 15,-47 \leq 1 \leq 47\end{array}$ \\
\hline$\theta$ Range (deg) & $1.668-41.299$ & $1.623-42.170$ & $1.059-28.794$ & $2.12-51.008$ \\
\hline
\end{tabular}


No. of Reflections

Collected

No. of Unique

Reflections

No. of Parameters

Data/Parameter

Ratio

Refinement

Method

$\mathrm{R}(F)^{\mathrm{a}}$

$\mathrm{R}_{w}\left(F^{2}\right)^{\mathrm{b}}$

$\mathrm{GOF}_{\mathrm{w}}{ }^{\mathrm{c}}$

Largest Diff Peak and Hole
Full-matrix least-squares of $F^{2}$

0.0373

0.0871

1.029

1.830 and -0.635

$\left(\mathrm{e}^{-} / \AA^{3}\right)$
Full-matrix least-squares of $F^{2}$

0.0399

0.0886

1.028

1.078 and -1.405
Full-matrix

Full-matrix

least-squares of $F^{2}$

0.0609

0.0519

0.1400

0.1286

1.035

1.065

0.65 and -0.68

${ }^{\mathrm{a}} \mathrm{R}=\left[\Sigma|\Delta F| / \Sigma\left|F_{\mathrm{a}}\right|\right] \quad{ }^{\mathrm{b}} \mathrm{R}_{\mathrm{w}}=\left[\Sigma w(\Delta \mathrm{F})^{2} / \Sigma w F_{\mathrm{a}}{ }^{2}\right] \quad{ }^{\mathrm{c}}$ Goodness of fit on $F^{2}$

\section{$\mathrm{C}_{6} \mathrm{H}_{3}\left(\mathrm{C}_{6} \mathrm{H}_{4} \mathrm{SiPh}_{2} \mathrm{OH}\right)_{3}(1)$}
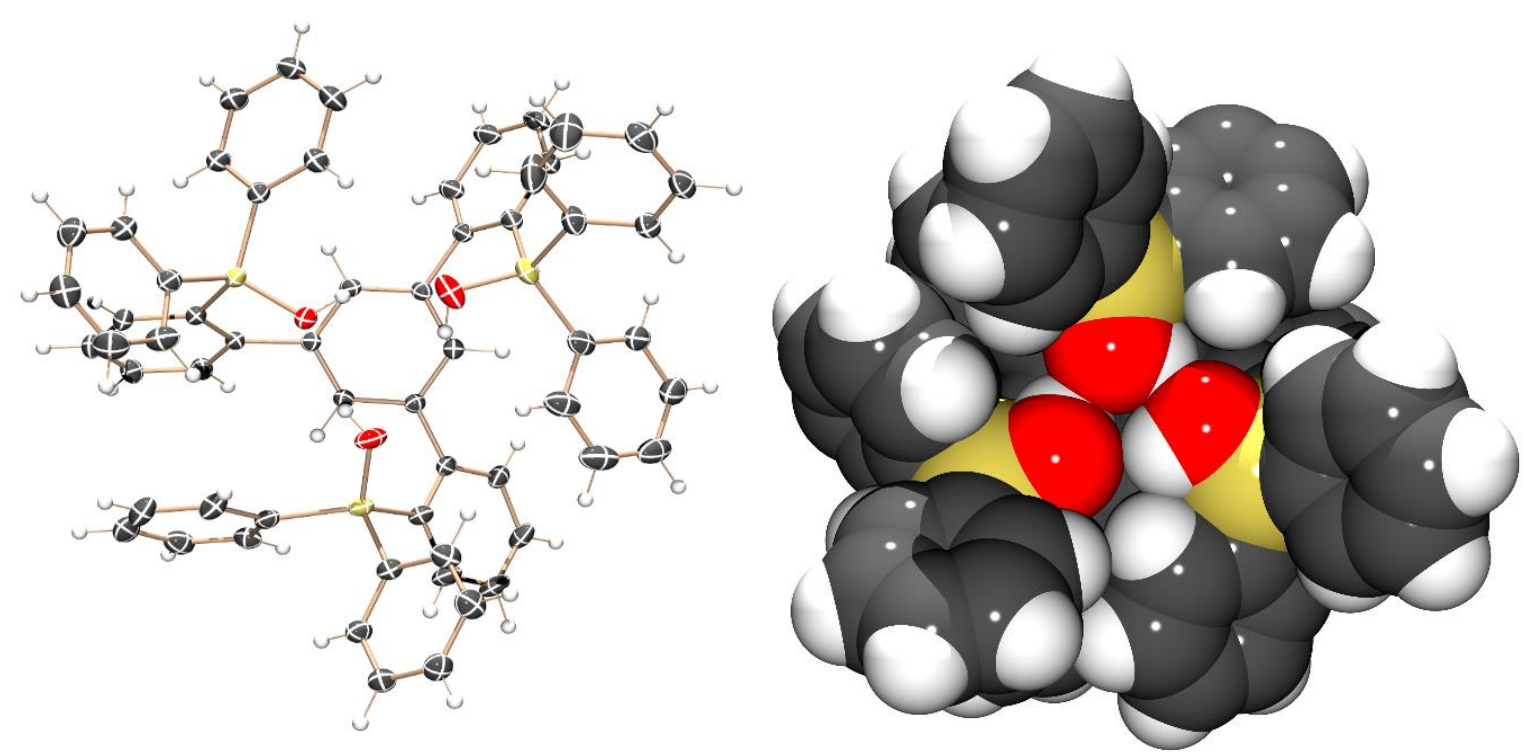

Figure S22. Crystal structure of $\mathbf{1}$ (left) with solvent removed for clarity, ellipsoids for nonhydrogen atoms are shown at the 50\% probability level. Space-filling model of $\mathbf{1}$ (right). 


\section{$\left[\mathrm{C}_{6} \mathrm{H}_{3}\left(\mathrm{C}_{6} \mathrm{H}_{4} \mathrm{SiPh}_{2} \mathrm{O}\right)_{3}\right] \mathrm{Mo} \equiv \mathrm{CMes}(2)$}
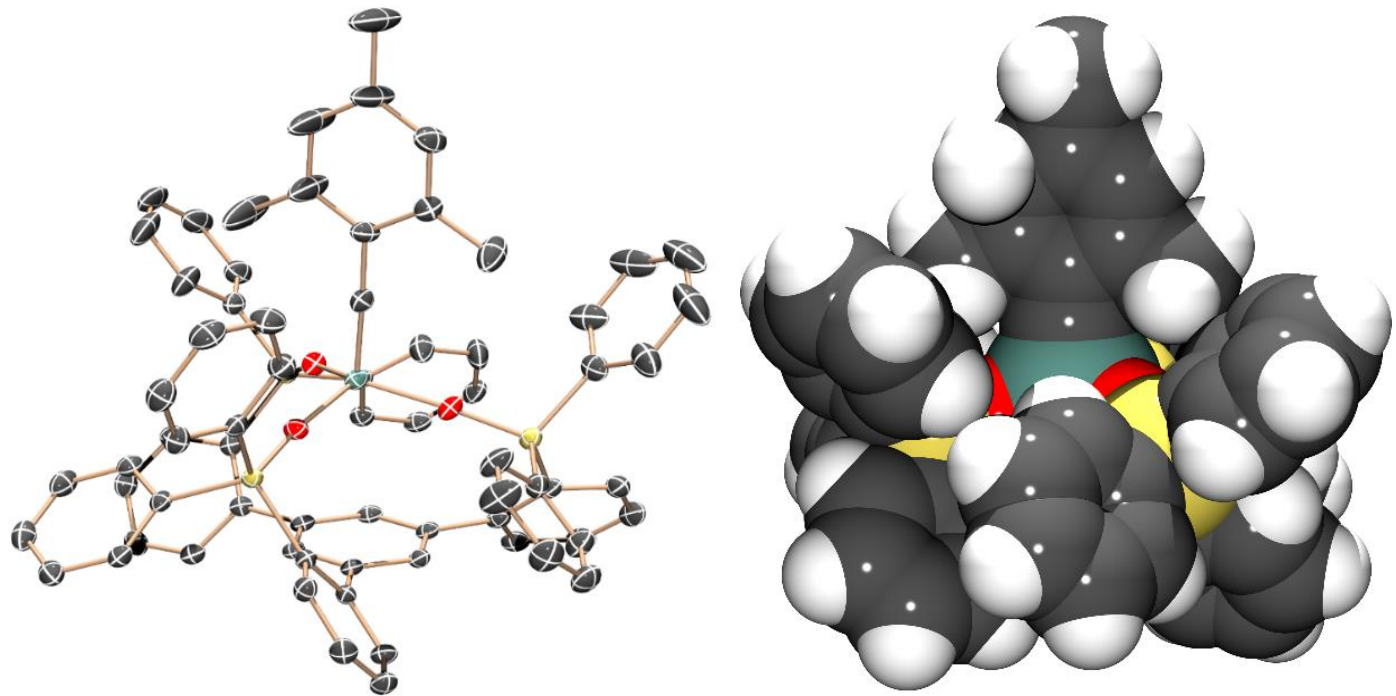

Figure S23. ORTEP of 2 (left) with hydrogen atoms and solvent omitted for clarity, ellipsoids for the non-hydrogen atoms are shown at the 50\% probability level. Space-filling model of 2 (right).

\section{$\left[\mathrm{C}_{6} \mathrm{H}_{3}\left(\mathrm{C}_{6} \mathrm{H}_{4} \mathrm{SiPh}_{2} \mathrm{O}\right)_{3}\right] \mathrm{Mo} \equiv \mathrm{CTol}(3)$}
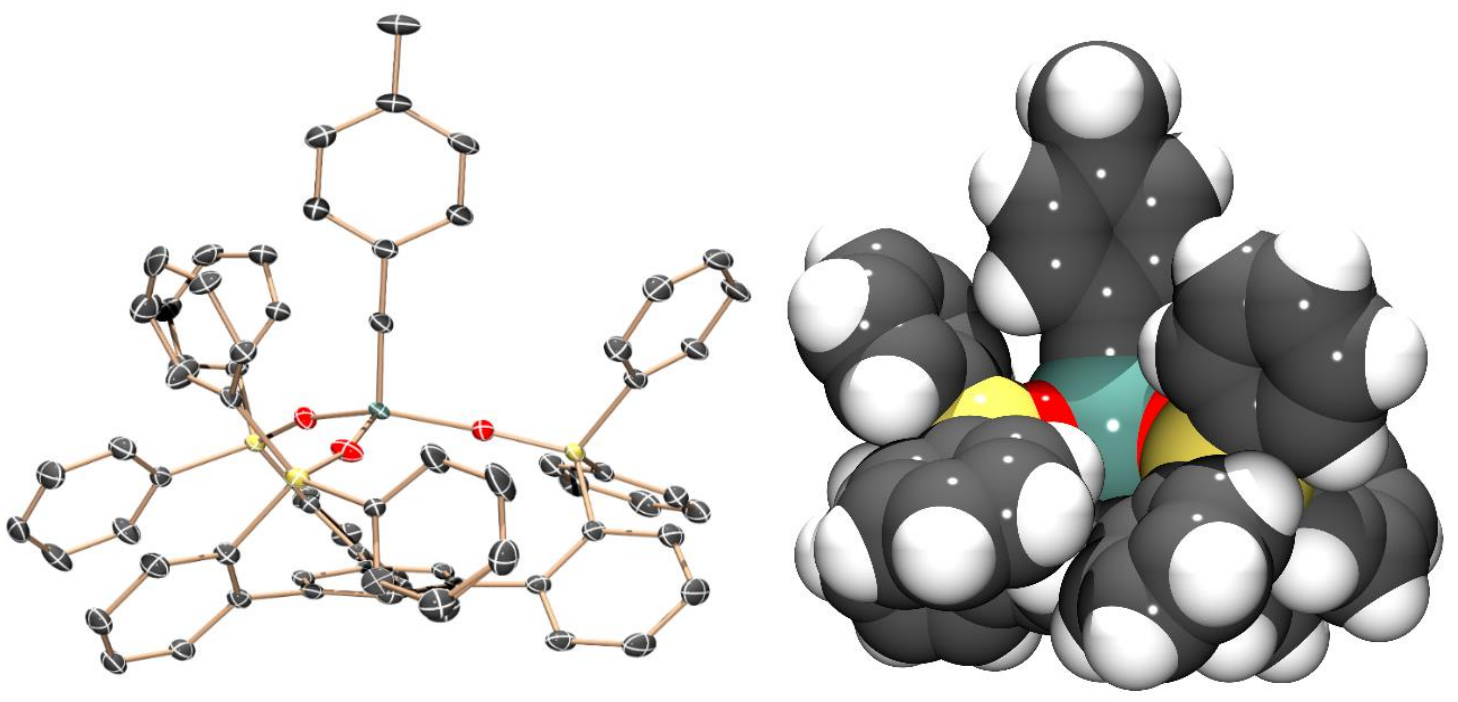

Figure S24. ORTEP of $\mathbf{3}$ (left) with hydrogen atoms, disordered atoms and solvent omitted for clarity, ellipsoids for the non-hydrogen atoms are shown at the 50\% probability level. Spacefilling model of $\mathbf{3}$ (right). 
$\left(\mathrm{Ph}_{3} \mathrm{SiO}\right)_{3} \mathrm{Mo} \equiv \mathrm{CMes}(4)$
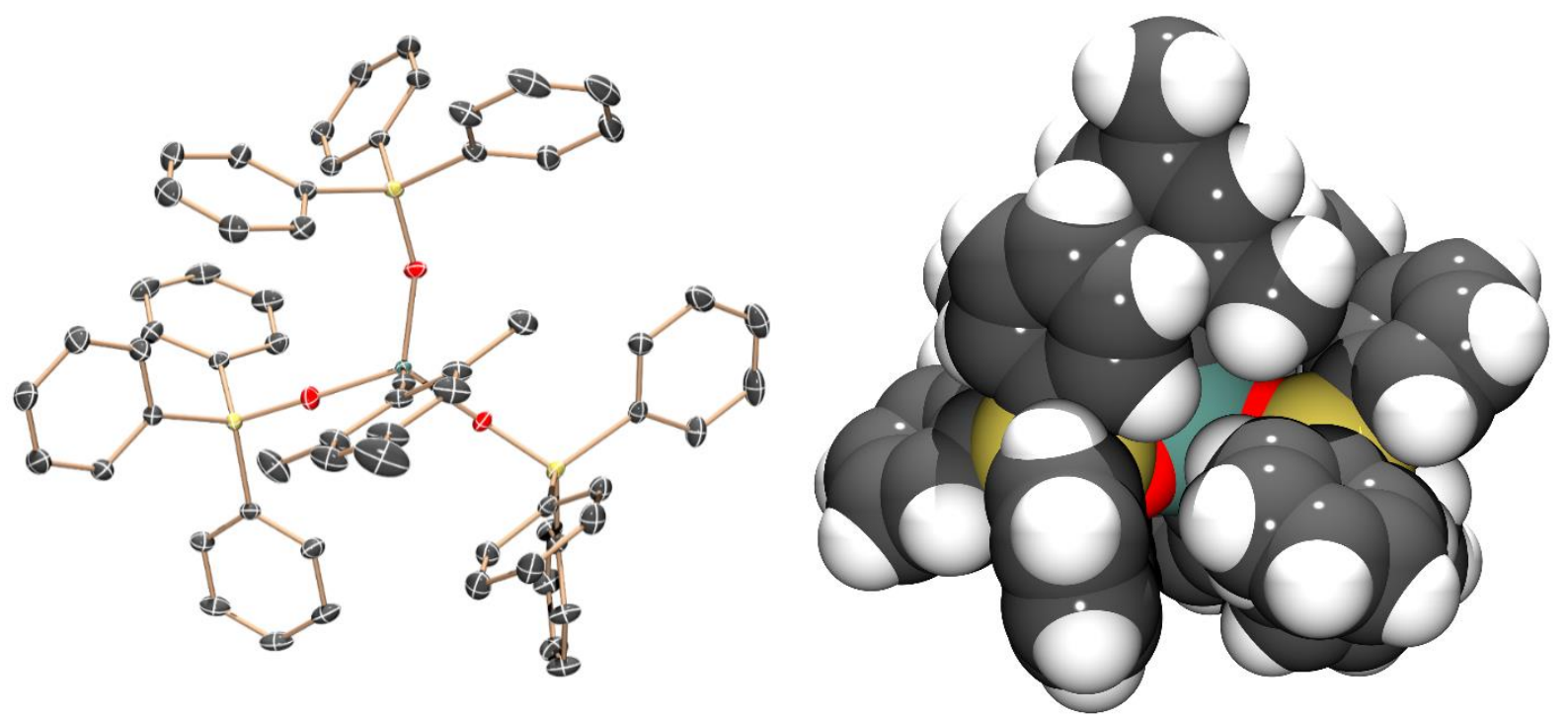

Figure S25. ORTEP of 4 (left) with hydrogen atoms omitted for clarity, ellipsoids for the nonhydrogen atoms are shown at the 50\% probability level. Space-filling model of $\mathbf{4}$ (right).

\section{$\left(\mathrm{Ph}_{3} \mathrm{SiO}\right)_{3} \mathrm{Mo} \equiv \mathrm{CTol}(5)$}
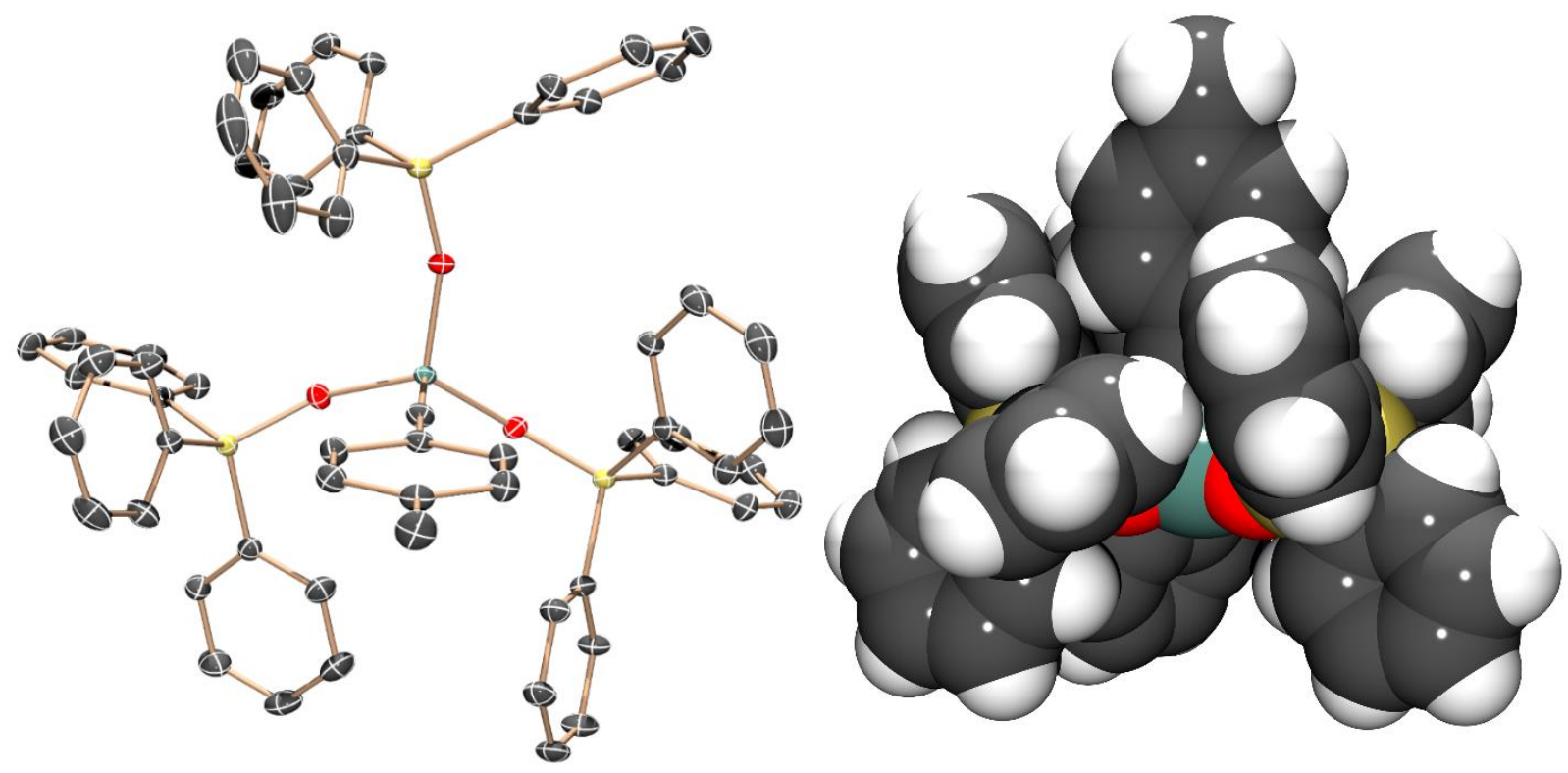

Figure S26. ORTEP of 5 (left) with hydrogen atoms omitted for clarity, ellipsoids for the nonhydrogen atoms are shown at the 50\% probability level. Space-filling model of 5 (right).

$\left[\mathrm{K}\left(\mathrm{Et}_{2} \mathrm{O}\right)\right]\left[\left(\mathrm{Ph}_{3} \mathrm{SiO}\right)_{4} \mathrm{Mo} \equiv \mathrm{CTol}\right](6)$ 


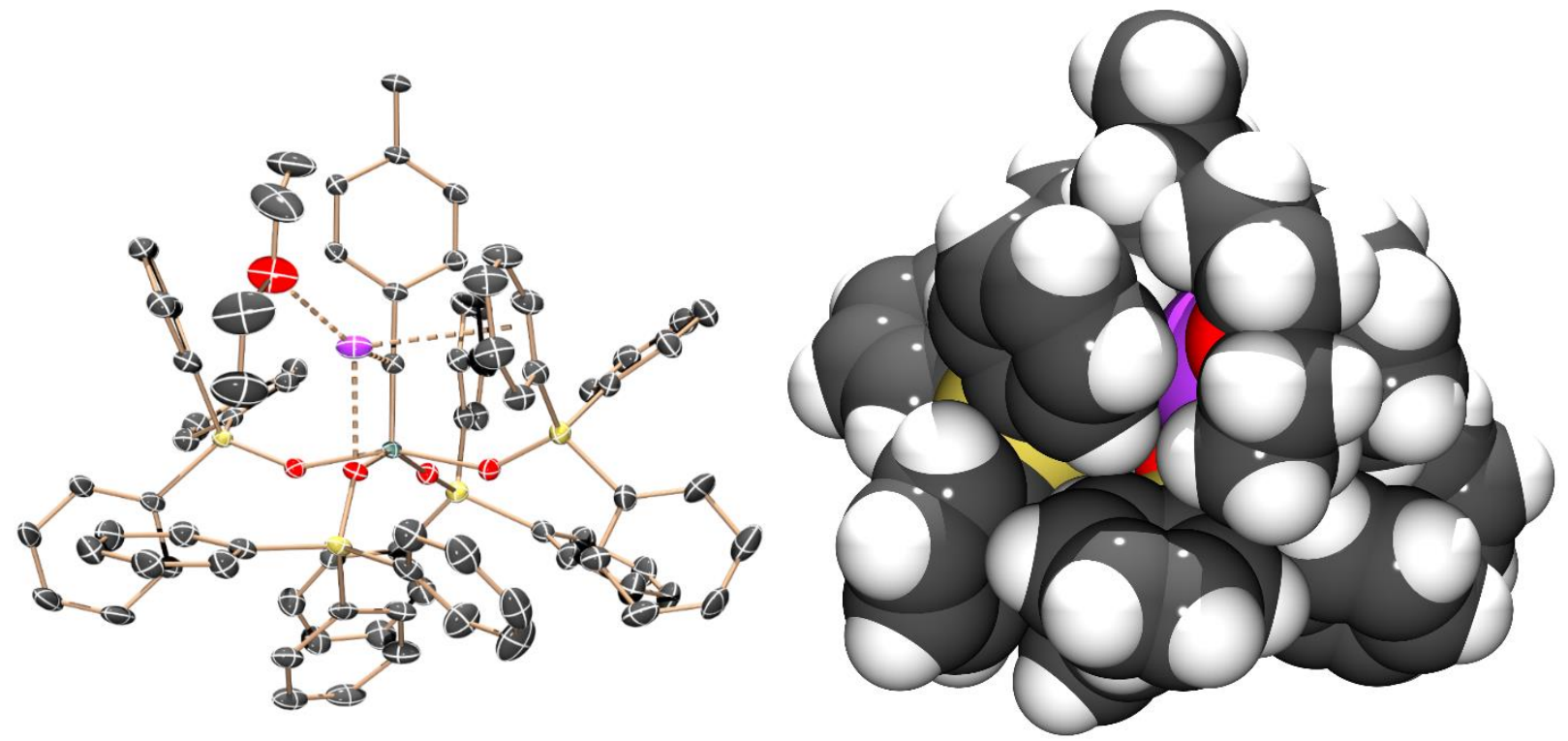

Figure S27. ORTEP of 6 (left) with hydrogen atoms and disordered atoms omitted for clarity, ellipsoids for the non-hydrogen atoms are shown at the $50 \%$ probability level. Space-filling model of 6 (right). $\tau_{5}=0.075$
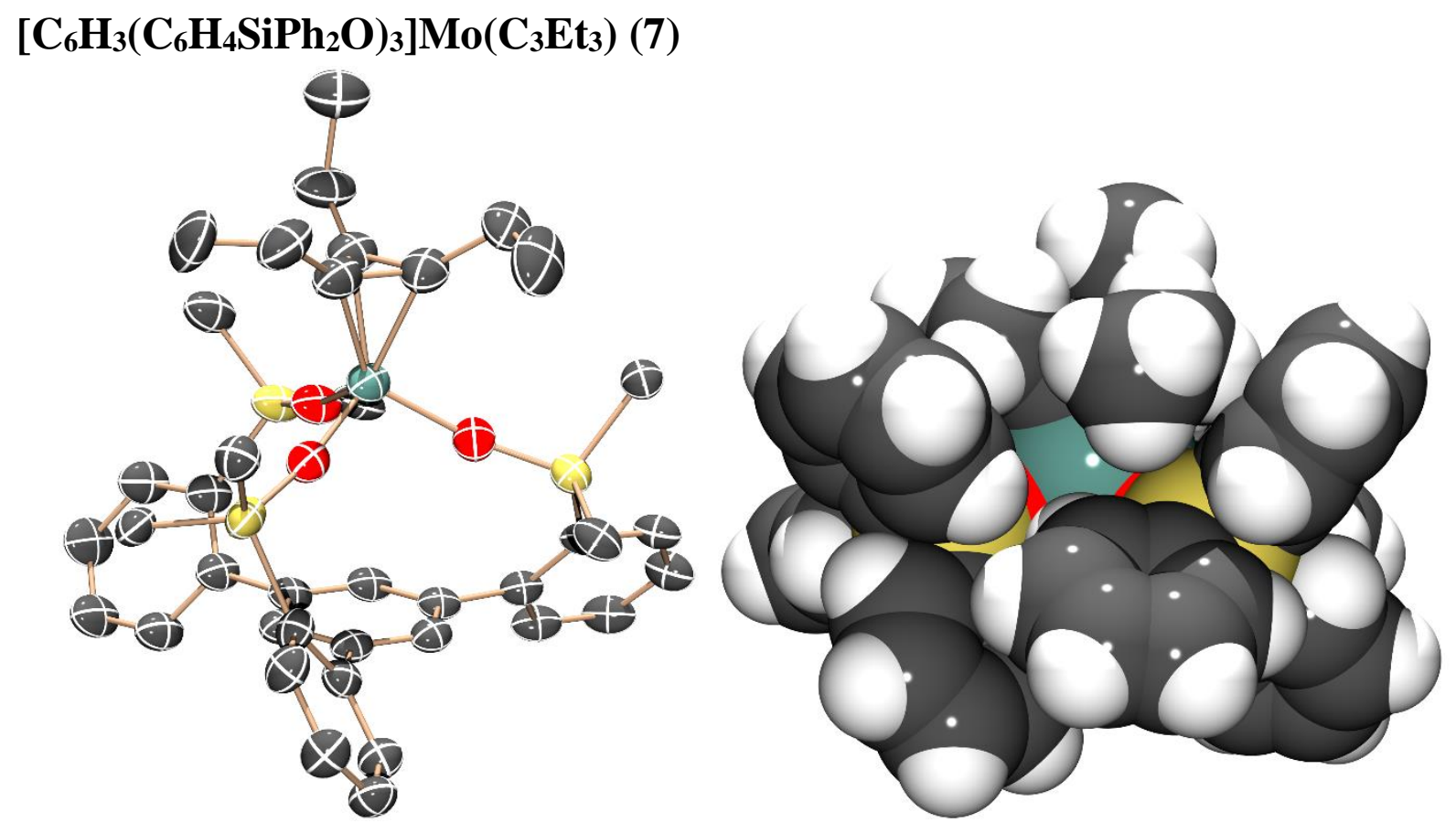

Figure S28. ORTEP of 7 (left) with hydrogen atoms and disordered atoms omitted for clarity, ellipsoids for the non-hydrogen atoms are shown at the $50 \%$ probability level. Space-filling model of 7 (right). 


\section{Computational details}

\section{General Remarks}

Optimizations of compounds 3 and $\mathbf{5}$ were performed using restricted B3LYP-D3/def2SVPLANL2DZ(Mo) level of the theory ${ }^{7}$ in implicit solvent (benzene) using CPCM as solvation model $^{8}$ as implemented in Gaussian09. All other optimizations of intermediates and transition states were calculated without constraints using B3LYP/LANL2DZ level of theory in the gas phase using Gaussian09. Frequency calculations, at the same level of theory, were used to obtain thermal corrections (at 298K) and to characterize optimized structures as transition states (only a single imaginary frequency) or intermediate (if no imaginary frequencies were found). Intrinsic reaction coordinate (IRCs) calculations were undertaken to ensure transition states connected illustrated ground states. Single point energy calculations in implicit solvent (benzene) using B3LYP-D3/def2TZVP-SDD(Mo) were also performed on all structures. ${ }^{9}$ All reported charges are from Mulliken population analysis. ${ }^{10}$ All 3-D structures were generated using CYLview. ${ }^{11}$

\section{Full Reference of Gaussian 09 Software}

Gaussian 09, Revision E.01, M. J. Frisch, G. W. Trucks, H. B. Schlegel, G. E. Scuseria, M. A. Robb, J. R. Cheeseman, G. Scalmani, V. Barone, B. Mennucci, G. A. Petersson, H. Nakatsuji, M. Caricato, X. Li, H. P. Hratchian, A. F. Izmaylov, J. Bloino, G. Zheng, J. L. Sonnenberg, M. Hada, M. Ehara, K. Toyota, R. Fukuda, J. Hasegawa, M. Ishida, T. Nakajima, Y. Honda, O. Kitao, H. Nakai, T. Vreven, J. A. Montgomery, Jr., J. E. Peralta, F. Ogliaro, M. Bearpark, J. J. Heyd, E. Brothers, K. N. Kudin, V. N. Staroverov, R. Kobayashi, J. Normand, K. Raghavachari, A. Rendell, J. C. Burant, S. S. Iyengar, J. Tomasi, M. Cossi, N. Rega, J. M. Millam, M. Klene, J. E. Knox, J. B. Cross, V. Bakken, C. Adamo, J. Jaramillo, R. Gomperts, R. E. Stratmann, O. Yazyev, A. J. Austin, R. Cammi, C. Pomelli, J. W. Ochterski, R. L. Martin, K. Morokuma, V. G. Zakrzewski, G. A. Voth, P. Salvador, J. J. Dannenberg, S. Dapprich, A. D. Daniels, Ö. Farkas, J. B. Foresman, J. V. Ortiz, J. Cioslowski, and D. J. Fox, Gaussian, Inc., Wallingford CT, 2009. 

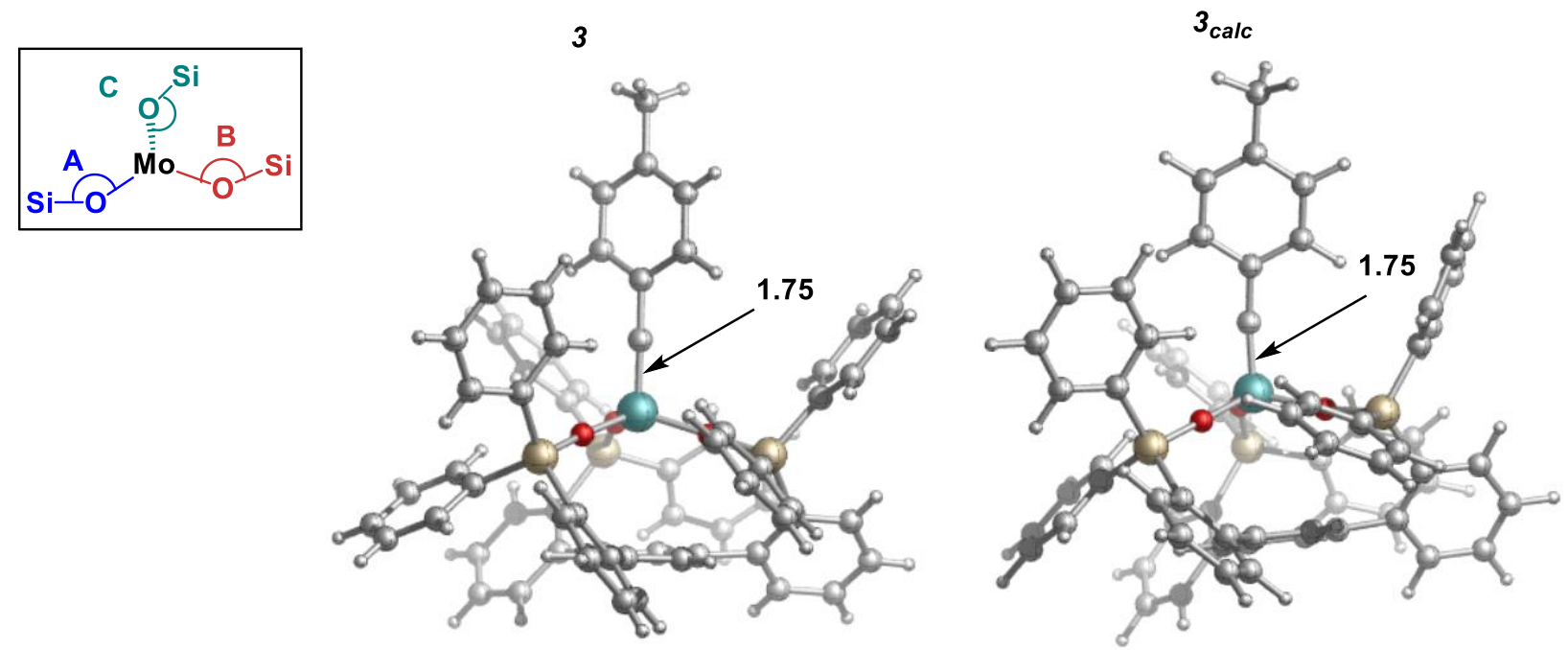

Si-O-Mo (A)
Si-O-Mo (B)

$166.5^{\circ}$

$173.5^{\circ}$

$161.0^{\circ}$

$145.6^{\circ}$

Figure S29. Experimental structure of $\mathbf{3}$ and computed structure $\mathbf{3}$ Calc optimized at the B3LYPD3/def2SVP-LANL2DZ(Mo)-CPCM (benzene) level of theory. Key bond lengths and angles are given for comparison.

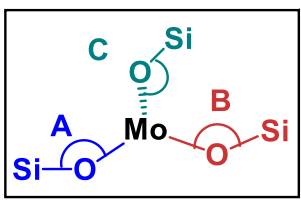

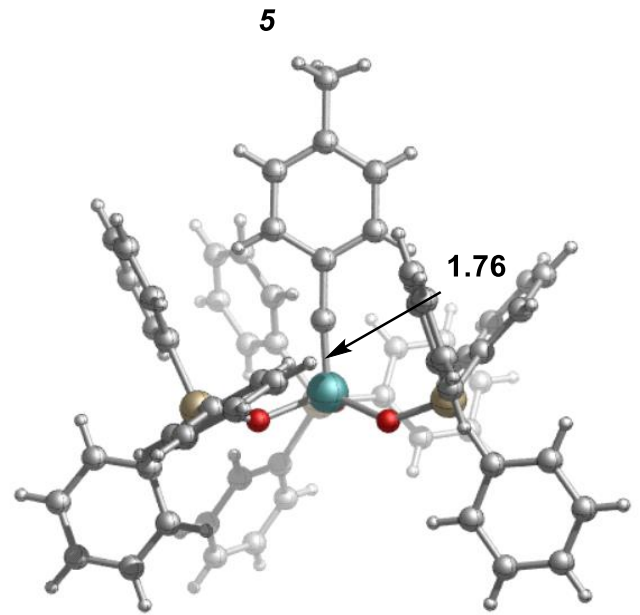

Si-O-Mo (A)

Si-O-Mo (B)

Si-O-Mo (C) $147.3^{\circ}$

$139.9^{\circ}$

$160.2^{\circ}$

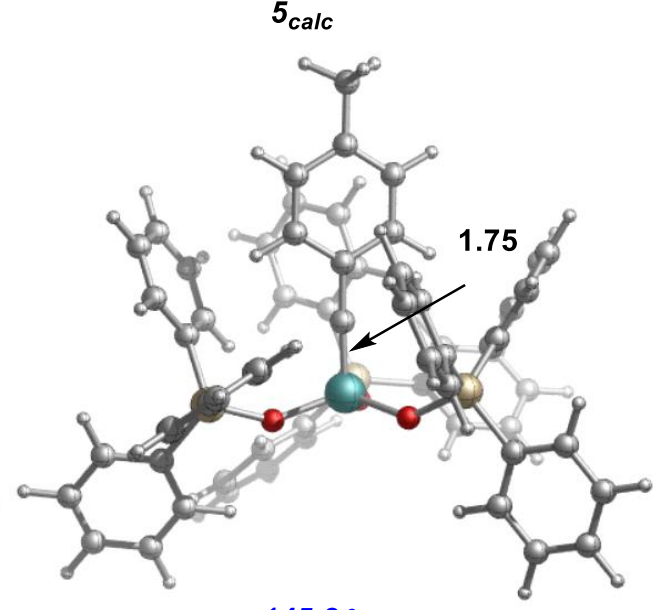

$145.8^{\circ}$

$139.3^{\circ}$

$153.6^{\circ}$

Figure S30. Experimental structure of 5 and computed structure $\mathbf{5}$ Calc optimized at the B3LYPD3/def2SVP-LANL2DZ(Mo)-CPCM (benzene) level of theory. Key bond lengths and angles are given for comparison. 


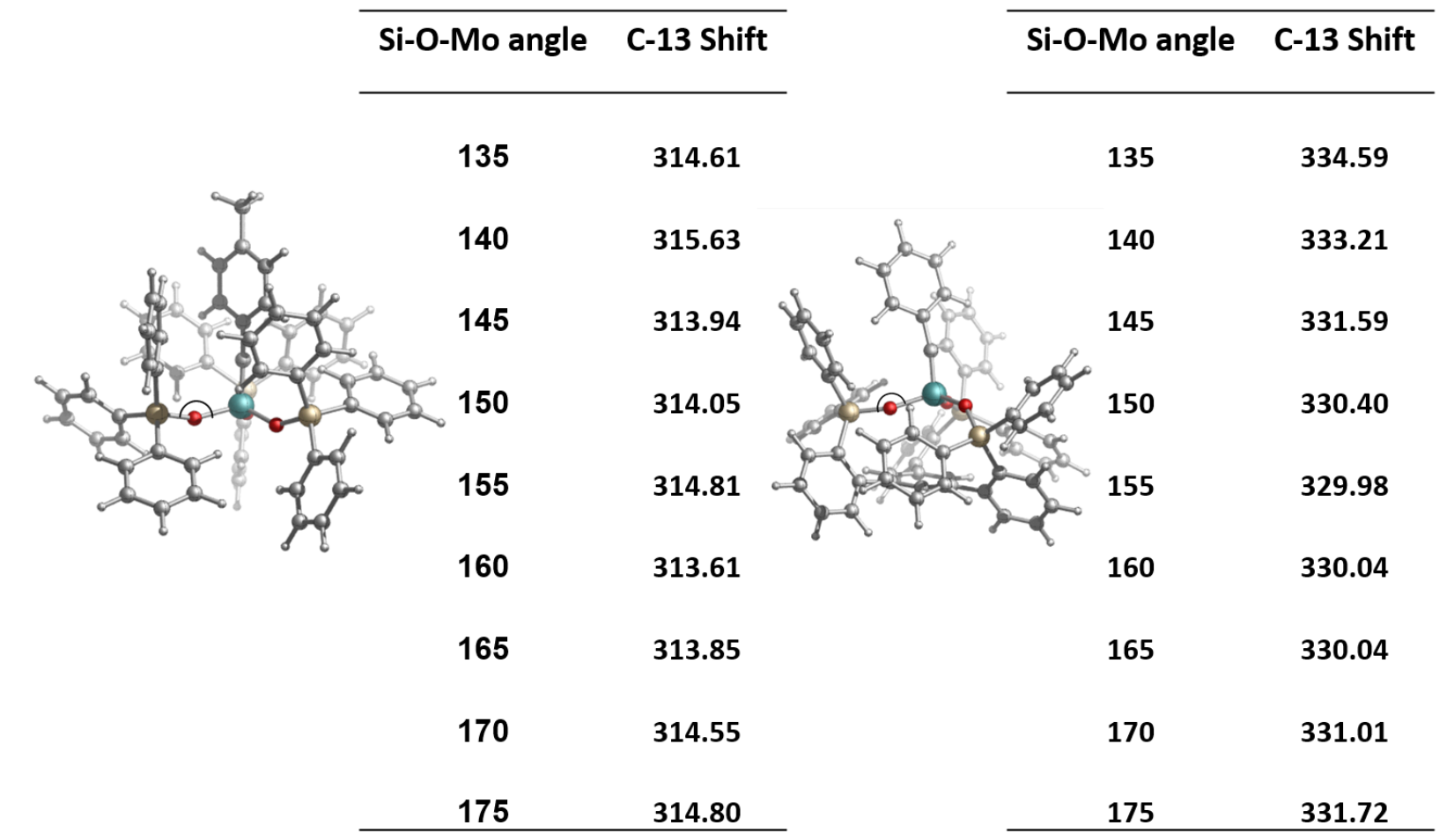

Figure S31. Predicted ${ }^{13} \mathrm{C}$ chemical shifts of 5 (left) and $\mathbf{3}$ (right) as a function of a single-fixed Mo-O-Si bond angle computed at the B3LYP-D3/def2TZVP-SDD(Mo)CPCM(benzene)//B3LYP-D3/def2SVP-LANL2DZ(Mo)-CPCM(benzene) level of theory relative to a TMS standard. 


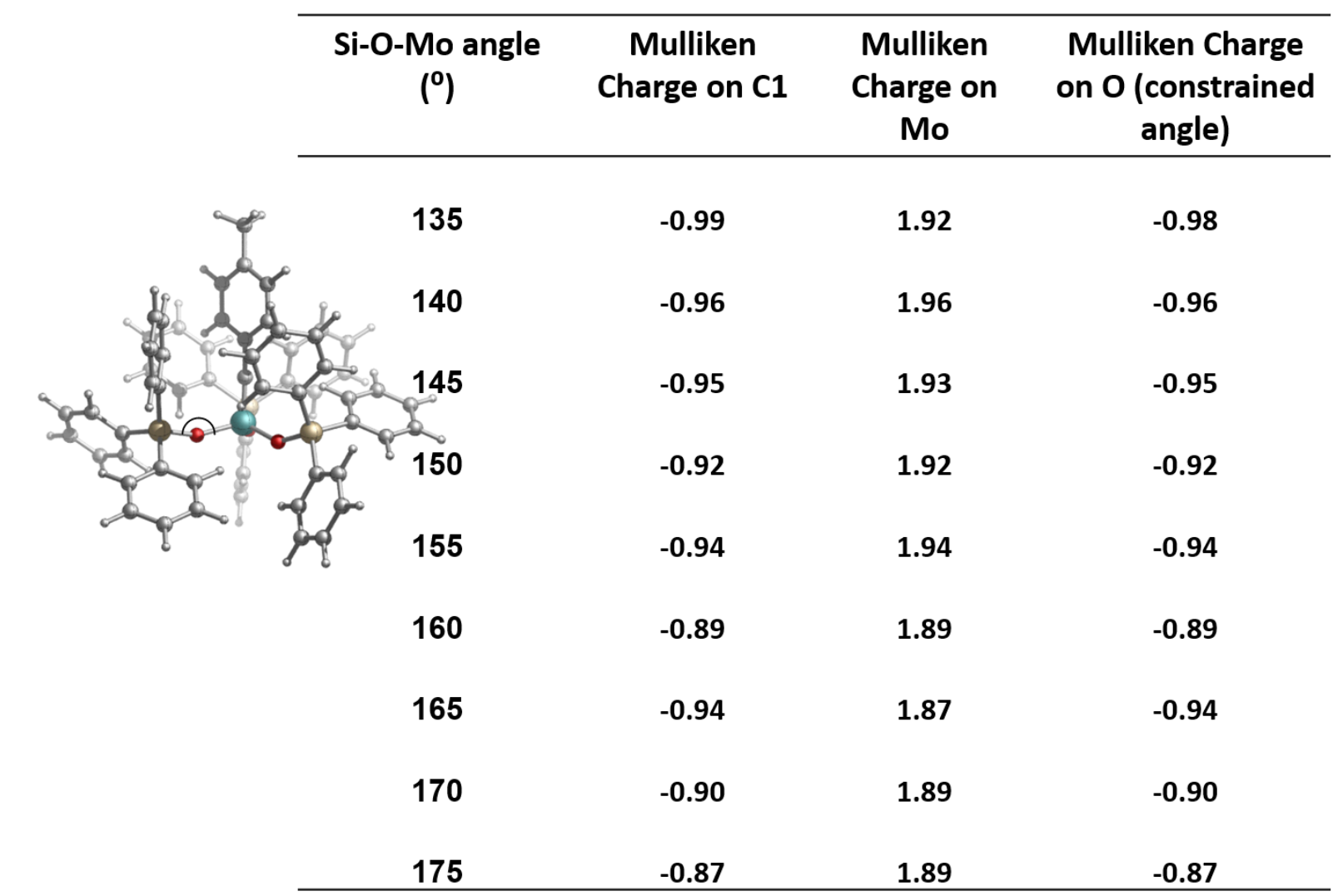

Figure S32. Mulliken charges of 5 as a function of a single-fixed Mo-O-Si bond angle computed at the B3LYP-D3/def2TZVP-SDD(Mo)-CPCM(benzene)//B3LYP-D3/def2SVPLANL2DZ(Mo)-CPCM(benzene) level of theory with the Si-O-Mo angle constrained. 


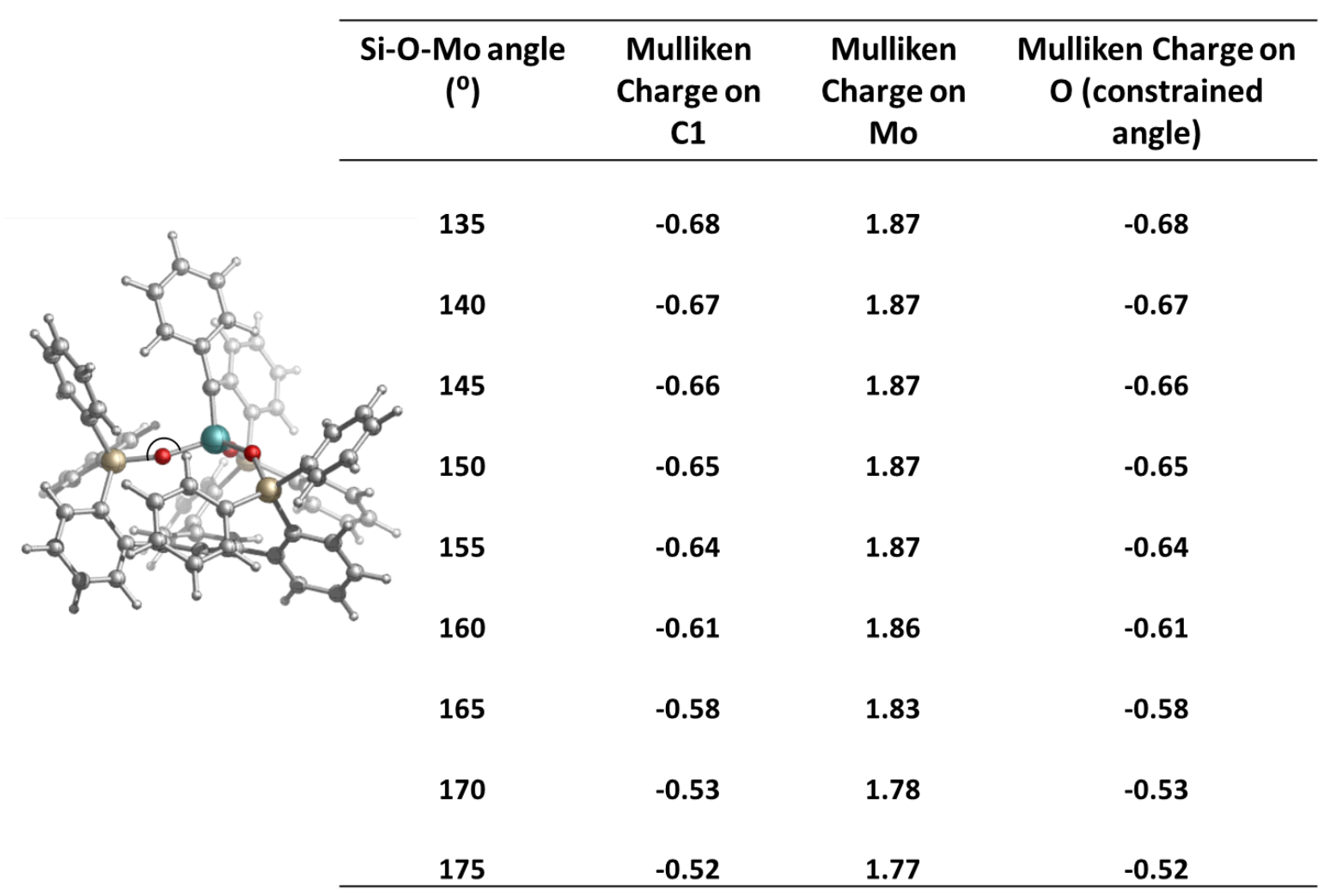

Figure S33. Mulliken charges of $\mathbf{3}$ as a function of a single-fixed Mo-O-Si bond angle computed at the B3LYP-D3/def2TZVP-SDD(Mo)-CPCM(benzene)//B3LYP-D3/def2SVP-LANL2DZ(Mo) -CPCM(benzene) level of theory with the Si-O-Mo angle constrained. 


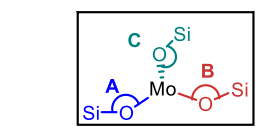

Mo-Carbyne Distance

Si-O-Mo (A)

Si-O-Mo (B)

Si-O-Mo (C)

Mulliken Charge (Mo)

Mulliken Charge (Carbyne C)

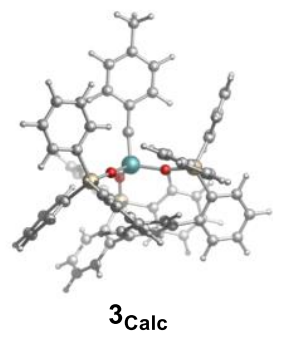

$330.02 \mathrm{ppm}$

$1.75 \AA$

$160.0^{\circ}$

$145.6^{\circ}$

$173.5^{\circ}$

1.86

$-0.61$

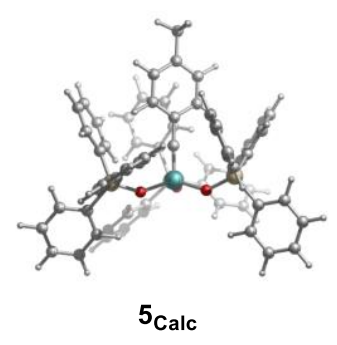

$314.92 \mathrm{ppm}$

$1.75 \AA$

$153.6^{\circ}$

$145.8^{\circ}$

$139.3^{\circ}$

1.94

$-0.95$

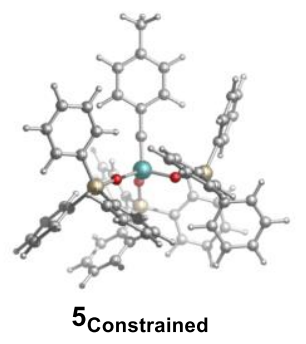

$328.73 \mathrm{ppm}$

$1.75 \AA$

$160.0^{\circ}$

$145.6^{\circ}$

$173.5^{\circ}$

1.84

$-0.70$

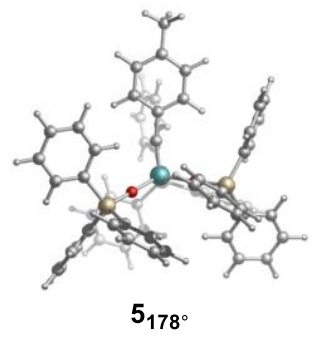

320.99 ppm

$1.75 \AA$

$178^{\circ}$

$178^{\circ}$

$178^{\circ}$

1.87

$-0.69$

Figure S34. Optimized structures of $\mathbf{3}$ Calc, $\mathbf{5}$ Calc, 5 constrained to the geometry of $\mathbf{3}$ Calc and $\mathbf{5}$ constrained to all Si-O-Mo bond angles of $178^{\circ}$. A bond angle of $180^{\circ}$ is not allowed in the Gaussian09 program due to convergence issues so instead a nearly linear angle of $178^{\circ}$ was used. All structures given are optimized at the B3LYP-D3/def2SVP-LANL2DZ(Mo)-CPCM(benzene) level of theory while ${ }^{13} \mathrm{C}$ shifts are computed relative to TMS standard at the B3LYPD3/def2TZVP-SDD(Mo)-CPCM(benzene)//B3LYP-D3/def2SVP-LANL2DZ(Mo)$\mathrm{CPCM}$ (benzene) level of theory. 


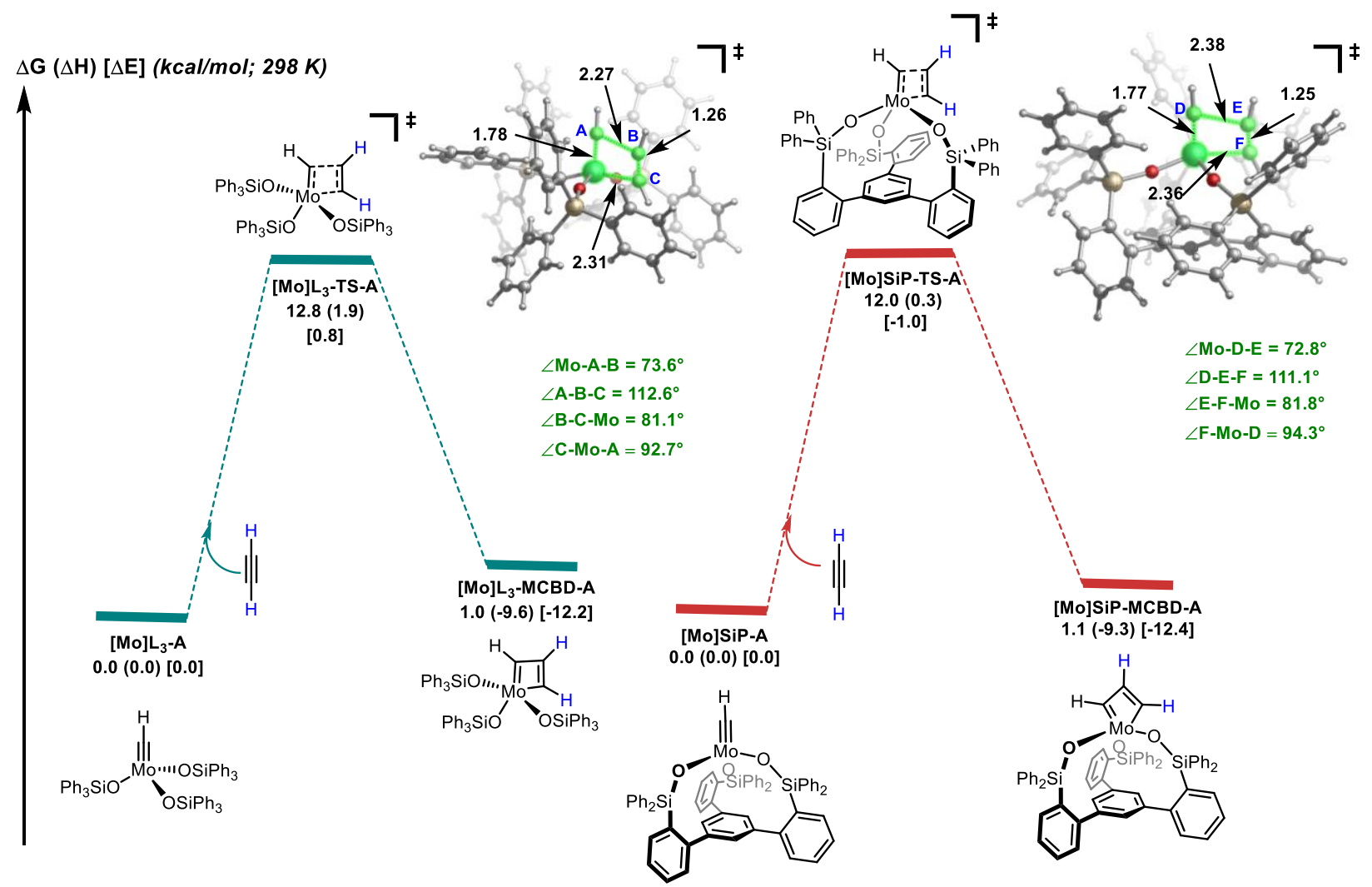

Figure S35. Energetics of MCBD formation with the acetylene substrate via [2+2] cycloaddition for [Mo]L3 (left, green) and [Mo]SiP (right, red) computed at the B3LYPD3/defTZVP-SDD(Mo)-CPCM(benzene)//B3LYP/LANL2DZ level of theory. Free energies are given as well as enthalpies (parenthesis) and the Hartree-Fock (HF) energy (brackets). The barriers to MCBD formation for $[\mathbf{M o}] \mathbf{L}_{3}$ and $[\mathbf{M o}] \mathbf{S i P}$ are very similar, with the barrier 0.8 $\mathrm{kcal} / \mathrm{mol}$ lower in free energy for the [Mo]SiP complex. 


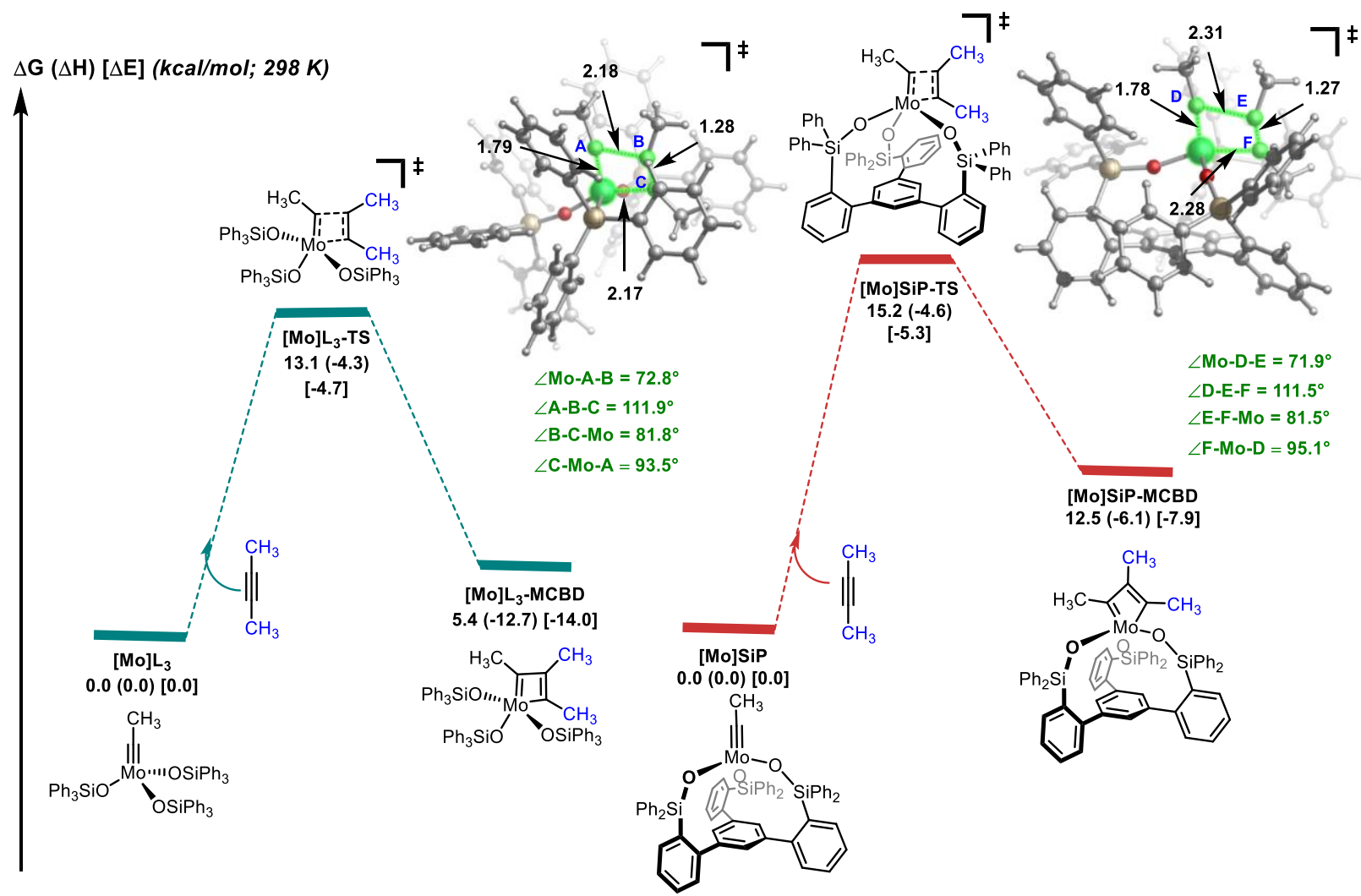

Figure S36. Energetics of MCBD formation with the butyne substrate via [2+2] cycloaddition for $[\mathbf{M o}] \mathbf{L} 3$ (left, green) and [Mo]SiP (right, red) computed at the B3LYP-D3/defTZVPSDD(Mo)-CPCM(benzene)//B3LYP/LANL2DZ level of theory. Free energies are given as well as enthalpies (parenthesis) and the Hartree-Fock (HF) energy (brackets). The barriers to MCBD formation for [Mo]L3 is $2.1 \mathrm{kcal} / \mathrm{mol}$ lower in free energy than that for the [Mo]SiP complex, agreeing with experimental results that the [Mo]L3 system reaches equilibrium faster. 


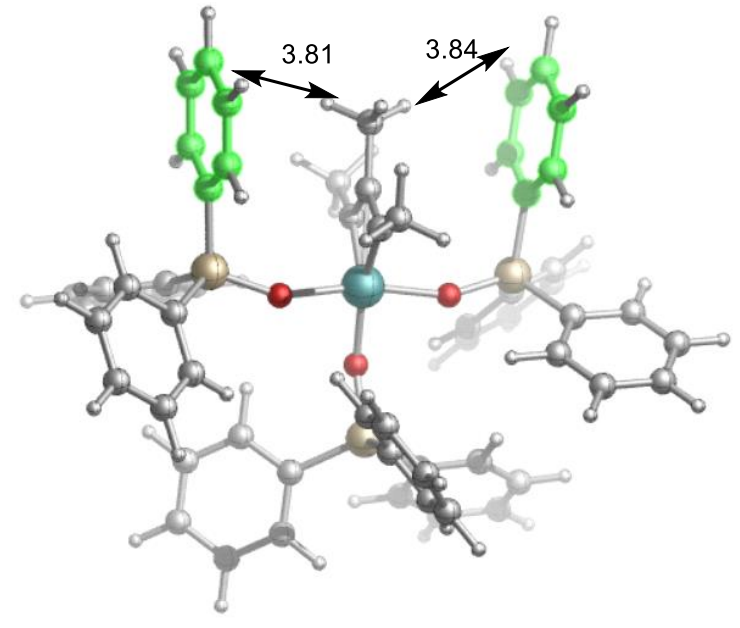

$\left[\mathrm{Mo} \mathrm{L}_{3}-\mathrm{MCBD}\right.$

$5.4(-12.7)[-14.0]$

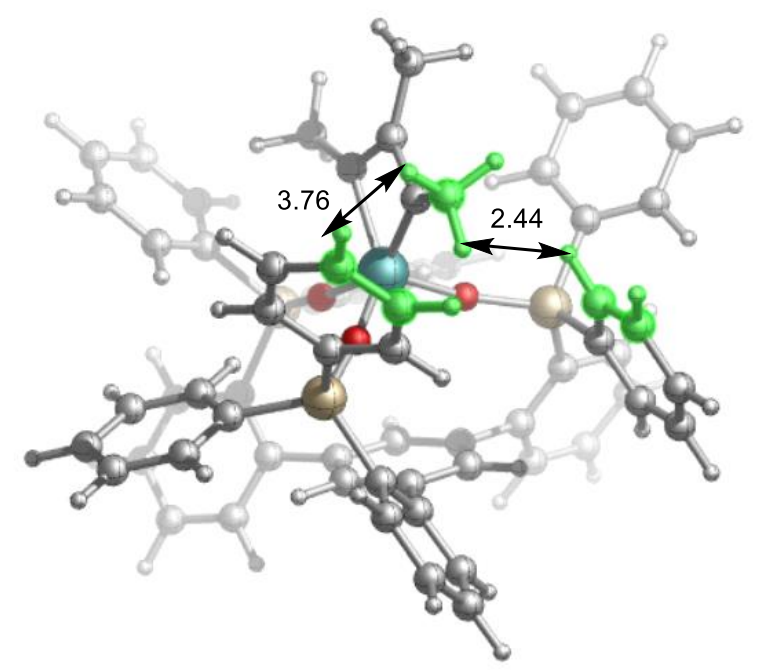

[Mo]SiP-MCBD

$12.5(-6.1)[-7.9]$

Figure S37. Comparison of MCBD intermediates [Mo]L3-MCBD (left) and [Mo]SiP-MCBD (right). Free energies are given as well as enthalpies (parenthesis) and the Hartree-Fock (HF) energy (brackets) computed at the B3LYP-D3/defTZVP-SDD(Mo)CPCM(benzene)//B3LYP/LANL2DZ level of theory. [Mo]SiP-MCBD is higher in energy by $7.1 \mathrm{kcal} / \mathrm{mol}$ than [Mo]L-M-MCBD, presumably due to the steric clashing between the methyl groups and neighboring phenyl groups (highlighted in green), which are closer than those in [Mo]L3-MCBD. Key distances between neighboring atoms are given.

$\Delta G(\Delta \mathrm{H})[\Delta \mathrm{E}](\mathrm{kcal} / \mathrm{mol} ; 298 \mathrm{~K})$

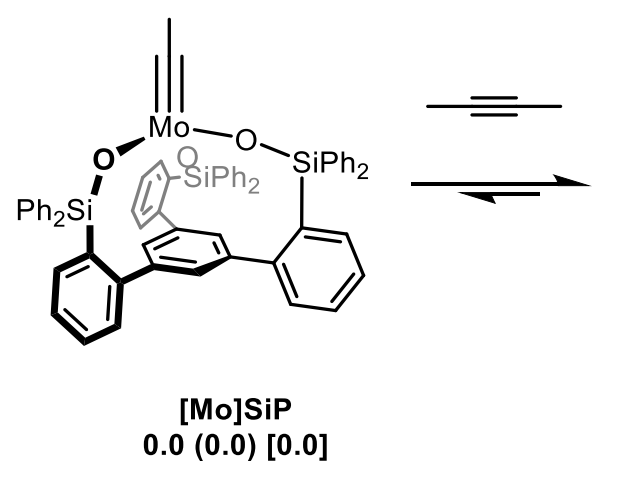

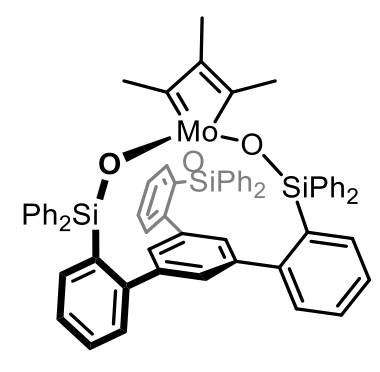

[Mo]SiP-MCBD

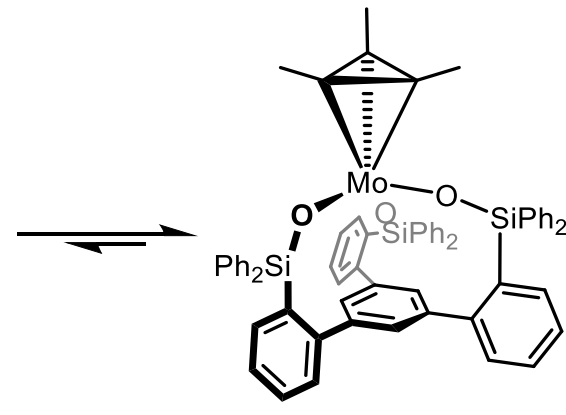

[Mo]SiP-MTd $1.3(-18.1)[-19.9]$

Figure S38. Energetic comparison of [Mo]SiP-MCBD and metallatetrahedron computed at the B3LYP-D3/defTZVP-SDD(Mo)-CPCM(benzene)//B3LYP/LANL2DZ level of theory. Free energies are given as well as enthalpies (parenthesis) and the Hartree-Fock (HF) energy (brackets). The metallatetrahedron [Mo]SiP-MTd is lower in free energy than the $[\mathbf{M o}] \mathrm{SiP}$ MCBD intermediate by $11.2 \mathrm{kcal} / \mathrm{mol}$. 


\section{Calculated Structures and Energies}

3 calc

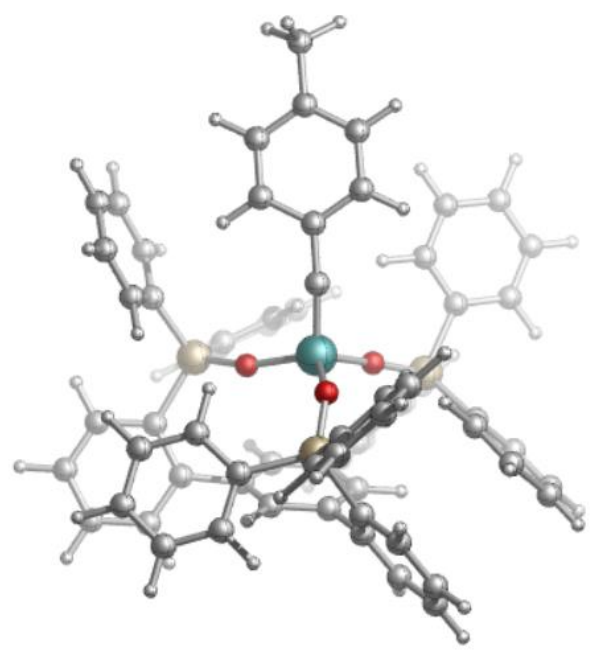

B3LYP-D3/def2SVP-LANL2DZ(Mo)-CPCM(benzene)

Zero-point correction $=$

0.998704 (Hartree/Particle)

Thermal correction to Energy=

1.064236

Thermal correction to Enthalpy=

1.065180

Thermal correction to Gibbs Free Energy $=\quad 0.890796$

Sum of electronic and zero-point Energies $=\quad-3781.479020$

Sum of electronic and thermal Energies= $\quad-3781.413488$

Sum of electronic and thermal Enthalpies $=\quad-3781.412544$

Sum of electronic and thermal Free Energies $=\quad-3781.586928$

B3LYP-D3/def2TZVP-SDD(Mo)-CPCM(benzene)//B3LYP-D3/def2SVP-LANL2DZ(Mo)CPCM(benzene)

$\mathrm{HF}=-3786.564347$ 
5 calc

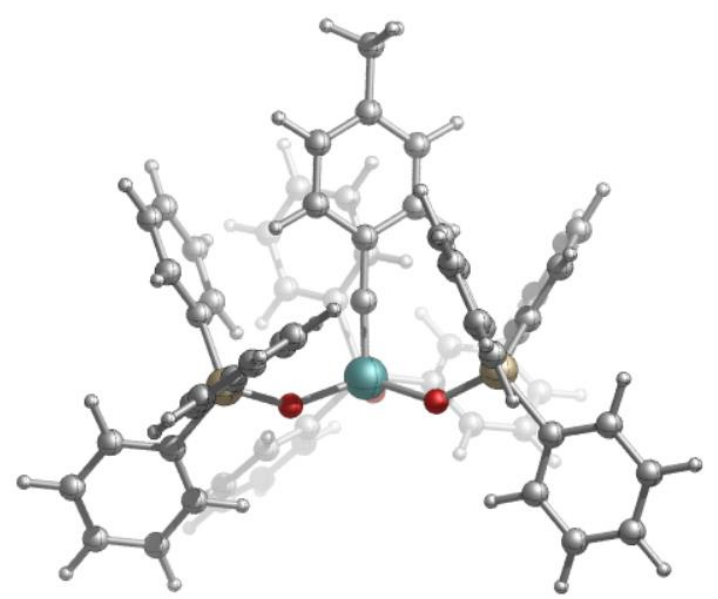

B3LYP-D3/def2SVP-LANL2DZ(Mo)-CPCM(benzene)

Zero-point correction $=\quad 0.959946($ Hartree/Particle $)$

Thermal correction to Energy= $\quad 1.023915$

Thermal correction to Enthalpy= $\quad 1.024860$

Thermal correction to Gibbs Free Energy $=\quad 0.849371$

Sum of electronic and zero-point Energies $=\quad-3553.019670$

Sum of electronic and thermal Energies $=\quad-3552.955701$

Sum of electronic and thermal Enthalpies $=\quad-3552.954757$

Sum of electronic and thermal Free Energies $=\quad-3553.130245$

B3LYP-D3/def2TZVP-SDD(Mo)-CPCM(benzene)//B3LYP-D3/def2SVP-LANL2DZ(Mo)CPCM(benzene)

$\mathrm{HF}=-3557.834686$ 
$3_{135^{\circ}}$

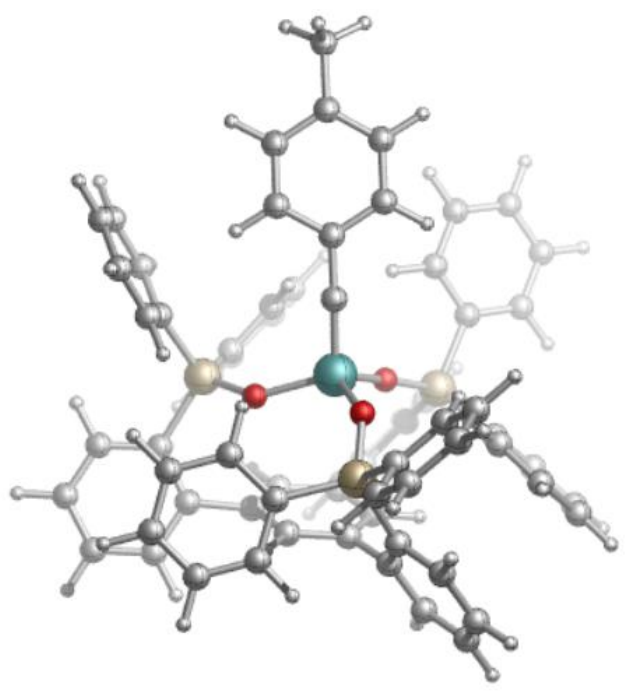

B3LYP-D3/def2SVP-LANL2DZ(Mo)-CPCM(benzene)

B3LYP-D3/def2TZVP-SDD(Mo)-CPCM(benzene)//B3LYP-D3/def2SVP-LANL2DZ(Mo)CPCM(benzene)

$\mathrm{HF}=-3786.559506$

$3_{140^{\circ}}$

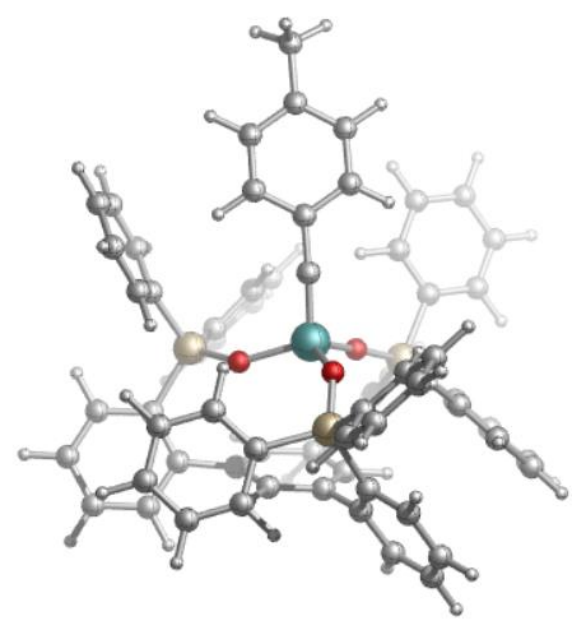

B3LYP-D3/def2SVP-LANL2DZ(Mo)-CPCM(benzene)

B3LYP-D3/def2TZVP-SDD(Mo)-CPCM(benzene)//B3LYP-D3/def2SVP-LANL2DZ(Mo)CPCM(benzene)

$\mathrm{HF}=-3786.561291$ 
$\mathbf{3}_{145^{0}}$

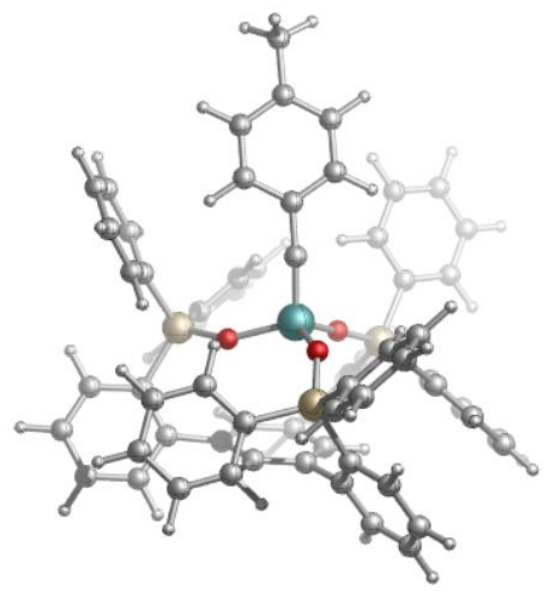

B3LYP-D3/def2SVP-LANL2DZ(Mo)-CPCM(benzene)

B3LYP-D3/def2TZVP-SDD(Mo)-CPCM(benzene)//B3LYP-D3/def2SVP-LANL2DZ(Mo)CPCM(benzene)

$\mathrm{HF}=-3786.562751$

$3150^{\circ}$

B3LYP-D3/def2SVP-LANL2DZ(Mo)-CPCM(benzene)

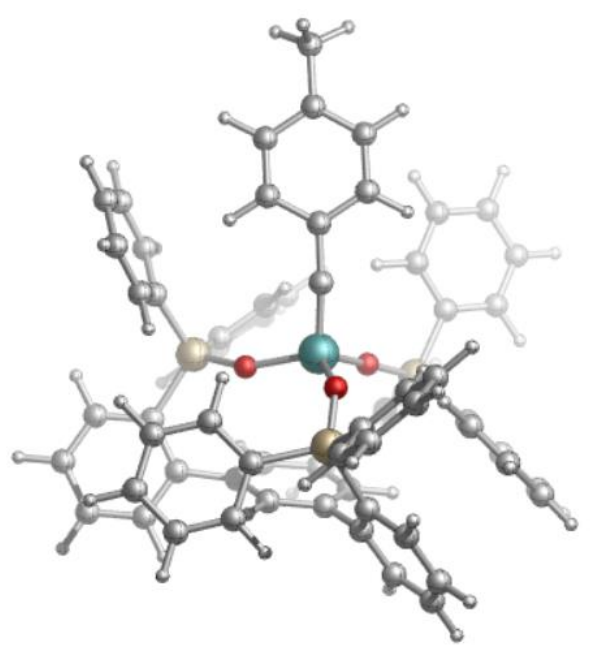

B3LYP-D3/def2SVP-LANL2DZ(Mo)-CPCM(benzene)

B3LYP-D3/def2TZVP-SDD(Mo)-CPCM(benzene)//B3LYP-D3/def2SVP-LANL2DZ(Mo)CPCM(benzene)

$\mathrm{HF}=-3786.563763$ 
$3_{155^{\circ}}$

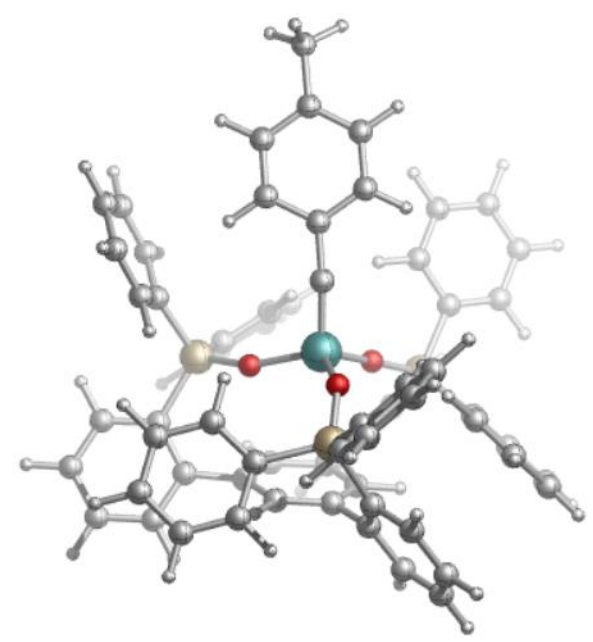

B3LYP-D3/def2SVP-LANL2DZ(Mo)-CPCM(benzene)

B3LYP-D3/def2TZVP-SDD(Mo)-CPCM(benzene)//B3LYP-D3/def2SVP-LANL2DZ(Mo)CPCM(benzene)

$\mathrm{HF}=-3786.56432$

$3160^{\circ}$

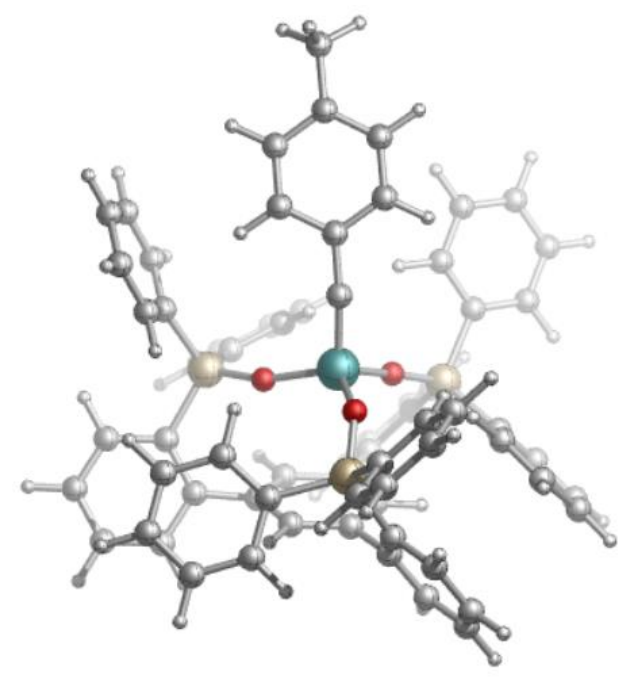

B3LYP-D3/def2SVP-LANL2DZ(Mo)-CPCM(benzene)

B3LYP-D3/def2TZVP-SDD(Mo)-CPCM(benzene)//B3LYP-D3/def2SVP-LANL2DZ(Mo)CPCM(benzene)

$\mathrm{HF}=-3786.564351$ 
$3165^{\circ}$

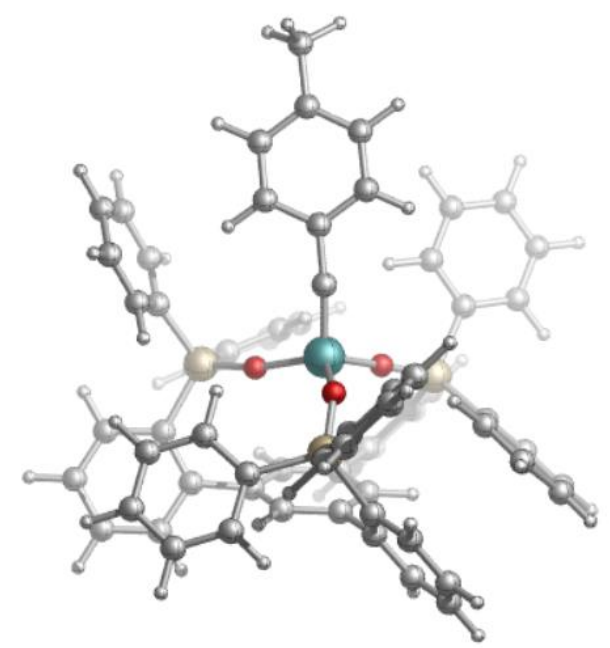

B3LYP-D3/def2SVP-LANL2DZ(Mo)-CPCM(benzene)

B3LYP-D3/def2TZVP-SDD(Mo)-CPCM(benzene)//B3LYP-D3/def2SVP-LANL2DZ(Mo)CPCM(benzene)

$\mathrm{HF}=-3786.564212$

$3170^{\circ}$

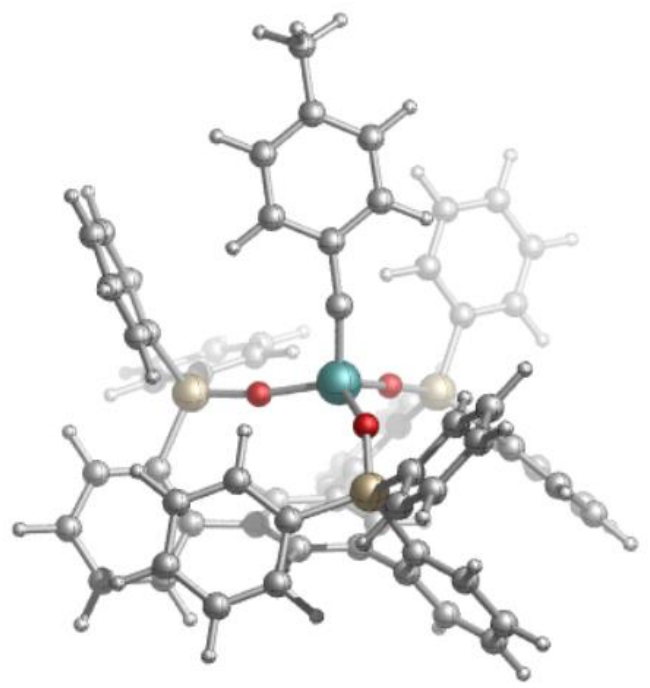

B3LYP-D3/def2SVP-LANL2DZ(Mo)-CPCM(benzene)

B3LYP-D3/def2TZVP-SDD(Mo)-CPCM(benzene)//B3LYP-D3/def2SVP-LANL2DZ(Mo)$\mathrm{CPCM}($ benzene $)$

$\mathrm{HF}=-3786.563991$ 
$3_{175^{0}}$

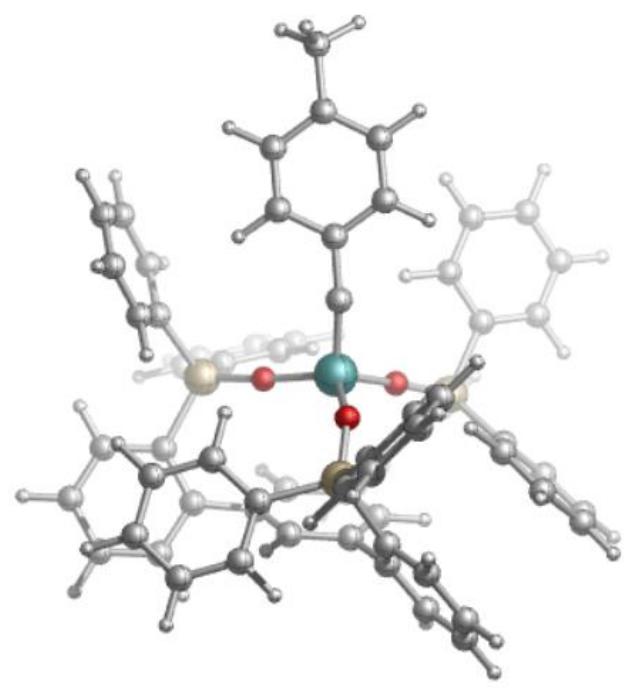

B3LYP-D3/def2SVP-LANL2DZ(Mo)-CPCM(benzene)

B3LYP-D3/def2TZVP-SDD(Mo)-CPCM(benzene)//B3LYP-D3/def2SVP-LANL2DZ(Mo)CPCM(benzene)

$\mathrm{HF}=-3786.563659$

$5135^{\circ}$

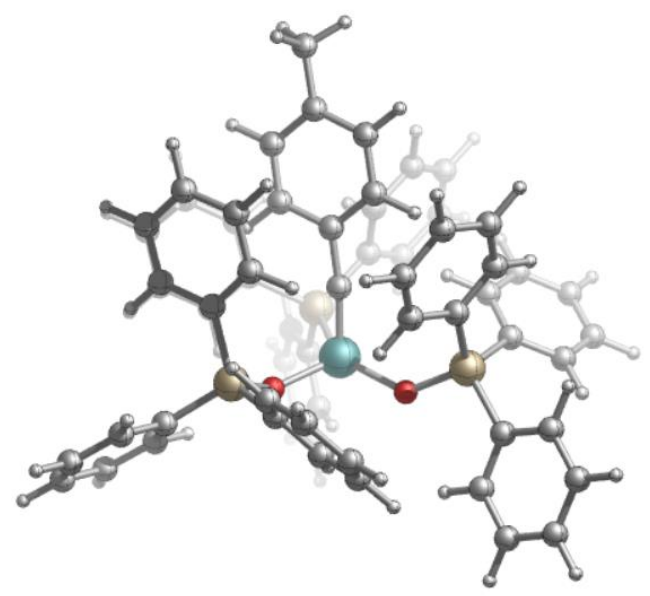

B3LYP-D3/def2SVP-LANL2DZ(Mo)-CPCM(benzene)

B3LYP-D3/def2TZVP-SDD(Mo)-CPCM(benzene)//B3LYP-D3/def2SVP-LANL2DZ(Mo)CPCM(benzene)

$\mathrm{HF}=-3557.835154$ 
$5140^{\circ}$

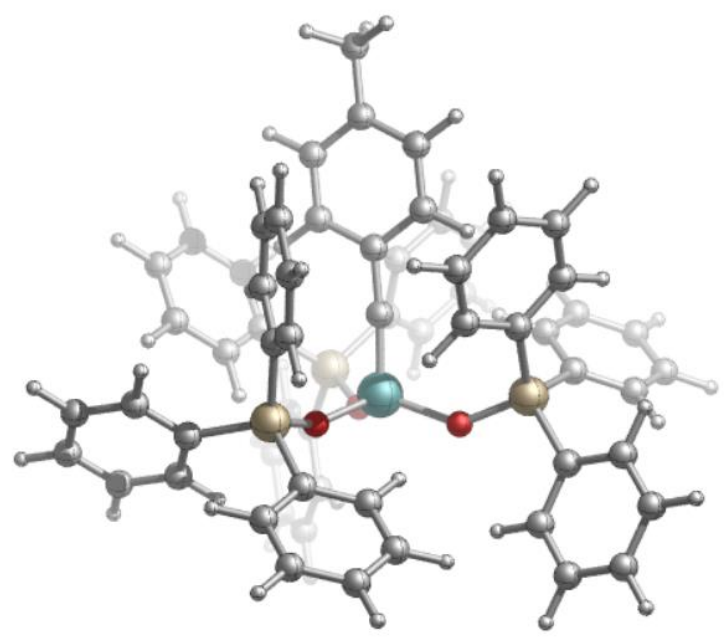

B3LYP-D3/def2SVP-LANL2DZ(Mo)-CPCM(benzene)

B3LYP-D3/def2TZVP-SDD(Mo)-CPCM(benzene)//B3LYP-D3/def2SVP-LANL2DZ(Mo)$\mathrm{CPCM}($ benzene $)$

$\mathrm{HF}=-3557.834154$

$5145^{\circ}$

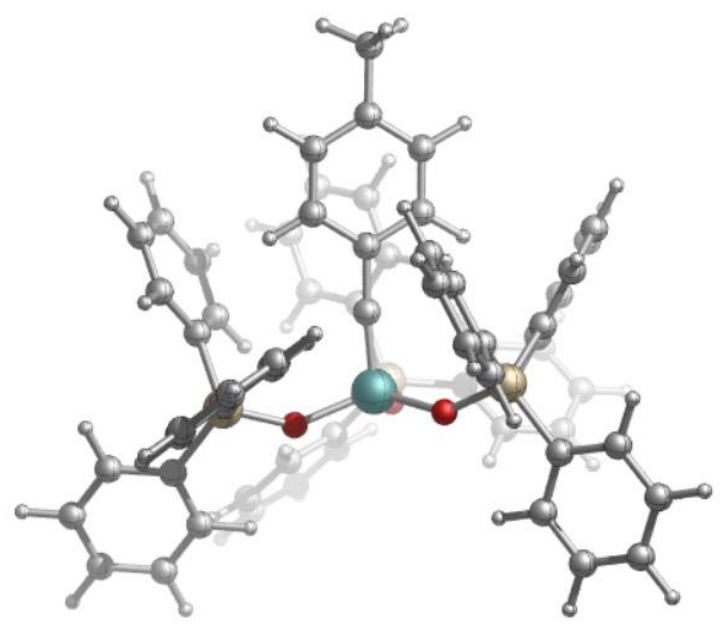

B3LYP-D3/def2SVP-LANL2DZ(Mo)-CPCM(benzene)

B3LYP-D3/def2TZVP-SDD(Mo)-CPCM(benzene)//B3LYP-D3/def2SVP-LANL2DZ(Mo)$\mathrm{CPCM}($ benzene)

$\mathrm{HF}=-3557.83427$ 
$5150^{\circ}$

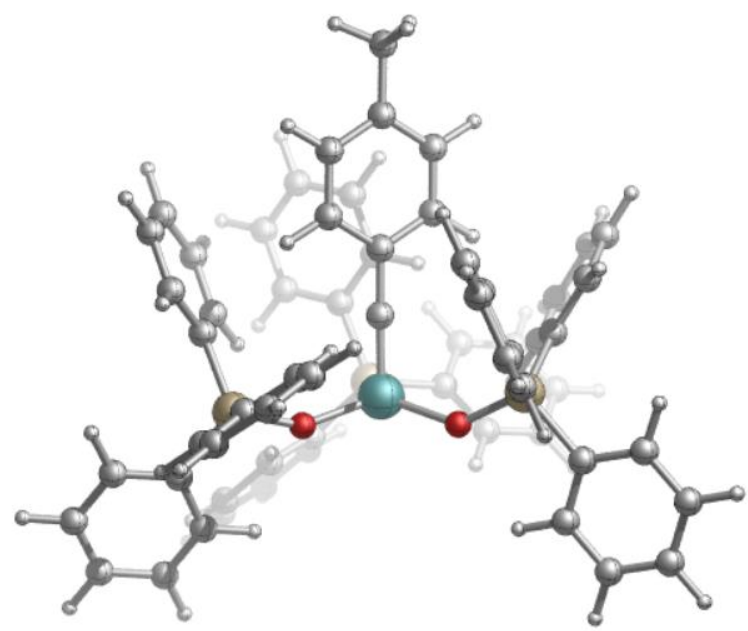

B3LYP-D3/def2SVP-LANL2DZ(Mo)-CPCM(benzene)

B3LYP-D3/def2TZVP-SDD(Mo)-CPCM(benzene)//B3LYP-D3/def2SVP-LANL2DZ(Mo)$\mathrm{CPCM}($ benzene $)$

$\mathrm{HF}=-3557.834502$

$5155^{\circ}$

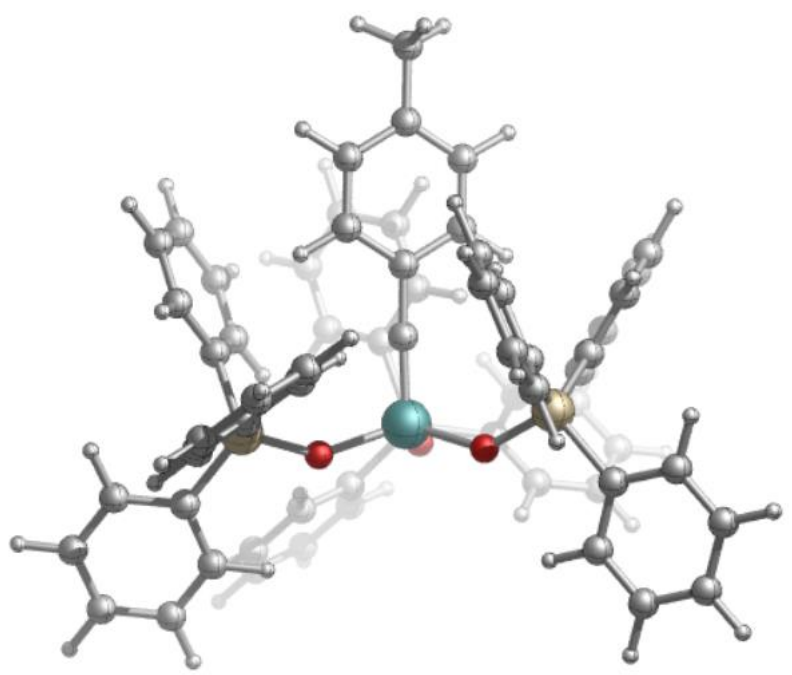

B3LYP-D3/def2SVP-LANL2DZ(Mo)-CPCM(benzene)

B3LYP-D3/def2TZVP-SDD(Mo)-CPCM(benzene)//B3LYP-D3/def2SVP-LANL2DZ(Mo)$\mathrm{CPCM}($ benzene $)$

$\mathrm{HF}=-3557.834718$ 
$5160^{\circ}$

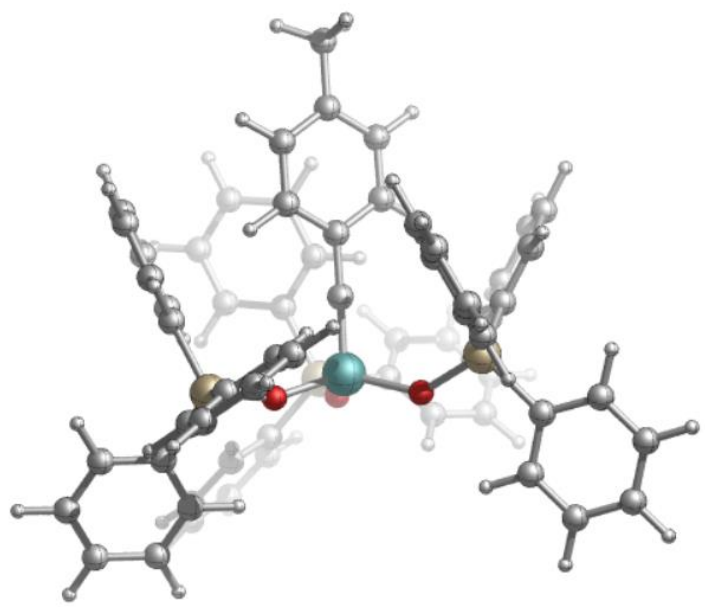

B3LYP-D3/def2SVP-LANL2DZ(Mo)-CPCM(benzene)

B3LYP-D3/def2TZVP-SDD(Mo)-CPCM(benzene)//B3LYP-D3/def2SVP-LANL2DZ(Mo)$\mathrm{CPCM}($ benzene)

$\mathrm{HF}=-3557.833552$

$5165^{\circ}$

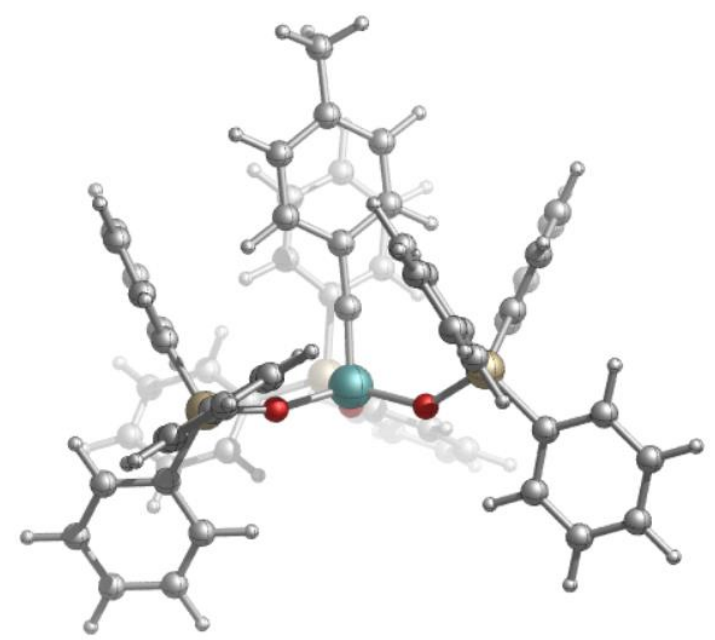

B3LYP-D3/def2SVP-LANL2DZ(Mo)-CPCM(benzene)

B3LYP-D3/def2TZVP-SDD(Mo)-CPCM(benzene)//B3LYP-D3/def2SVP-LANL2DZ(Mo)$\mathrm{CPCM}($ benzene $)$

$\mathrm{HF}=-3557.835148$ 
$5170^{\circ}$

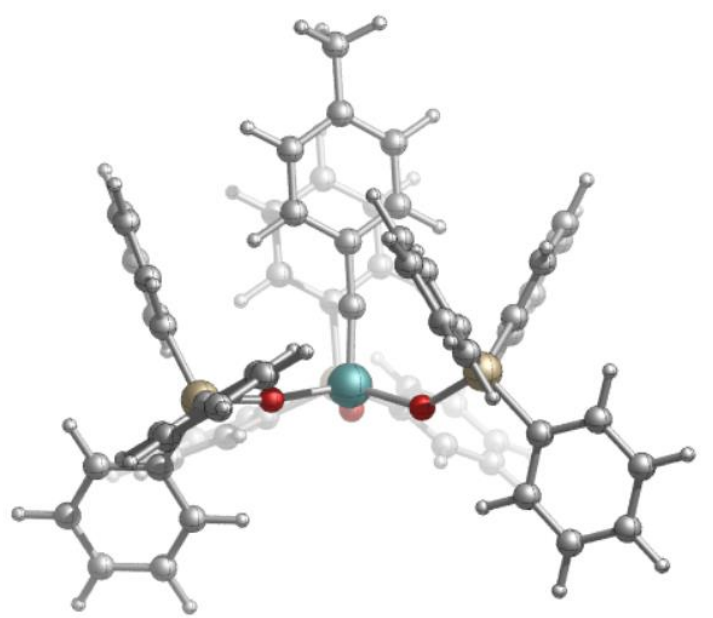

B3LYP-D3/def2SVP-LANL2DZ(Mo)-CPCM(benzene)

B3LYP-D3/def2TZVP-SDD(Mo)-CPCM(benzene)//B3LYP-D3/def2SVP-LANL2DZ(Mo)$\mathrm{CPCM}($ benzene $)$

$\mathrm{HF}=-3557.832422$

$5175^{\circ}$

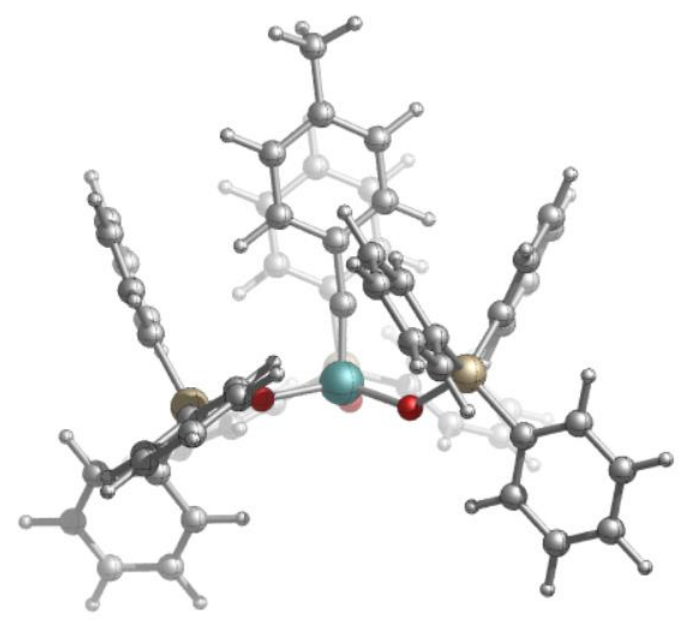

B3LYP-D3/def2SVP-LANL2DZ(Mo)-CPCM(benzene)

B3LYP-D3/def2TZVP-SDD(Mo)-CPCM(benzene)//B3LYP-D3/def2SVP-LANL2DZ(Mo)CPCM(benzene)

$\mathrm{HF}=-3557.831075$ 
5constrained

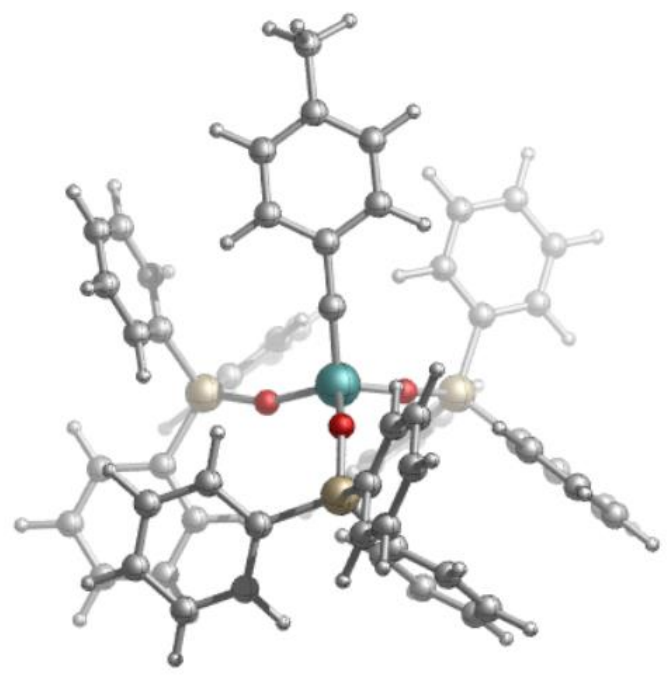

B3LYP-D3/def2SVP-LANL2DZ(Mo)-CPCM(benzene)

B3LYP-D3/def2TZVP-SDD(Mo)-CPCM(benzene)//B3LYP-D3/def2SVP-LANL2DZ(Mo)$\mathrm{CPCM}($ benzene $)$

$\mathrm{HF}=-3557.820722$

$5178^{\circ}$

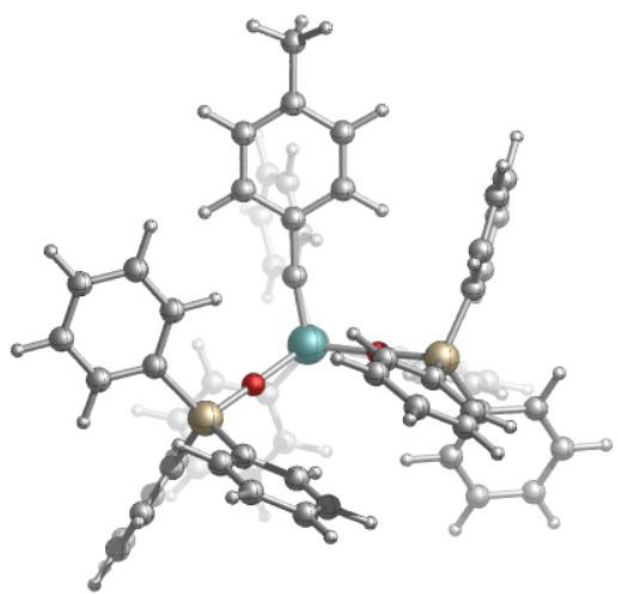

B3LYP-D3/def2SVP-LANL2DZ(Mo)-CPCM(benzene)

B3LYP-D3/def2TZVP-SDD(Mo)-CPCM(benzene)//B3LYP-D3/def2SVP-LANL2DZ(Mo)CPCM(benzene)

$\mathrm{HF}=-3557.814798$ 


\section{[Mo]L3-A}

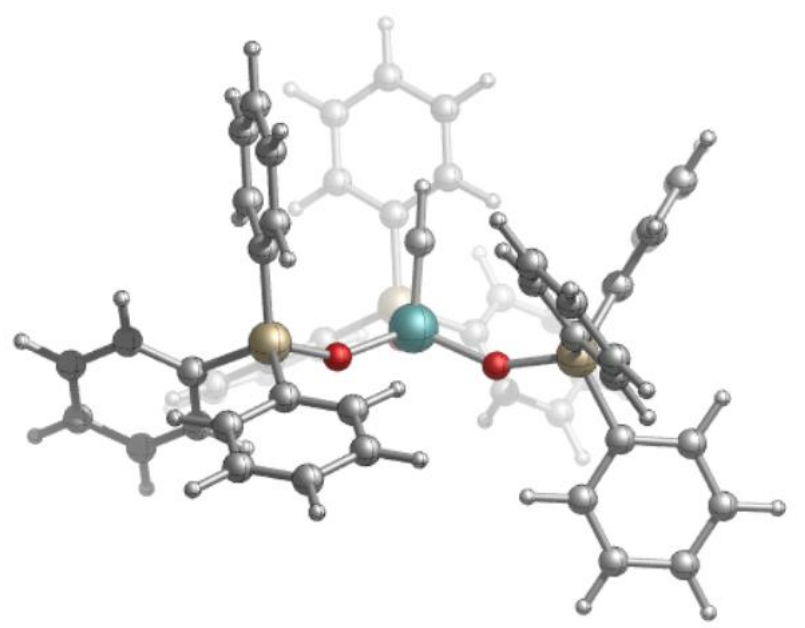

\section{B3LYP/LANL2DZ}

Zero-point correction=

Thermal correction to Energy=

Thermal correction to Enthalpy=

Thermal correction to Gibbs Free Energy=

Sum of electronic and zero-point Energies=

Sum of electronic and thermal Energies=

Sum of electronic and thermal Enthalpies=

Sum of electronic and thermal Free Energies=

B3LYP-D3/defTZVP-SDD(Mo)-CPCM(benzene)//B3LYP/LANL2DZ
0.855096 (Hartree/Particle)

0.912957

0.913901

0.744990

$-2427.480289$

$-2427.422428$

$-2427.421484$

$-2427.590395$

$\mathrm{HF}=-3287.30568$ 


\title{
[Mo]L3-TS-A
}

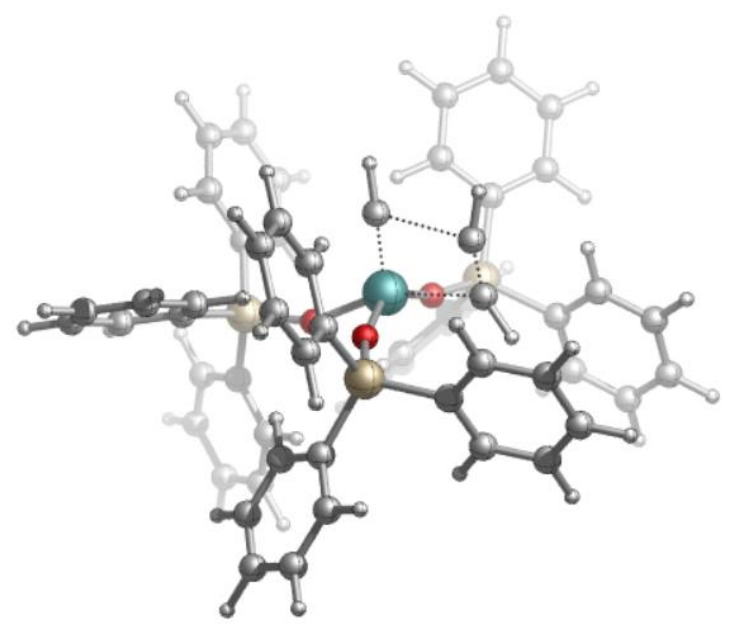

\author{
B3LYP/LANL2DZ \\ Imaginary frequency $=-194.49 \mathrm{~cm}^{-1}$ \\ Zero-point correction= \\ 0.884385 (Hartree/Particle) \\ Thermal correction to Energy $=\quad 0.944370$ \\ Thermal correction to Enthalpy $=\quad 0.945315$ \\ Thermal correction to Gibbs Free Energy $=0.775746$ \\ Sum of electronic and zero-point Energies $=\quad-2504.748744$ \\ Sum of electronic and thermal Energies $=\quad-2504.688759$ \\ Sum of electronic and thermal Enthalpies $=\quad-2504.687815$ \\ Sum of electronic and thermal Free Energies $=\quad-2504.857384$ \\ B3LYP-D3/defTZVP-SDD(Mo)-CPCM(benzene)//B3LYP/LANL2DZ \\ $\mathrm{HF}=-3364.67008$
}




\section{[Mo]L3-MCBD-A}

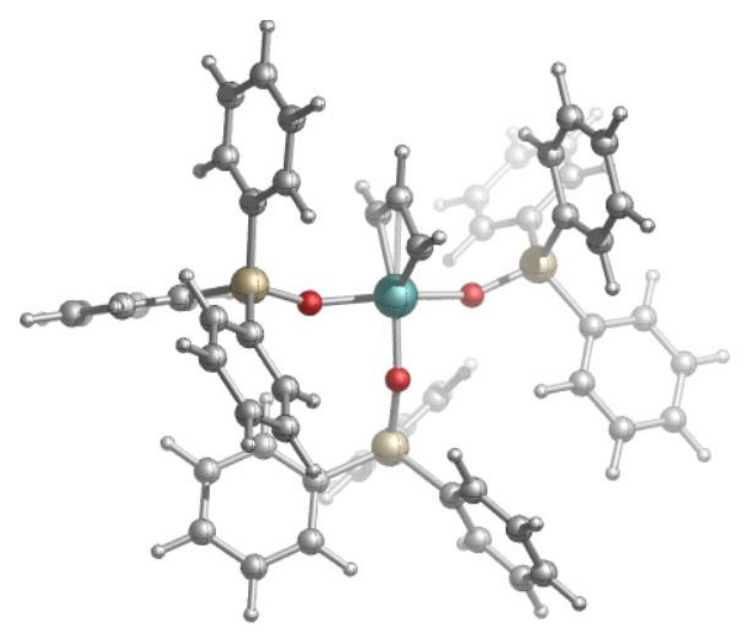

\section{B3LYP/LANL2DZ}

Zero-point correction $=$

0.887142 (Hartree/Particle)

Thermal correction to Energy=

0.946733

Thermal correction to Enthalpy=

0.947677

Thermal correction to Gibbs Free Energy=

0.777577

Sum of electronic and zero-point Energies= $-2504.764443$

Sum of electronic and thermal Energies= $-2504.704852$

Sum of electronic and thermal Enthalpies= $-2504.703908$

Sum of electronic and thermal Free Energies $=\quad-2504.874008$

B3LYP-D3/defTZVP-SDD(Mo)-CPCM(benzene)//B3LYP/LANL2DZ

$\mathrm{HF}=-3364.690761$ 


\section{[Mo]SiP-A}

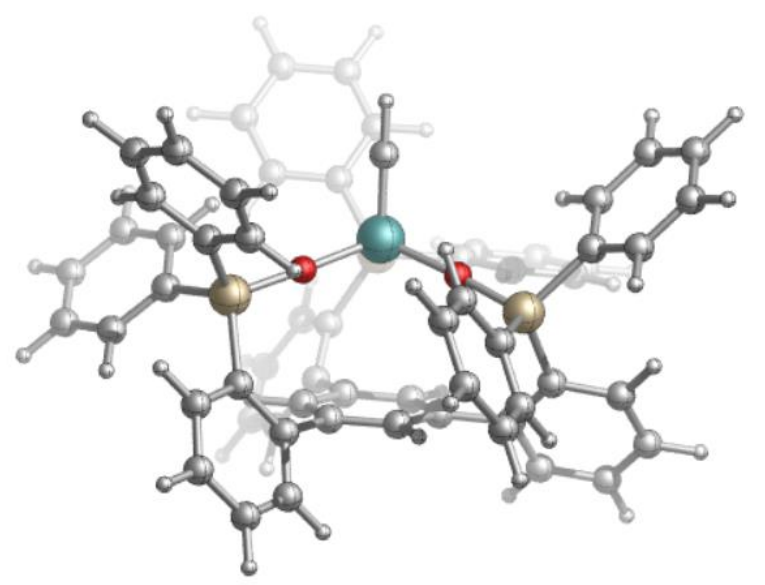

\section{B3LYP/LANL2DZ}

Zero-point correction $=$

Thermal correction to Energy=

Thermal correction to Enthalpy=

Thermal correction to Gibbs Free Energy $=\quad 0.790917$

Sum of electronic and zero-point Energies $=\quad-2656.040134$

Sum of electronic and thermal Energies $=\quad-2655.980959$

Sum of electronic and thermal Enthalpies $=\quad-2655.980015$

Sum of electronic and thermal Free Energies $=\quad-2656.143355$

B3LYP-D3/defTZVP-SDD(Mo)-CPCM(benzene)//B3LYP/LANL2DZ

$\mathrm{HF}=-3516.041367$ 


\section{[Mo]SiP-TS-A}

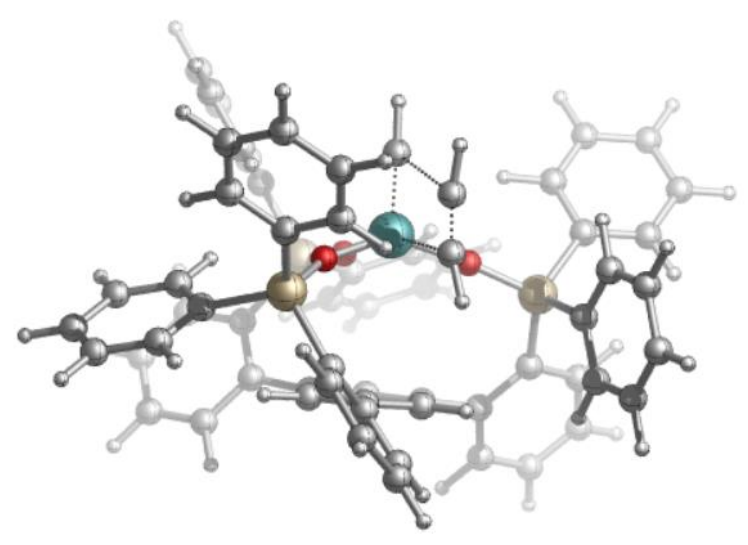

\section{B3LYP/LANL2DZ}

Imaginary frequency $=-162.03 \mathrm{~cm}^{-1}$

Zero-point correction $=$

0.923945 (Hartree/Particle)

Thermal correction to Energy=

0.984959

Thermal correction to Enthalpy=

0.985904

Thermal correction to Gibbs Free Energy $=\quad 0.823172$

Sum of electronic and zero-point Energies $=\quad-2733.310218$

Sum of electronic and thermal Energies $=\quad-2733.249203$

Sum of electronic and thermal Enthalpies $=\quad-2733.248259$

Sum of electronic and thermal Free Energies $=\quad-2733.410990$

B3LYP-D3/defTZVP-SDD(Mo)-CPCM(benzene)//B3LYP/LANL2DZ

$H F=-3593.408562$ 


\section{[Mo]SiP-MCBD-A}

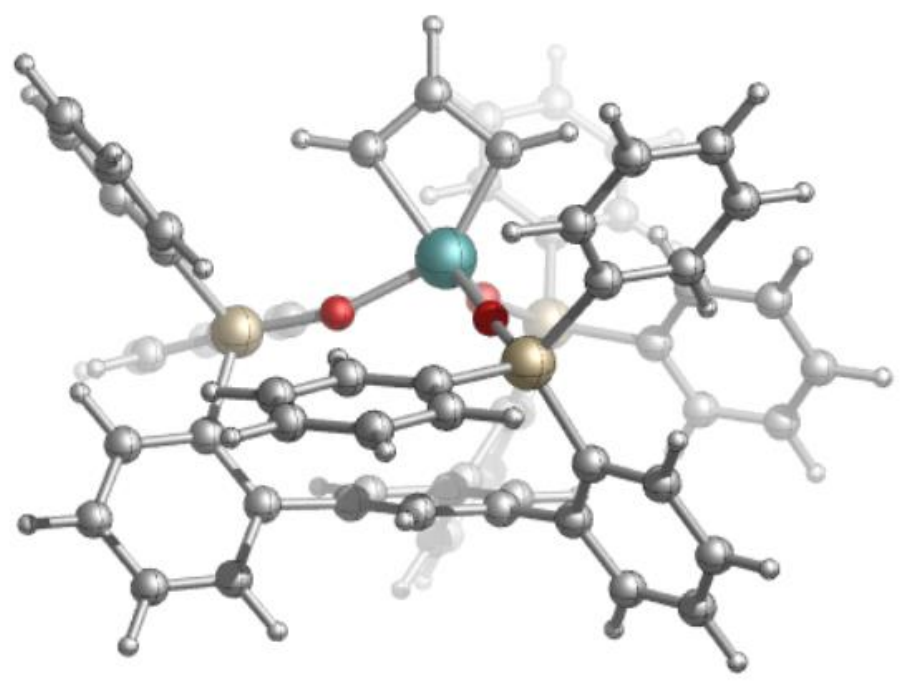

\section{B3LYP/LANL2DZ}

Zero-point correction=

Thermal correction to Energy=

Thermal correction to Enthalpy=
0.926876 (Hartree/Particle)

0.987986

0.988930

Thermal correction to Gibbs Free Energy $=\quad 0.824013$

Sum of electronic and zero-point Energies $=\quad-2733.334944$

Sum of electronic and thermal Energies= $\quad-2733.273834$

Sum of electronic and thermal Enthalpies $=\quad-2733.272890$

Sum of electronic and thermal Free Energies $=\quad-2733.437807$

B3LYP-D3/defTZVP-SDD(Mo)-CPCM(benzene)//B3LYP/LANL2DZ

$\mathrm{HF}=-3593.426794$ 


\section{$[\mathrm{Mo}] \mathrm{L}_{3}$}

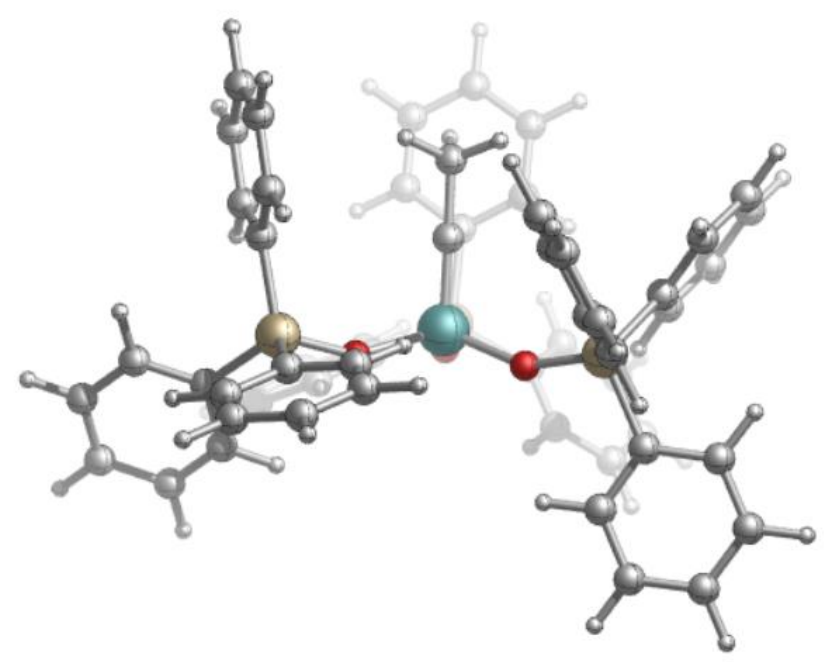

\section{B3LYP/LANL2DZ}

Zero-point correction $=$

0.883827 (Hartree/Particle)

Thermal correction to Energy=

0.943520

Thermal correction to Enthalpy=

0.944464

Thermal correction to Gibbs Free Energy=

0.772681

Sum of electronic and zero-point Energies= $-2466.773269$

Sum of electronic and thermal Energies= $-2466.713576$

Sum of electronic and thermal Enthalpies $=\quad-2466.712632$

Sum of electronic and thermal Free Energies $=\quad-2466.884415$

B3LYP-D3/defTZVP-SDD(Mo)-CPCM(benzene)//B3LYP/LANL2DZ $\mathrm{HF}=-3326.652717$ 


\section{[Mo]L3-TS}

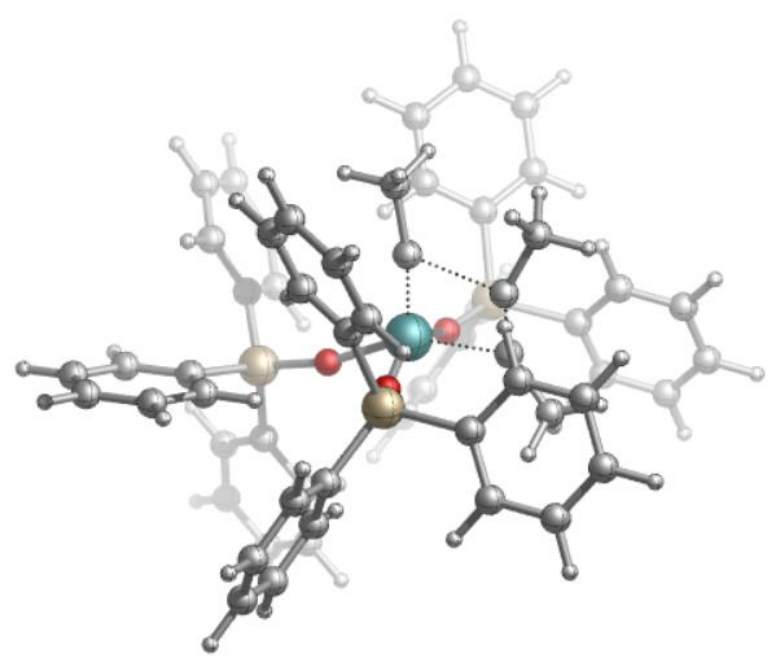

\section{B3LYP/LANL2DZ}

Imaginary frequency $=-143.85 \mathrm{~cm}^{-1}$

Zero-point correction $=$ 0.970828 (Hartree/Particle)

Thermal correction to Energy= 1.035662

Thermal correction to Enthalpy= 1.036606

Thermal correction to Gibbs Free Energy $=\quad 0.857047$

Sum of electronic and zero-point Energies $=\quad-2622.618924$

Sum of electronic and thermal Energies= $-2622.554089$

Sum of electronic and thermal Enthalpies $=\quad-2622.553145$

Sum of electronic and thermal Free Energies $=\quad-2622.732705$

B3LYP-D3/defTZVP-SDD(Mo)-CPCM(benzene)//B3LYP/LANL2DZ

$\mathrm{HF}=-3482.706355$ 


\section{[Mo]L3-MCBD}

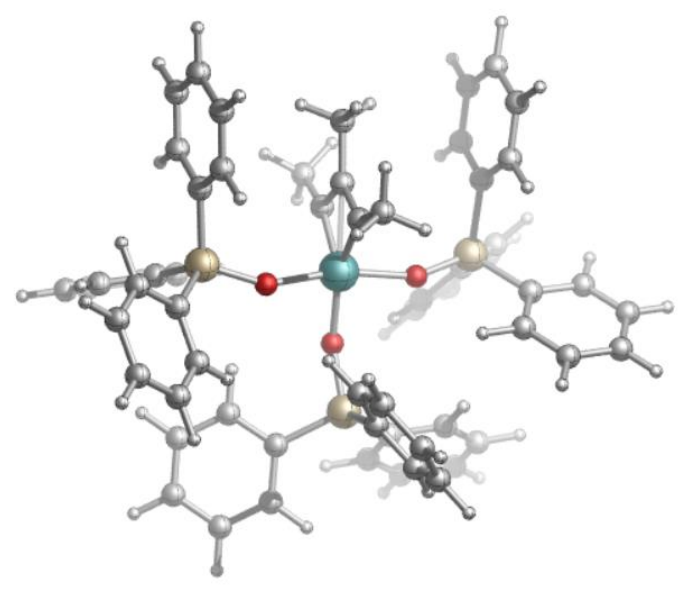

\section{B3LYP/LANL2DZ}

Zero-point correction=

0.972362 (Hartree/Particle)

Thermal correction to Energy=

1.037104

Thermal correction to Enthalpy=

1.038048

Thermal correction to Gibbs Free Energy $=\quad 0.859662$

Sum of electronic and zero-point Energies $=\quad-2622.629311$

Sum of electronic and thermal Energies $=\quad-2622.564568$

Sum of electronic and thermal Enthalpies $=\quad-2622.563624$

Sum of electronic and thermal Free Energies $=\quad-2622.742010$

B3LYP-D3/defTZVP-SDD(Mo)-CPCM(benzene)//B3LYP/LANL2DZ

$\mathrm{HF}=-3482.721135$ 


\section{[Mo]SiP}

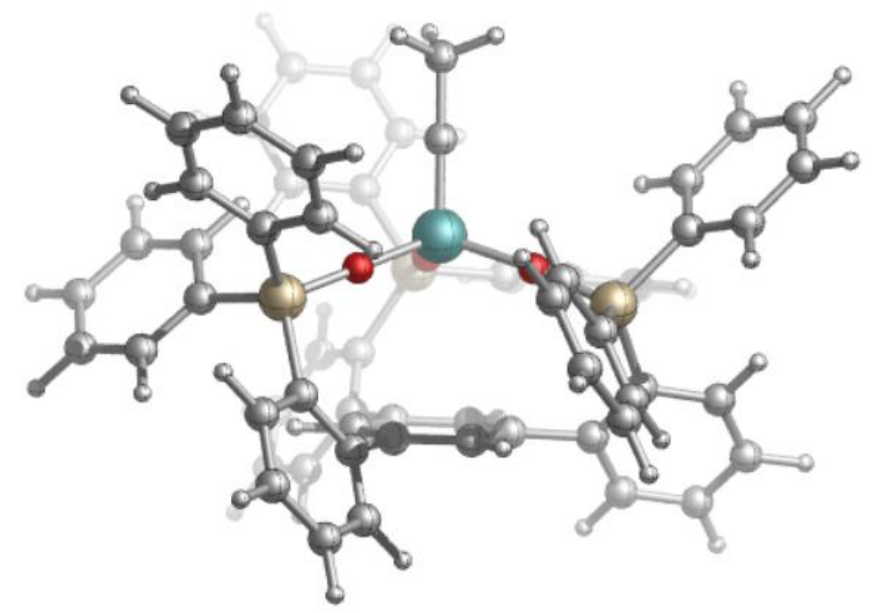

B3LYP/LANL2DZ

Zero-point correction=

0.922753 (Hartree/Particle)

Thermal correction to Energy=

0.983853

Thermal correction to Enthalpy=

0.984797

Thermal correction to Gibbs Free Energy $=\quad 0.816858$

Sum of electronic and zero-point Energies $=\quad-2695.332843$

Sum of electronic and thermal Energies $=\quad-2695.271743$

Sum of electronic and thermal Enthalpies $=\quad-2695.270799$

Sum of electronic and thermal Free Energies $=\quad-2695.438738$

B3LYP-D3/defTZVP-SDD(Mo)-CPCM(benzene)//B3LYP/LANL2DZ

$\mathrm{HF}=-3555.385737$ 


\section{[Mo]SiP-TS}

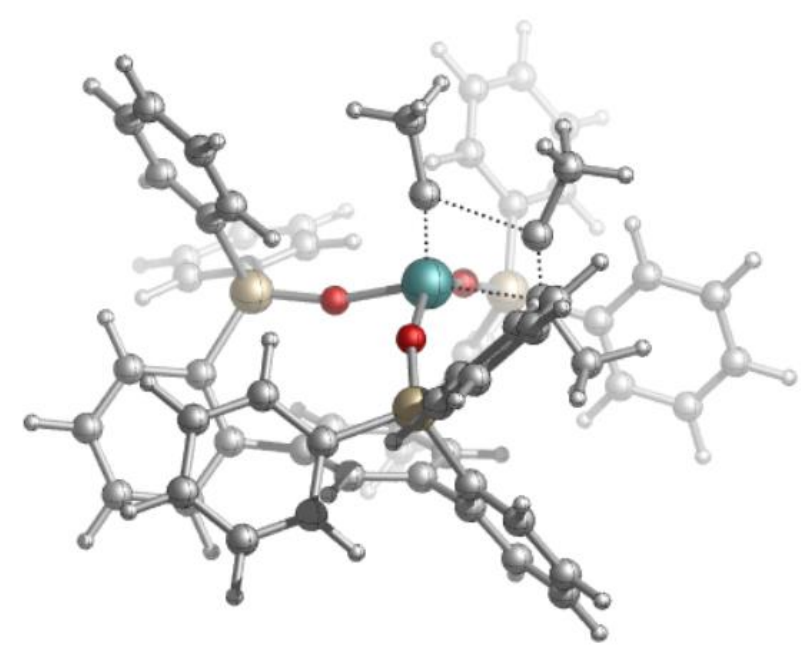

\section{B3LYP/LANL2DZ}

Imaginary frequency $=-109.99 \mathrm{~cm}^{-1}$

Zero-point correction $=$ 1.010705 (Hartree/Particle)

Thermal correction to Energy= 1.076493

Thermal correction to Enthalpy= 1.077438

Thermal correction to Gibbs Free Energy=

0.905500

Sum of electronic and zero-point Energies= $-2851.173523$

Sum of electronic and thermal Energies= $-2851.107735$

Sum of electronic and thermal Enthalpies= $-2851.106791$

Sum of electronic and thermal Free Energies= $-2851.278728$

B3LYP-D3/defTZVP-SDD(Mo)-CPCM(benzene)//B3LYP/LANL2DZ $\mathrm{HF}=-3711.440283$ 


\section{[Mo]SiP-MCBD}

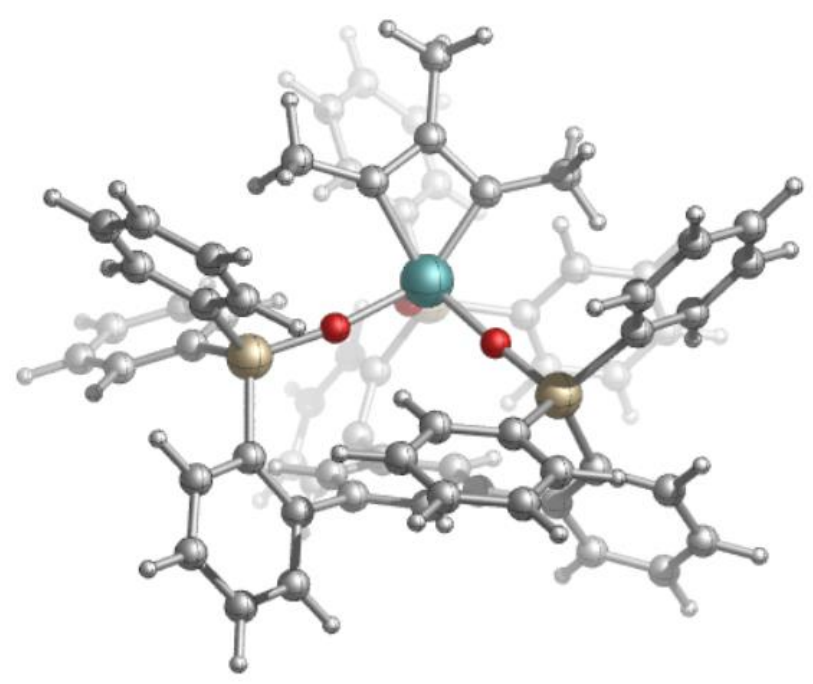

B3LYP/LANL2DZ

Zero-point correction $=$

1.012285 (Hartree/Particle)

Thermal correction to Energy=

1.078178

Thermal correction to Enthalpy=

1.079122

Thermal correction to Gibbs Free Energy $=\quad 0.905441$

Sum of electronic and zero-point Energies $=\quad-2851.191493$

Sum of electronic and thermal Energies $=\quad-2851.125601$

Sum of electronic and thermal Enthalpies $=\quad-2851.124657$

Sum of electronic and thermal Free Energies $=\quad-2851.298337$

B3LYP-D3/defTZVP-SDD(Mo)-CPCM(benzene)//B3LYP/LANL2DZ

$\mathrm{HF}=-3711.444432$ 


\section{[Mo]SiP-MTd}

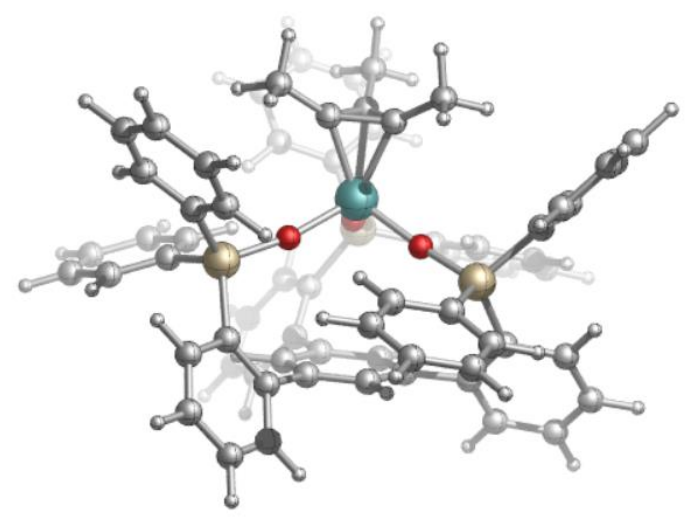

\section{B3LYP/LANL2DZ}

Zero-point correction=

1.012191 (Hartree/Particle)

Thermal correction to Energy=

1.078188

Thermal correction to Enthalpy=

1.079132

Thermal correction to Gibbs Free Energy=

0.906679

Sum of electronic and zero-point Energies= $-2851.193081$

Sum of electronic and thermal Energies= $-2851.127083$

Sum of electronic and thermal Enthalpies= $-2851.126139$

Sum of electronic and thermal Free Energies $=\quad-2851.298592$

B3LYP-D3/defTZVP-SDD(Mo)-CPCM(benzene)//B3LYP/LANL2DZ

$\mathrm{HF}=-3711.463559$ 


\section{$\underline{\text { References }}$}

1. Trawny, D.; Quennet, M.; Rades, N.; Lentz, D.; Paulus, B.; Reissig, H., Syntheses, Structures and Conformational Dynamics of 1,3,5-Tris(3"-ethynylbi-phen-yl-2'-yl)benzene Derivatives. Eur. J. Org. Chem. 2015, 4667-4674.

2. J. Dosso, J. Tasseroul, F. Fasano, D. Marinelli, N. Biot, A. Fermi, D. Bonifazi, Synthesis and Optoelectronic properites of Hexa-peri-hexabenzoborazinocoronene. Angew. Chem. Int. Ed. 2017, 56, 4483-4487.

3. SAINT; Bruker AXS, Inc.: Madison, WI, USA. 2009.

4. Sheldrick, G. M., SADABS;. 2007, University of Gottingen, Germany.

5. Sheldrick, G. M., Acta Cryst. 2008 A64, 112-122.

6. Sheldrick, G. M. (2014). SHELXL-2014. University of Gottingen, Germany.

7. a) Becke, A. D. Density-functional thermochemistry. III. The role of exact exchange. $J$. Chem. Phys., 1993, 98, 5648-5652. b) Grimme, S. Semiempirical GGA-type density functional constructed with a long-range dispersion correction. J. Comp. Chem., 2006, 27, 1787-1799. c) Weigend, F.; Ahlrichs, R. Balanced basis sets of split valence, triple zeta valence and quadruple zeta valence quality for $\mathrm{H}$ to $\mathrm{Rn}$ : Design and assessment of accuracy. Phys. Chem. Chem. Phys., 2005, 7, 3297-3305. d) Hay, P. J.; Wadt, W. R. Ab initio effective core potentials for molecular calculations - potentials for the transitionmetal atoms Sc to Hg. J. Chem. Phys., 1985, 82, 270-283.

8. Tomasi, J.; Mennucci, B.; Cammi, R. Quantum mechanical continuum solvation models. Chem. Rev., 2005, 105, 2999-3093.

9. a) Weigend, F. Accurate Coulomb-fitting basis sets for $\mathrm{H}$ to Rn. Phys. Chem. Chem. Phys., 2006, 8, 1057-1065. b) Fuentealba, P.; Preuss, H.; Stoll, H.; Szentpály, L. V. A Proper Account of Core-polarization with Pseudopotentials - Single Valence-Electron Alkali Compounds. Chem. Phys. Lett., 1982, 89, 418-22.

10. Mulliken, R. S., Electronic Population Analysis on LCAO-MO Molecular Wave Functions. I. J. Chem. Phys. 1955, 23, 1833-1840.

11. CYLview, 1.0b; Legault, C. Y., Université de Sherbrooke, 2009 (http://www.cylview.org) 